\title{
Stigma, Attitudes, and Intentions to Seek Mental Health Services in College Student-Athletes
}

Robert C. Hilliard M.S.

West Virginia University, rchilliard@mix.wvu.edu

Follow this and additional works at: https://researchrepository.wvu.edu/etd

Part of the Counseling Commons, and the Sports Studies Commons

\section{Recommended Citation}

Hilliard, Robert C. M.S., "Stigma, Attitudes, and Intentions to Seek Mental Health Services in College Student-Athletes" (2019). Graduate Theses, Dissertations, and Problem Reports. 4126.

https://researchrepository.wvu.edu/etd/4126

This Dissertation is protected by copyright and/or related rights. It has been brought to you by the The Research Repository @ WVU with permission from the rights-holder(s). You are free to use this Dissertation in any way that is permitted by the copyright and related rights legislation that applies to your use. For other uses you must obtain permission from the rights-holder(s) directly, unless additional rights are indicated by a Creative Commons license in the record and/ or on the work itself. This Dissertation has been accepted for inclusion in WVU Graduate Theses, Dissertations, and Problem Reports collection by an authorized administrator of The Research Repository @ WVU.

For more information, please contact researchrepository@mail.wvu.edu. 
Stigma, attitudes, and intentions to seek mental health services in college student-athletes

\author{
Robert C. Hilliard Jr. \\ Dissertation submitted \\ to the College of Physical Activity and Sport Sciences \\ at West Virginia University \\ in partial fulfillment of the requirements for the degree of \\ Doctorate of Philosophy in \\ Sport, Exercise, and Performance Psychology \\ Jack C. Watson II, PhD, Chair \\ Samuel Zizzi, EdD \\ Edward Etzel, EdD \\ Aaron Metzger, PhD \\ Department of Sport Sciences \\ Morgantown, WV \\ 2019
}

Keywords: counseling; help-seeking behavior; well-being; sport psychology; quantitative

Copyright 2019 Robert Hilliard 


\begin{abstract}
Stigma, attitudes, and intentions to seek mental health services in college student-athletes
\end{abstract}

\title{
Robert Hilliard
}

Previous researchers have found several factors that act as barriers to college student-athletes seeking mental health services (López \& Levy, 2013; Moore, 2017). One common factor throughout these studies is stigma, which is known to be associated with less favorable attitudes toward seeking help (Moreland et al., 2018). However, researchers have not explored how stigma and attitudes might influence intentions to seek counseling and actual help-seeking behaviors in student-athletes. Additionally, there is a dearth of research identifying the topics for which student-athletes are most willing to seek help. Therefore, the purposes of this study were to investigate predictors of mental health help-seeking as well as identify topics for which college student-athletes are most likely to seek help. The sample consisted of participants $(\mathrm{N}=$ 325) from three Division II and III universities. Findings indicated public stigma was significantly related to self-stigma, but social network stigma was not. Self-stigma was related to attitudes and attitudes were related to intentions. Using logistic regression analysis, self-stigma and attitudes were found to be significant predictors of help-seeking behavior. Specifically, both were associated with an increased likelihood of having sought mental health services in the past. Regarding help-seeking topics, drug problems, depression, and excessive alcohol use were the highest rated issues for which student-athletes were likely to seek help, whereas concerns about sexuality, difficulty with friends, and body image were rated the lowest. The results of this study can be used to help sport psychologists and other mental health staff develop programming that might lead to increased service use amongst collegiate student-athletes. Specifically, it appears that using a multifaceted approach to improving attitudes could have the most meaningful effect on encouraging service use. 


\section{Acknowledgements}

I have saved this section for last because I have struggled to find the words to thank the people in my life who deserve to be in this section. The truth is that the words that are on this page will not ultimately be enough, but I will give it my best shot.

My chair, Dr. Jack Watson II, is my obvious starting point. I cannot thank you enough for deciding to take me in four years ago as your student. I have spoken with so many friends across different universities who have had an advisor that has absolutely made or broken their experience in graduate school, and I am lucky enough that I am on the made side. I cannot thank you enough for the opportunities to be involved that you have given me, but also the incredible mentorship that has gone outside of research. Throughout this dissertation process you have inspired me to become a prolific reviewer who mandates everyone uses active voice by writing in first person so that I can begin shifting paradigms. But on a serious note, thank you for the stories, the support, and the confidence to get through this journey. I will be forever grateful.

Dr. Sam Zizzi, your influence on my development as a graduate student also cannot be understated. In addition to the guidance up research mountain, your perspectives have constantly challenged me to become a better scholar, practitioner, and person. I will always be thankful for that.

Dr. Ed Etzel, you have been such an integral part of my experience at WVU. I am so thankful that you agreed to be part of my committee despite retirement, but again, your role extends far beyond the dissertation. Your continual kindness and compassion is what I will remember the most and I can only hope to one day portray even a sliver of that sort of care with clients and students.

Dr. Aaron Metzger, thank you so much for the guidance you have provided over the last year and a half. You are getting a lot of us trickling over into your department and you were always so willing to spend time helping me wade through the mass of confusion that can be statistics, particularly SEM.

I also need to thank the rest of the WVU faculty. In some way, each one of you has impacted my life positively and helped me challenge myself to grow. Your support has meant a lot to me and allowed me to enjoy my experience on this path.

To all of the WVU program that I have crossed paths with over these four years, thank you. As you all know, completing this journey is no easy task, and it would be substantially more difficult without people around you that you enjoy being with. Thank you for accepting me as I am and for the willingness to provide support whenever necessary. 
I also need to go further down the line with some thanks. Dr. Lindsey Blom and Dr. Robert Batsell, I cannot thank you enough for the mentoring you provided me through my Master's and undergraduate degrees. Writing this dissertation was a whole lot easier because of the way you challenged me to grow as a writer, and I am forever thankful for that.

To my family. Even though you still probably don't quite understand exactly what I am in school for, you instilled in me a love for education at an early age and always encouraged me to continue finding involvement in things that interested me. Although this journey has continually taken me further and further from home, you are always a part of me.

And finally, to my wife, Alisha. I suppose I owe Dr. Blom another acknowledgement of thanks here for bringing us into the same office, but she already knows what she did $\odot$. Our PhD journeys separated us for far too long, but even in that time, you were a constant source of support and sanity. I can't wait to start our real journey together, wherever that may take us. 
Table of Contents

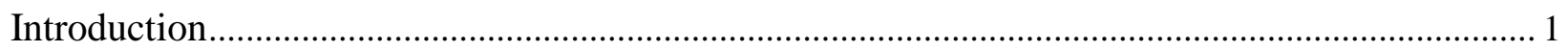

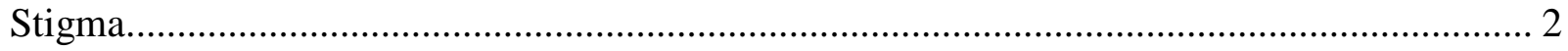

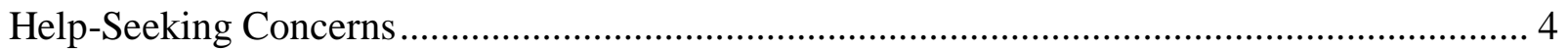

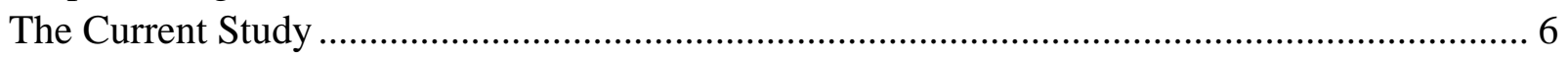

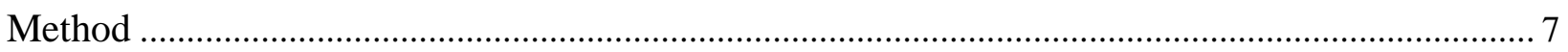

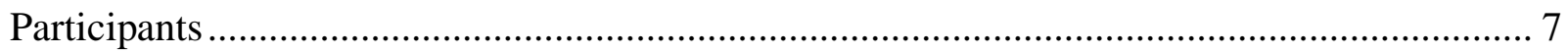

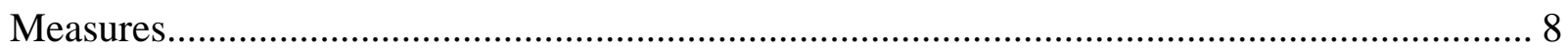

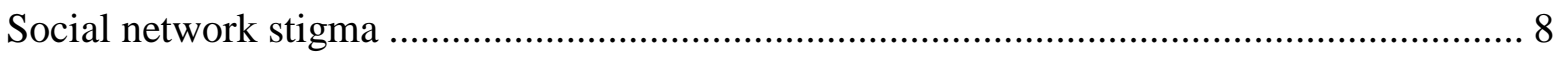

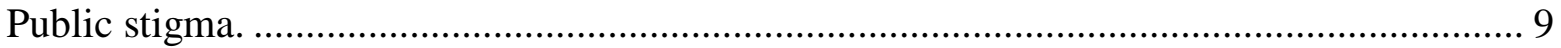

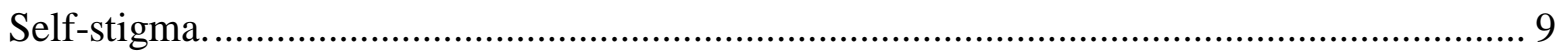

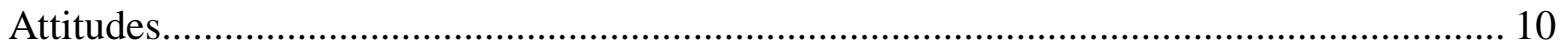

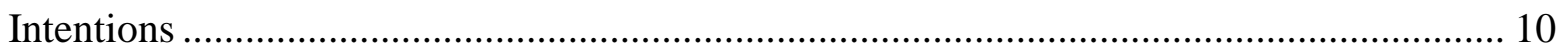

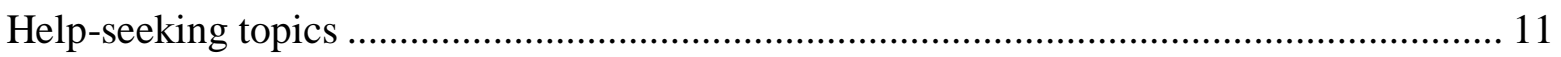

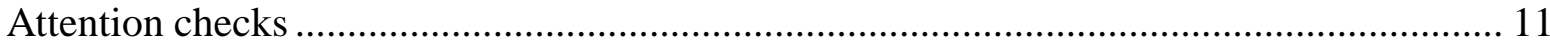

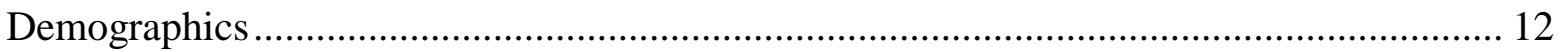

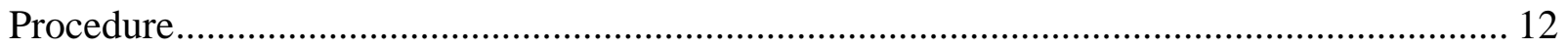

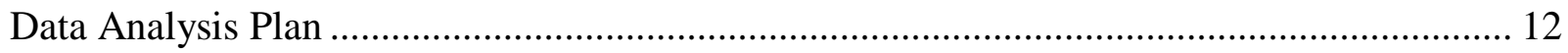

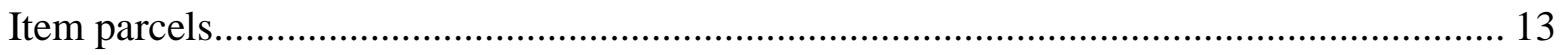

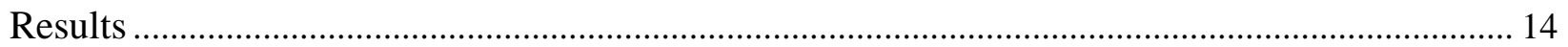

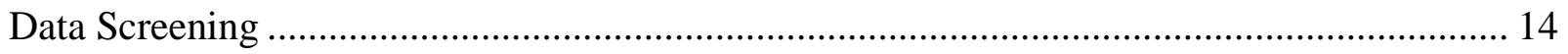

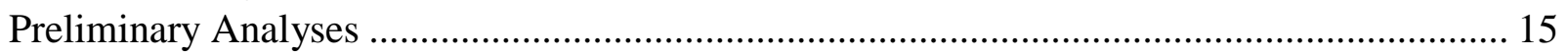

Relationships Between Stigma, Attitudes, and Intentions ............................................. 15

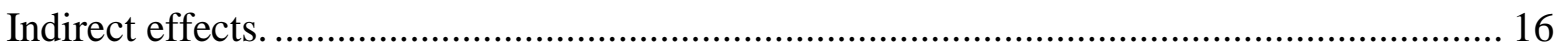

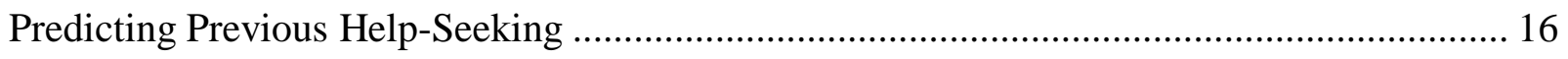

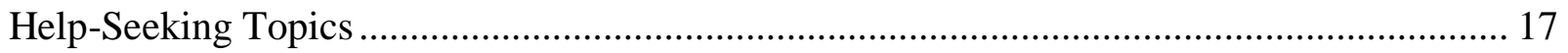

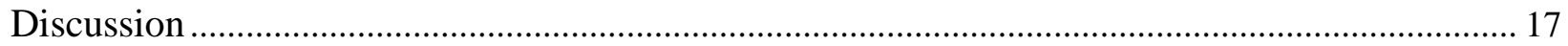

Help-Seeking Intentions and Behavior ...................................................................... 18

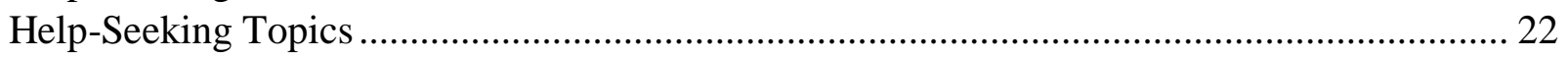

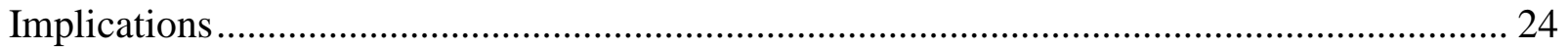

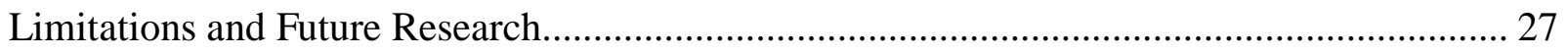

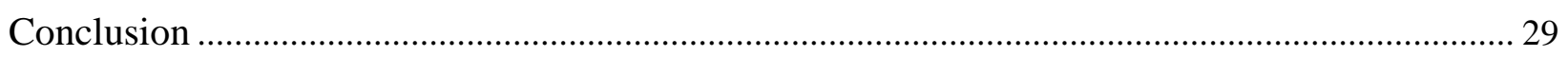

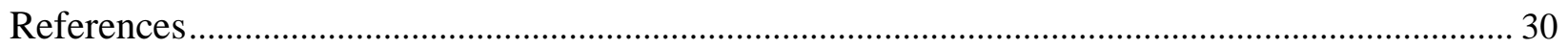

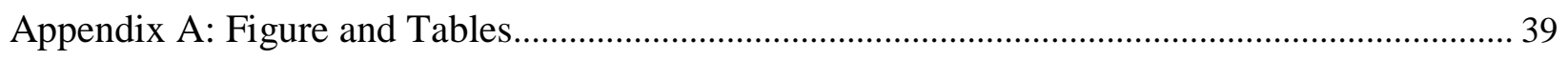

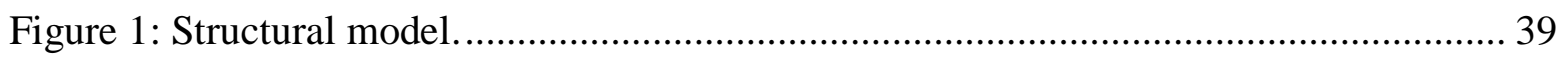

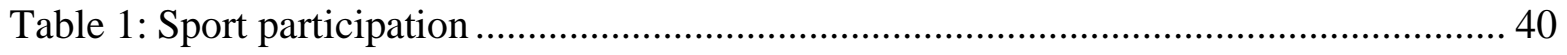

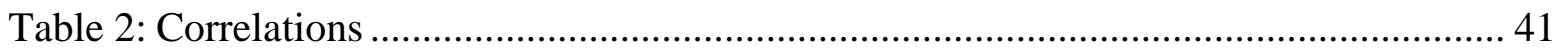




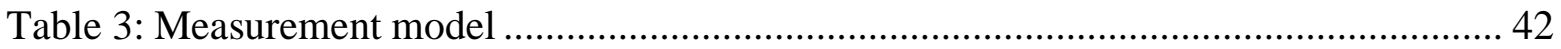

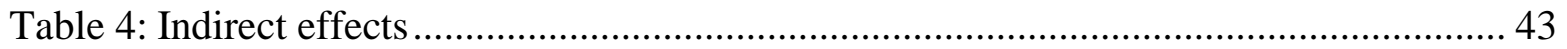

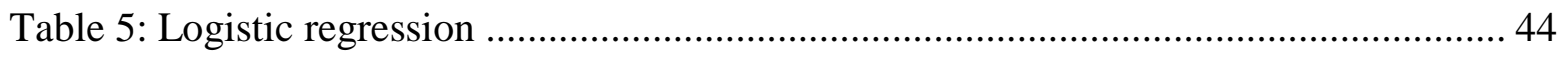

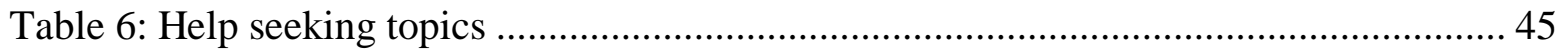

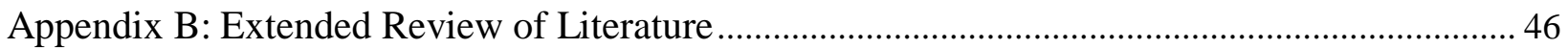

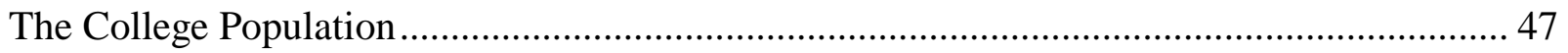

Stigma: An Important Construct Related to Attitudes Toward Help-Seeking ....................... 48

Media Influences on Public Stigma ......................................................................... 51

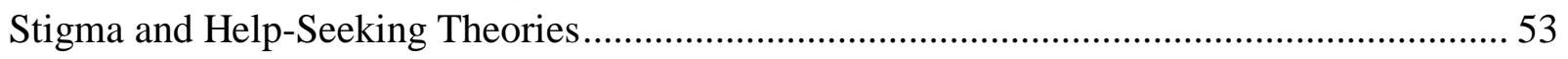

Measurement of Stigma, Attitudes, and Intentions ....................................................... 55

Attitudes and Intentions to Seek Help in the General Population ....................................... 61

Stigma, Attitudes, and Intentions Toward Help-Seeking in the General Population............... 65

Mental health interventions to reduce stigma in the general population.............................. 75

Summary of Stigma and Help-Seeking in the General Population...................................... 77

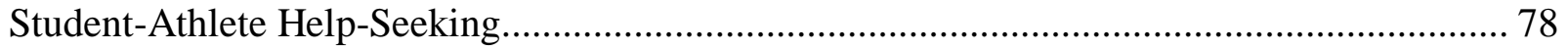

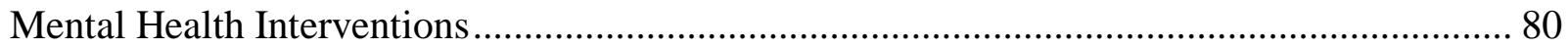

Barriers to Help-Seeking for Student-Athletes ................................................................ 84

Stigma and Attitudes Toward Help Seeking in Athletes................................................ 87

Likelihood of Seeking Counseling for Specific Issues ................................................. 93

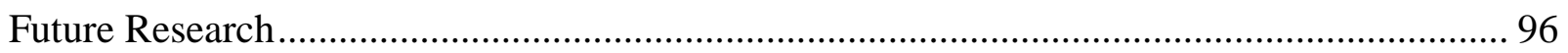

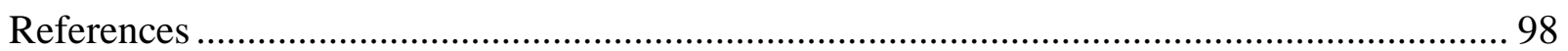

Appendix C: Perceptions of Stigmatization by Others for Seeking Help ................................. 119

Appendix D: Stigma Scale for Receiving Psychological Help .................................................. 120

Appendix E: Self Stigma of Seeking Help ............................................................................. 121

Appendix F: Attitudes Toward Seeking Professional Psychological Help Scale-Short Form .... 122

Appendix G: Mental Help Seeking Intention Scale .............................................................. 123

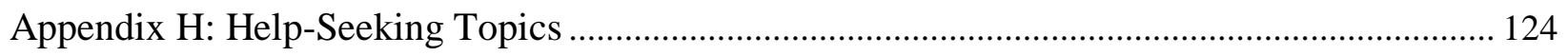

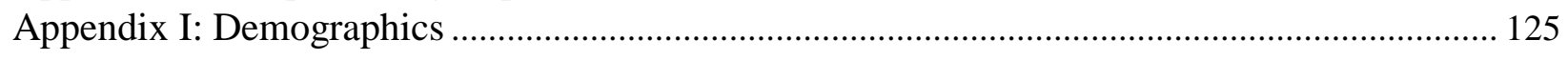

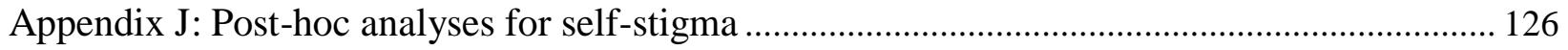

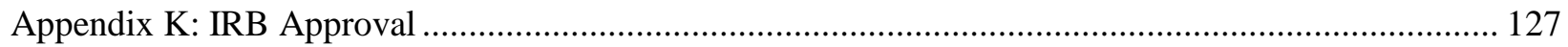




\section{Introduction}

The recent suicide of a Washington State quarterback sent shockwaves throughout the National Collegiate Athletics Association (NCAA). This is but one of many publicized incidents of mental health issues amongst NCAA athletes, as it is a topic that has been increasing in public awareness (e.g., Associated Press, 2018; Scott, 2018). Its importance is demonstrated through the release of the NCAA Mental Health Best Practices guidelines (NCAA, 2016b) and NCAA research grants that focus on mental health. One component of mental health that has often been studied is stigma associated with seeking counseling services. Although many articles have been devoted to studying stigma and help-seeking attitudes in the general population and even elite athletes, college student-athletes have received significantly less attention. Some authors argue that this population is unique in its needs because of the various cultural factors associated with being a college student-athlete, and therefore are worthy of study (e.g., Etzel, Watson, Visek, \& Maniar, 2006; Pinkerton, Hinz, \& Barrow, 1989). A myriad of reasons could contribute to the increased need for mental health services amongst student-athletes, such as intense time demands for their sport, highly regimented schedules, and pressures to be successful academically and athletically (Jolly, 2008). Providing evidence for the spread of mental health concerns amongst student-athletes, the results of a recent study at a single university found that mental health issues had an influence on athletic performance in the previous month in $62.6 \%$ of the sample (Kern et al., 2017). In a nationwide survey of student-athletes across multiple schools and divisions conducted by the NCAA (2016a), 30\% of student-athletes reported feeling overwhelmed in the last month. Gavrilova and Donohue (2018) listed anxiety, depression, substance use, eating disorders, stress, and relationship issues as the top concerns for student-athletes, which mirrors the general college population (Pérez-Rojas et al., 2017). For example, $23.7 \%$ of collegiate 
athletes reported clinically significant levels of depression in a recent study (Wolanin, Hong, Marks, Panchoo, \& Gross, 2016) and in another study at one university, 14\% of the studentathletes reported having a mental health condition (Sarac, Sarac, Pedroza, \& Borchers, 2018). Despite the clear need for mental health services, several authors argue that student-athletes are still underutilizing these services (e.g., López \& Levy, 2013; Moreland, Coxe, \& Yang, 2018). A myriad of factors act as barriers to help-seeking for student-athletes. These include lack of time, concerns about confidentiality and being identified in public, worry that clinicians will not understand their lifestyle, and not recognizing the need to seek services (López \& Levy, 2013; Moore, 2017; Watson, 2006). In addition to these variables, there is one factor that shows up repeatedly throughout the literature: stigma. As a result, it is likely that stigma plays a significant role in predicting help-seeking intentions and behavior.

\section{Stigma and Help-Seeking}

Corrigan (2004) asserts that two primary types of stigma exist regarding help-seeking, public and self-stigma. Public stigma is external and refers to a belief that society perceives seeking help for mental health treatment as undesirable and individuals who seek help are socially unacceptable. Self-stigma represents an internalization of public stigma in that an individual believes he or she is socially undesirable for seeking treatment. A further delineation of external stigma may also be helpful for understanding the roles that stigma may play in influencing counseling attitudes. Social network stigma is a form of external stigma (Topkaya, Vogel, \& Brenner, 2017) that specifically refers to perceived stigma from individuals who are directly within one's social network (Vogel, Wade, \& Ascheman, 2009). Social network stigma is important because an individual may perceive the general public to hold one particular set of beliefs regarding mental health treatment, but the individual might be most concerned about what 
close family and acquaintances think. In one study of Turkish college students that measured public and social network stigma, social network stigma was a unique predictor of self-stigma, although the strength of the pathway was much weaker than for public stigma (Topkaya et al., 2017). Further, there is extensive evidence that these forms of stigma influence attitudes and intentions toward help-seeking in a variety of populations (e.g., Garriott, Raque-Bogdan, Yalango, Schaefer Ziemer, \& Utley, 2017).

Similarly, stigma is often identified as a barrier to seeking counseling services for college student-athletes (e.g., López \& Levy, 2013; Moore, 2017; Moreland et al., 2018). Participants in qualitative studies using athletes across different levels have also reported stigma to be a substantial impediment to seeking counseling services (e.g., Biggin, Burns, \& Uphill, 2017; DeLenardo \& Lennox Terrion, 2014; Moore, 2017). One reason that stigma might be particularly salient amongst collegiate athletes is the sociocultural aspect of sport, where masculine tenets associated with the sport environment often de-emphasize the need for seeking help and perceive individuals who do so as weak (Gucciardi, Hanton, \& Fleming, 2017; Schinke, Stambulova, Si, \& Moore, 2018). Therefore, different forms of stigma, including social network stigma, selfstigma, and public stigma have all been associated with less favorable attitudes toward seeking counseling (e.g., Bird, Chow, Meir, \& Freeman, 2018; Hilliard, Redmond, \& Watson, 2018; Ramaeker \& Petrie, 2019; Wahto, Swift, \& Whipple, 2016).

Specifically, social network stigma was found to be associated with increased levels of self-stigma and consequently less positive attitudes in NCAA Division I athletes (Bird, Chow, et al. 2018), whereas public stigma was associated with greater self-stigma and lower attitudes with student-athletes competing across multiple divisions (Hilliard et al., 2018; Wahto et al., 2016). However, no studies have measured public and social network stigma in the same sample of 
student-athletes. Additionally, very little is known about factors that influence intentions to seek professional psychological help in student-athletes. Although attitudes are viewed as a proxy for intentions and behavior (e.g., Ajzen \& Fishbein, 1980) and researchers have found that attitudes are related to actual help-seeking behaviors (ten Have et al., 2010), examining actual behaviors would help to get a more accurate picture of student-athlete help-seeking. Recently, some authors have investigated how depression and anxiety symptoms influence help-seeking intentions (Tahtinen \& Kristjansdottir, 2018) and actual behavior (Drew \& Matthews, 2018). In a recent study of male athletes, attitudes were significantly associated with intentions, although this relationship only accounted for eight percent of the variance (Ramaeker \& Petrie, 2019). Additionally, conformity to masculine norms and stigma were indirectly related to intentions. This initial study provides support for the role stigma and attitudes might play in determining intentions. However, given the low variance accounting for intentions in this study, and the lack of an analysis related to actual help-seeking behaviors, more research is needed in this area.

\section{Help-Seeking Concerns}

Research in the general psychology literature has found that specific groups might vary on their willingness to seek counseling for various issues. There has been limited research on this topic amongst student-athletes; however, there is some insight that can be gleaned from this small body of research. One study examined preferences for concerns to discuss in sport psychology consultation amongst athletes from the U.S. and Japan (Naoi, Watson, Deaner, \& Sato, 2011). This list included ten options related to performance enhancement as well as various personal concerns. Overall, the top three issues were all performance related: burnout/overtraining, confidence, and dealing with stress. Personal and mental health concerns all ranked in the bottom. Although this makes student-athletes' willingness to seek help for 
personal concerns appear bleak, the participants were asked to respond to topics they would prefer for sport psychology consultation. They may not have felt that discussing mental health concerns or drug/alcohol issues would be appropriate with a sport psychology consultant, but feel differently about doing so with a mental health professional. However, Moore (2017) recently found of student-athletes that amongst a list of possible behavioral services such as medical, tutoring, and mental health services, mental health related topics received the lowest ratings of comfort. Comfort does not necessarily equate to willingness, as student-athletes are required to meet with academic advisors and sports medicine professionals, so it is understandable that comfort with those services would be higher. Further, when given an option, student-athletes reported a greater willingness to seek help for personal issues from informal sources such as coaches, friends, or family (e.g., Bird, Chow, et al., 2018; Naoi et al., 2011; Maniar, Curry, Sommers-Flanagan, \& Walsh, 2001). However, the research on specific presenting concerns for which student-athletes might be interested in seeking counseling is limited. Previous studies have either provided a limited number of sport-related concerns to rate such as overcoming a slump, dealing with injury, or seeking optimal performance (Maniar et al., 2001) or asked participants to rate topics to be discussed during sport psychology consultation (Naoi et al., 2011). Further, research on presenting concerns of college students has found minor differences between genders on why they seek counseling (Pérez-Rojas et al., 2017), but it is unknown if preferences for topics differ between male and female athletes and there has been no discussion of individuals who describe themselves as non-binary. This important line of inquiry can have implications for college counseling centers and sport psychology professionals. Further knowledge of the most and least salient presenting concerns can be used to promote appropriate mental health services and tailor outreach efforts. For example, counseling centers could 
specifically describe the ways they could help student-athletes with their highest rated concerns and destigmatize lower rated concerns that might still be important issues to be addressed with professional help.

\section{The Current Study}

Unlike the broader counseling psychology research investigating other populations, a major limitation of the research with college student-athletes is the lack of studies examining intentions and actual help-seeking behavior, especially when including stigma as a predicting variable. Although researchers have often collected data on previous experience with mental health services, that data has not been included in the analyses. Thus, analyzing the role of stigma in direct relation to attitudes, intentions, and help-seeking behavior would expand understanding of help-seeking factors among student-athletes. Social network stigma may play an important role with student-athletes who have concerns over close others being aware of them seeking counseling (e.g., López \& Levy, 2013; Moore, 2017). The measures for public and social network stigma have been found to be able to add unique variance in the prediction of self-stigma. Therefore, understanding the amount of influence of public and social network stigma on help-seeking could help practitioners tailor interventions and outreach to make more student-athletes feel comfortable seeking mental health services. Further, preferred presenting concerns for seeking help are vastly unexplored.

The primary aim of this study was to investigate the relationships between public stigma, social network stigma, self-stigma, attitudes, and intentions to seek counseling in college student-athletes. Additionally, the predictive validity of these variables on previous help-seeking was investigated. A secondary aim of this study was to explore willingness to seek counseling for specific topics. 
One framework that can help guide the understanding of health behavior is the Theory of Reasoned Action (TRA; Ajzen \& Fishbein, 1980). In the TRA, Ajzen and Fishbein (1980) posit that subjective norms and attitudes combine to form intentions to engage in a behavior, which for the current study was seeking mental health services. Attitudes refer to an individual's actual beliefs whereas subjective norms refer to the beliefs an individual perceives others to hold. Thus, public and social network stigma are measures that seem to adequately reflect components of TRA.

Based on previous research, it was hypothesized that public stigma and social network stigma would both be positively associated with self-stigma. Additionally, it was hypothesized that the relationship between these two external forms of stigma with intentions would be mediated through self-stigma and attitudes. Specifically, it was hypothesized that self-stigma would be negatively associated with attitudes toward counseling, and attitudes would positively relate to intentions to seek counseling. Further, it was hypothesized that all indirect effects in the model would be significant. The current study also explored two different research questions. The first question was: what variables predict if a student-athlete has previously sought mental health services? The second research question was: what are the presenting concerns for which male and female student-athletes are most willing to seek help?

\section{Participants}

\section{Method}

Participants $(N=328)$ from a convenience sample of three Division II or III universities in the Mid-Atlantic region of the United States completed surveys. These universities were selected because they did not have sport psychologists on campus, which could influence attitudes toward counseling. Additionally, Division II and III universities tend to have fewer resources available for athletes. The sample was primarily male $(n=224, n=101$ female, 3 did 
not report gender) and predominately from Division III ( $n=245, n=81$ Division II, 2 did not report). The student-athletes ranged in age from $18-24(M=19.53, S D=1.29)$ and contained freshman $(n=112)$, sophomore $(n=90)$, junior $(n=73)$, senior $(n=47)$, and graduate student $(n$ $=1$ ) athletes. The student-athletes primarily identified as White/Caucasian (84\%), followed by Black/African American (7\%), biracial (4\%), Hispanic/Latino (3\%), and less than $1 \%$ each of Native American and Asian. Eleven sports were represented, including baseball, basketball, cross country, football, golf, soccer, softball, swimming, track and field, volleyball, and wrestling. Full data related to sport participation can be seen in Table 1. A majority of the sample had no previous experience seeking mental health services $(80 \%$ no, $19 \%$ yes, $1 \%$ did not respond), most had no previous experience with a sport psychology practitioner $(88 \%=$ no, $10 \%$ $=$ yes, $1 \%$ did not respond), and only $2 \%$ were currently on psychiatric medications.

\section{Measures}

Social network stigma. Perceived stigma from others who are within one's social network was measured with the Perceptions of Stigmatization by Others for Seeking Help scale (PSOSH; Vogel et al., 2009). Participants responded to five items based on a five-point Likerttype scale ranging from 1 (not at all) to 5 (a great deal). The items can be combined for a total score or averaged together for a composite score. Higher scores represent greater perceived stigmatization by others. The internal reliability across five samples including more than 2000 college students was adequate in the validation study (i.e., $\alpha=.78$ to .89 ). A reliability of .88 was found in a sample of college student-athletes (Bird, Chow, et al., 2018). In the validation study, the authors found that social network stigma predicted variance in self-stigma beyond other public stigma measures and demonstrated test-retest reliability of $r=.77$ over three weeks (Vogel et al., 2009). The scale provides the following instructions: "Imagine you had a personal 
difficulty that you could not solve on your own. If you sought counseling services for this issue, to what degree do you believe that the people you interact with would __.". Following the recommendations of Vogel et al. (2009) to specify the sample, I specified those with whom you interact within the athletic context. A sample item is "think bad things of you." Cronbach's $\alpha=$ .82 in this study's sample. See Appendix C for the scale.

Public stigma. The Stigma Scale for Receiving Psychological Help (SSRPH; Komiya, Good, \& Sherrod, 2000) was used to measure public stigma. This is a five-item scale with anchors ranging from 0 (strongly disagree) to 3 (strongly agree). Higher scores represent more perceived public stigma. A sample item is "seeing a psychologist for emotional or interpersonal problems carries social stigma." In the validation study of 311 undergraduate students, the scale demonstrated adequate reliability $(\alpha=.72)$. Other samples using the scale have also found adequate validity above .70 (e.g., Topkaya et al., 2017; Vogel et al., 2009), including .81 in a sample of college student-athletes (Wahto et al., 2016). Komiya et al. (2000) found that a onefactor solution fit best and the scale correlated negatively with help-seeking attitudes. In the current study, Cronbach's $\alpha=.64$. See Appendix D for the scale.

Self-stigma. Self-stigma for seeking treatment was measured using the Self-Stigma of Seeking Help scale (SSOSH; Vogel, Wade, \& Haake, 2006). This is a 10-item scale containing five reverse-scored items that is measured on a five-point Likert-scale ranging from 1 (strongly disagree) to 5 (strongly agree). A sample question is "I would feel worse about myself if I could not solve my own problems." After reverse scoring, higher scores reflect greater levels of selfstigma for seeking help. Vogel et al. (2006) validated the scale in several samples of college students, which included more than 1000 participants. The internal consistency across those samples was good (i.e., $\alpha=.86$ to .91 ). Additionally, factor analyses confirmed a 
unidimensional structure. Self-stigma predicted counseling attitudes and intentions to seek help above other variables known to influence attitudes and was found to have a two-month test-retest reliability of $r=.72$. Similar stable psychometric properties have been found in samples of college student-athletes (e.g., Bird, Chow, et al., 2018; Ramaeker \& Petrie, 2019). Cronbach's $\alpha$ $=.83$ in the current study. See Appendix E for the scale.

Attitudes. Attitudes toward seeking counseling was measured using the Attitudes Toward Seeking Professional Psychological Help-Short Form (ATSPPH-SF; Fischer \& Farina, 1995). This scale is a shortened version of the original scale. This short version correlated highly with the full version in the initial validation study, $r=.87$. This scale contains ten items on a Likert-type scale ranging from 0 (disagree) to 3 (agree). Five of the items are reversed scored. After reverse scoring, higher scores indicate more positive attitudes toward counseling. A sample item is "I would want to get psychological help if I were worried or upset for a long period of time." The scale had a one-month test-rest reliability of $r=.80$ and had an internal consistency of $\alpha=.84$, similar to the internal consistency in samples of college athletes (Ramaeker \& Petrie, 2019). Cronbach's $\alpha=.78$ in this study. See Appendix F for the scale.

Intentions. The Mental Help-Seeking Intention Scale (MHSIS; Hammer \& Spiker, 2018) was used to measure one's intentions to seek counseling. The scale was created using a guide on developing Theory of Planned Behavior related instruments, which is an extension of TRA. The MHSIS is a three-item measure that examines intentions using a 7-point Likert-type scale that ranges from 1 to 7 . Each of the three questions has different anchors (e.g., extremely unlikely to extremely likely). The three items are averaged together and a higher score represents greater intentions to seek counseling. This three-item version created by Hammer and Spiker was found to be unidimensional and had the greatest predictive validity compared with two other commonly 
used intentions measures. The scale had an internal consistency of $\alpha=.94$ in the validating study of 405 adults, which was similar to the $\alpha=.95$ in this study. See Appendix G for the scale.

Help-seeking topics. Presenting concerns that student-athletes would be most willing to seek help for were measured using a modified version of the Intentions to Seek Counseling Inventory (ISCI; Cash, Begley, McCown, \& Weise, 1975). The original ISCI is a 17-item measure that contains three subscales: academic concerns, psychological and interpersonal concerns, and drug use concerns (Cepeda-Benito \& Short, 1998). The four-point Likert-type scale ranges from 1 (very unlikely) to 4 (very likely). Some sample items for which participants indicate they might seek help include loneliness, drug problems, and depression. However, the list omits items that might be relevant to the student-athlete population (e.g., athletic performance). Additionally, some of the language was outdated and might not relate to contemporary college students. Therefore, after conducting a literature search and receiving feedback from licensed psychologists with experience working with collegiate students and student-athletes, some items were modified to reflect recent reports of prominent presenting problems in college counseling centers (Pérez-Rojas et al., 2017) and additional items were added that would be relevant to athletes (e.g., Gavrilova \& Donohue, 2018). The final scale contained 20 items. Higher scores indicate a greater willingness to seek help. In this study, Cronbach's $\alpha=.87$. See Appendix H for the scale.

Attention checks. To reduce the possibility of getting a response set from participants, one attention check question was interspersed throughout the questions as well as a brief distraction scale. Because survey packets were counterbalanced, two separate forms of attention checks were used depending on their place in the packet. One was "please write in the number for 'a lot' (4) to answer this question" and the other was "please circle 2 in response to this 
question." The social identity subscale of the Athletic Identity Measurement Scale (Brewer \& Cornelius, 2001) was used as the distractor scale. This is a three-item measure that examines the strength that athletes identify with social aspects of that role. These items include "I consider myself an athlete", "I have many goals related to sports", and "most of my friends are athletes."

Demographics. The participants also responded to several demographic questions to provide basic background information. Some of the topics included sport, previous mental health treatment experience, and division of participation. See Appendix I for the questions.

\section{Procedure}

After receiving university IRB approval (Appendix K), the researcher contacted coaches at three universities. If the coach agreed to participate in the study, the researcher met with the team at a convenient time and place to administer the counterbalanced survey packet in person. No coaches or athletic staff were present during data collection. Following data collection, the researcher debriefed participants and they were released. Participants were not compensated and all provided consent. In total, the researcher contacted 26 coaches to participate, and 13 granted permission.

\section{Data Analysis Plan}

A power analysis was conducted prior to collecting data using Soper's (2013) online calculator for structural equation modeling (SEM). Given the number of latent and observed variables in this study, with a power level of 0.80 and a probability level of .05 , the minimum sample size was 268. Therefore, the sample of 312 used for SEM in this study was perceived to be sufficient. To test the hypotheses, AMOS 25.0 (Arbuckle, 2017) was used to examine the data. A two-step model was followed wherein the measurement model was first examined, followed by the structural model (Kline, 2016). This hypothesized model was also compared 
with a plausible alternative model. Finally, mediation through indirect effects via bootstrapping was used to compute bias-corrected percentile confidence intervals, which can be used in cases of multivariate nonnormality (Preacher \& Hayes, 2008; Shrout \& Bulger, 2002). SEM was used to test the three hypotheses that public and social network stigma will be associated with selfstigma, that the relationship of these two stigmas with intentions will be mediated through selfstigma and attitudes, and finally that self-stigma will negatively relate to attitudes and attitudes will positively relate to intentions. The goodness-of-fit for the models was assessed using the comparative fit index (CFI), incremental fit index (IFI), root mean square error of approximation (RMSEA), and the standardized root mean residual (SRMR). The guidelines put forth by Hu and Bentler (1999) for good fit were utilized: CFI and IFI $\geq .95, \mathrm{RMSEA} \leq .06$, and $\mathrm{SRMR} \leq .08$.

To answer the first research question, a logistic regression was used to test the predictive validity of the variables on previous help-seeking experience. Gender was entered in the first step because it is known to relate to help-seeking, and all three forms of stigma, attitudes, and intentions were entered in step two. Finally, to answer the second research question related to help-seeking topics, descriptive statistics and frequencies were calculated using SPSS. The alpha level for all analyses was set at .05.

Item parcels. All scales used in the structural model were unidimensional, which eliminated the possibility of using subscales to represent the latent variable. Thus, to reduce the total number of parameters and improve model fit, parcels were created to represent each latent variable following steps outlined by Russell, Kahn, Spoth, and Altmaier (1998). The scales for public stigma and social network stigma both contained five items, so two parcels were created for each. The scales for self-stigma and attitudes each contained ten items and were given three parcels. Because the intentions scale was only three items, each item was used to represent the 
latent variable. To create necessary parcels, an exploratory factor analysis fit to a one-factor solution was run for the required measures. The factor loadings were balanced on parcels in a way that each parcel would be approximately equal. This was done by alternating highest and lowest loadings on each parcel (Russell et al., 1998).

\section{Data Screening}

\section{Results}

Initially, 334 surveys were returned out of a possible 336 participants. Six failed the attention check and were subsequently deleted (Spiker \& Hammer, 2018). These 328 participants were eligible for the secondary analysis regarding help-seeking topics. This analysis did not rely on statistical assumptions and only required responses to each of the individual items. However, for the main analysis, further cleaning was required. Six additional participants were deleted because they did not complete at least one entire scale, not including the MHSIS. Parent (2013) and Garriot et al. (2017) recommend deleting participants who complete less than $80 \%$ of a scale. Parent (2013) further recommended deletion if the overall sample was going to be negligible and under 5\%. The participants deleted from the current study did not complete any of the items on a particular scale, falling well under the $80 \%$ range. Additionally, Hammer and Spiker (2018) state that a mean should not be calculated for individuals who do not complete all three items on the MHSIS, which resulted in eight deletions. This left 314 participants to examine missingness and statistical assumptions. Overall, there were 16 missing values out of a total of 10,362 values. Percentage of missingness ranged from $0.3-1.3 \%$. Due to such low missingness, values were replaced using expectation maximization (Schlomer, Bauman, \& Card, 2010).

Next, steps outlined by Tabachnick and Fidell (2013) were followed for examining outliers and assumptions. All variables appeared to be normally distributed, although the 
skewness ratio for social network stigma exceeded 3.29, suggesting possible nonnormality

(Tabachnick \& Fidell, 2013). However, according to Byrne (2016), extreme kurtosis is more concerning for SEM, and the skewness values were not above the threshold indicating problematic nonnormality. As a result, to ease interpretation, the variable was left untransformed. There was one univariate outlier with a $z$-score above 3.29 that was deleted, and one multivariate outlier with a Mahalanobis distance value exceeding the critical value for the degrees of freedom in this study, and was subsequently deleted. This meant that 312 participants were included in the SEM and logistic regression analyses. The data met all other multivariate assumptions. The last step was to check for multivariate normality, and Mardia's coefficient was 9.46, suggesting mild multivariate nonnormality (Byrne, 2016).

\section{Preliminary Analyses}

Means, standard deviations, and correlations were examined between the variables included in the SEM and logistic regression analyses. These values can be seen in Table 2. The correlations between all variables were significant and in the expected direction. The strongest relationship was between attitudes and intentions, $r=.61, p<.001$, and the weakest was between social network stigma and intentions, $r=-.12, p=.04$.

\section{Relationships Between Stigma, Attitudes, and Intentions}

The measurement model provided good fit to the data, $\chi^{2}(55, N=312)=109.19, p<.01$, $\mathrm{CFI}=.98, \mathrm{RMSEA}=.05[90 \% \mathrm{CI}=.04, .07], \mathrm{IFI}=.98, \mathrm{SRMR}=.04$. All items loaded significantly on their observed factors, with loadings ranging from $\beta=.56$ to .97 . Table 3 displays the full values from the measurement model. Overall, the goodness-of-fit and the loadings suggested that the latent variables were adequately measured. 
The structural model was examined next. The researcher first tested the hypothesized model with public and social network stigma as exogenous variables whose relationship with intentions was mediated through self-stigma and attitudes. This model demonstrated good fit to the data, $\chi^{2}(60, N=312)=119.75, p<.01, \mathrm{CFI}=.98, \mathrm{RMSEA}=.06[90 \% \mathrm{CI}=.04, .07]$, IFI $=$ .98, SRMR $=.05$. This model accounted for $47 \%$ of the variance in self-stigma, $41 \%$ of the variance in attitudes, and $50 \%$ of the variance in intentions. This model can be seen in Figure 1. Of note, all hypothesized pathways were significant, except for the one between social network stigma and self-stigma $(\beta=-.02, p=.83)$.

Next, a plausible alternative model (Kline, 2016) was tested, where public and social network stigma each had a direct path to intentions. This partially mediated model also demonstrated good fit, $\chi^{2}(58, N=312)=118.34, p<.01, \mathrm{CFI}=.98, \mathrm{RMSEA}=.06[90 \% \mathrm{CI}=$ $.04, .07], \mathrm{IFI}=.98, \mathrm{SRMR}=.05$. The original pathways all remained significant, but the two new direct pathways from public and social network stigma to intentions were not significant. A test to compare the two models found that they fit the data equally, $\chi^{2}(2, N=312)=1.41, p=$ .49. Given that the additional pathways were not significant, the original, smaller parsimonious model was utilized to test indirect effects.

Indirect effects. To calculate indirect effects, 5000 bias-corrected bootstrap samples were requested using AMOS. As shown in Table 4, all indirect effects in the model were significant with the exception of any pathways that included social network stigma. In addition to the AMOS output for significance, the $95 \%$ confidence intervals for the pathways deemed significant did not contain zero, confirming that they are significant (Shrout \& Bulger, 2002). Predicting Previous Help-Seeking 
To answer the first research question, the researcher conducted a binary logistic regression using the measured variables as predictors of previous help-seeking history. An additional assumption for logistic regression includes testing the linearity of the logit, and this assumption was met. Results from this regression analysis are seen in Table 5. The model was not significant after only including gender in step one, but the full model was significant, $\chi^{2}(6, N$ $=310)=28.19, p<.001$. The Hosmer-Lemeshow test for this model indicated good fit, $\chi^{2}(8)=$ 5.63, $p=.69$. As seen in the table, self-stigma $(\operatorname{Exp} \beta=2.28, p=.01)$ and attitudes $(\operatorname{Exp} \beta=3.76$, $p=.001)$ significantly predicted previous mental health service use. These odds ratios both suggest that as the individual scored higher in self-stigma or attitudes, they were more likely to have previously sought mental health services.

\section{Help-Seeking Topics}

To answer the second research question, the researcher compiled means and standard deviations for each variable on the ISCI. Overall, drug problems, depression, and excessive alcohol use were the highest rated issues for which student-athletes were likely to seek help. The lowest rated topics were concerns about sexuality, difficulty with friends, and body image. When split by gender, the results remained primarily the same. For women, the highest ranked topics were anxiety, depression, and drug problems, whereas the lowest ranked were concerns about sexuality, difficulty with friends, and difficulty with sleeping. For men, the highest and lowest rated topics were identical to the overall sample, although the order varied for the lowest ranked. Body image was the second lowest ranked topic, followed by difficulty with friends at third. The results for all 20 items on this scale can be seen in Table 6.

\section{Discussion}


The purpose of the current study was to explore the role of various stigmas on intentions to seek counseling and how these factors were associated with previous help-seeking experience. An additional aim of this study was to determine which topics student-athletes are most and least willing to seek help for professionally. The researcher hypothesized that public stigma and social network stigma would be positively associated with self-stigma. In turn, self-stigma would be negatively associated with attitudes toward counseling, and attitudes would then be positively associated with intentions to seek counseling. Further, it was hypothesized that all indirect effects would be significant. There were no hypotheses for the research questions. Overall, the hypotheses were mostly supported.

\section{Help-Seeking Intentions and Behavior}

Previous researchers have identified stigma as having a strong association with attitudes toward help-seeking in college athletes (Bird, Chow, et al., 2018; Wahto et al., 2016). Specifically, public stigma, social network stigma, and self-stigma have all been linked with counseling attitudes, with self-stigma having the strongest link (Bird, Chow, et al., 2018; Hilliard et al., 2018; Wahto et al., 2016). In the current study, social network stigma was not significantly associated with self-stigma. The overall low scores and restricted range of responses of social network stigma may have contributed to its lack of significance. Alternatively, it is possible that contemporary athletes receive more positive messages from teammates and coaches related to mental health help-seeking than in the past and thus these beliefs are not being internalized in the form of self-stigma. However, public stigma, selfstigma, and attitudes were related to intentions. This aligns with the findings of a recent study of male college student-athletes, where self-stigma and attitudes were associated with intentions (Ramaeker \& Petrie, 2019). This suggests that those with more positive attitudes toward seeking 
help will also endorse greater intentions to seek mental health counseling if necessary. When comparing the overall levels of stigma and attitudes to other studies of student-athletes, there are minimal differences (Bird, Chow, et al., 2018; Hilliard et al., 2018; Wahto et al., 2016). The largest difference between means on a measure was 0.21 for public stigma on a 5 -point scale (Hilliard et al., 2018). Thus, when interpreting these results within the broader literature, the current sample does not appear to be different from other study populations.

These findings support the assertions of the TRA (Ajzen \& Fishbein, 1980) that more positive attitudes toward a health behavior will result in increased intentions of engaging in that behavior. Subjective norms is another component of the TRA and was measured via public stigma. Public stigma contributed to inform intentions, as seen through the indirect relationship between public stigma and intentions through mediating pathways, including self-stigma, an important variable related to attitudes. The importance of these variables in this theoretical construct was further established when examining predictors of previous help-seeking behavior. Similar to the structural model, more positive attitudes were indicative of the greatest increase in likelihood that an individual had previously sought mental health services. Attitudes have previously been associated with actual service use (ten Have et al., 2010), and in this sample they were the strongest predictor of previous help seeking. This finding is slightly inconsistent with the TRA, where the most proximal measure of behavior (i.e., intentions) should be the strongest predictor.

Additionally, there was a strong correlation between attitudes and intentions present in the study. Given this information, future researchers may want to examine the utility of intentions over and above attitudes for examining student-athlete help-seeking behavior. One possibility for why attitudes may have been more important than intentions may be the 
unpredictability associated with intentions. Half of the variance in intentions was accounted for in this study. In the only other study of student-athletes to measure intentions in line with this framework, $38 \%$ of the variance in attitudes was accounted for, but only $8 \%$ for intentions (Ramaeker \& Petrie, 2019). Part of this low variance may be due to the measure of intentions that was used by Ramaeker and Petrie, which is arguably not a good measure of actual helpseeking intentions (Hammer \& Spiker, 2018). It is difficult for an individual to predict how one might act in a certain situation, which is what intention measures ask participants to do. Given the low number of individuals who were currently seeking help and the scores on the various measures, it appears that the sample in the current study was at fairly low risk. This may have contributed to ambivalent intentions scores. Attitudinal measures, on the other hand, probe what the participant currently believes. This is not to say that intentions measures have no use in examining help-seeking behavior, as multiple meta-analyses have found that they are relatively accurate predictors of behavior (e.g., Armitage \& Conner, 2001; Sheppard, Hartwick, \& Warshaw, 1988). In fact, in a recent sample of college students, intention was found to predict previous mental health service use, although attitudes were not included in the logistic regression so a comparison could not be made (Li, Denson, \& Dorstyn, 2018). In their study, the odds ratio for intentions varied between 1.03-1.04 across various blocks, indicating a fairly weak influence. However, the decision to seek help is often not a fully rational or linear process, and therefore intentions may not always be a strong predictor future behavior. Thus, future research using variables to measure the full TRA model and using the MHSIS as the intentions measure would clarify the relationship between intentions and help-seeking behavior.

An unusual finding in this study was that self-stigma was associated with an increased likelihood of having sought services in the past. This is a novel finding that contrasts previous 
studies of help-seeking. It is unknown why this occurred in the present sample, but there are a few potential statistical and practical explanations for this relationship. Levels of self-stigma did not vary between groups of individuals who had or had not previously sought counseling and there was no correlation between self-stigma and previous help-seeking. Further, in post-hoc logistic regressions to explore this finding, self-stigma was only a significant predictor when coupled with attitudes (See Appendix J). Thus, it is possible that attitudes were having a statistical influence on self-stigma and this finding was an anomaly. However, this finding supports the assertions of Schomerus and Angermeyer (2008) that the relationship between attitudes, self-stigma, and help-seeking behavior might not be as clear as previously believed. Regardless, further research is needed to corroborate this result.

Practically, one possible explanation is that self-stigma was developed as a response to seeking treatment. No research was located that temporally examined the development of selfstigma, and it is possible that negative experiences with a counselor led to increased levels of self-stigma. A second plausible explanation is that the levels of self-stigma was overpowered by other needs of the individuals. Previous researchers have found that individuals who recognize they have a mental health issue or concern are more likely to endorse greater levels of selfstigma (e.g., Corrigan \& Watson, 2002; Jones, Keeling, Thandi, \& Greenberg, 2015). Further, some individuals reject the meaning of the self-stigma, even if they possess it (Corrigan \& Watson, 2002). Therefore, it is possible that the student-athletes in the current study who had previously sought mental health services were aware of their concerns, which led to increased levels of self-stigma. However, as student-athletes, they might have also recognized that their mental health influences their performance. A previous study has confirmed this as one reason why student-athletes sought mental health services (Bird, Chow, \& Cooper, 2018). With the 
desire to be as healthy as possible to compete at their highest level, their athletic identity or competitive desires may have played a more prominent role in the decision to seek help, negating the negative effects of self-stigma. However, this is currently speculation. Future examination of the temporal associations of self-stigma and other help-seeking related variables would clarify this relationship.

\section{Help-Seeking Topics}

The second research question was designed to assess the topics for which student-athletes report being most willing to seek help, ranking them from most to least likely. The results indicated that overall, student-athletes would be most likely to seek help for drug problems, depression, and excessive alcohol use and least likely to seek help for concerns regarding sexuality, difficulties with friends, and body image. These results were similar across gender as well, except that anxiety was rated as highest for women, eliminating excessive alcohol use, and difficulty sleeping was the lowest rated, eliminating body image concerns.

These results fall in stark contrast to the preferences of the student-athletes in Naoi et al. (2011). In their study, mental health concerns and alcohol and drug issues ranked ninth and tenth, respectively, out of a list of ten items. However, the differences in methodology explain this inconsistency. The participants in Naoi et al. (2011) were asked to rate preferences for topics when meeting with a sport psychology consultant. In the current study, participants responded to a list of topics for which people often seek counseling. Therefore, it was apparent that these issues would be discussed with a mental health professional and not a sport psychology consultant. This aligns with previous research that has found that student-athletes display preferences for professionals based on match regarding their particular concern (Maniar et al., 2001). Thus, it makes sense that the student-athletes reported high levels of willingness to seek 
help for drug and alcohol use and depression with a counselor, but did not prefer to discuss these issues with a sport psychology consultant (Naoi et al., 2011). Interestingly, seeking counseling for athletic performance was rated fairly low in this sample, which further indicates that the match with the professional might be an important indicator of their intentions to seek help for a particular issue.

The issues rated most highly in this study have also been identified as important mental health concerns that student-athletes face (Gavrilova \& Donohue, 2018). These findings also broadly mirror the results from a large-scale study of presenting concerns in college counseling centers, where the top three concerns for athletes were anxiety, stress, and depression (PérezRojas et al., 2017). However, alcohol and drug use was not included in their ranking system, so it is not known how many athletes presented with those concerns. Nevertheless, the high willingness to seek help for drug or alcohol issues is a promising step forward, as these are often deeply stigmatized issues. One possible explanation for the high rankings for these topics could be that the majority of the sample came from a Christian affiliated school with a strict drug and alcohol use policy. This environmental factor may have led to a greater willingness to seek help for those particular topics. Comparisons between the help-seeking topics scale and other studentathlete populations cannot be made.

Equally important to the highest rated topics are those that were ranked low amongst the athlete group. Although student-athletes could benefit from seeking mental health services for all items on the scale, the reasons for these three being lowest ranked warrant discussion. Regarding concerns about sexuality, it is possible that most student-athletes do not perceive this to be an issue they will face if they have not already, and consequently ranked it low. In a study of 8,481 NCAA student-athletes, 5\% reported being lesbian, gay, bisexual, or questioning (LGBQ; 
Rankin \& Merson, 2012). Additionally, the sports identified in the report as having an underrepresentation of LGBQ student-athletes comprised a majority of this sample. Therefore, without perceived relevance, the student-athletes may have rated it low.

Similar to perceived relevance, necessity for the counseling context might explain why difficulties with friends was ranked low. It is possible that student-athletes do not perceive this issue to be a concern that warrants seeking professional help. In fact, student-athletes most commonly report a preference for informal sources of help-seeking, such as friends, family, and coaches (Bird, Chow, et al., 2018; Naoi et al., 2011). Thus, student-athletes might take concerns about friendship to other groups of friends, their parents, or a coach to handle the situation.

Finally, the low rating of body image concerns is likely due to three aspects of the sample. First, student-athletes who compete in aesthetic sports are more likely to have body image concerns, and these sports were underrepresented in the current sample (Gavrilova \& Donohue, 2018). In addition to the lack of aesthetic sports, the sample was primarily male, which could have also reduced the ratings because female athletes generally report higher body image concerns (DeFeciani, 2016). This pattern is evidenced by the fact that when examining the topics by gender, body image concerns is ranked higher for the women than for the men. However, encouraging help-seeking for those with body image concerns is important regardless of gender, because of the potential myriad detrimental effects that could occur in association with poor body image (DeFeciani, 2016; Varnes et al., 2013). Further, in a recent meta-analysis, body image concerns were significantly higher in NCAA Division I athletes compared with Division III athletes (Varnes et al., 2013), and since this sample only contained Division II and III athletes, the low rating aligns with these previous findings.

\section{Implications}


The results of this study have several implications for those who are involved in working with collegiate student-athletes. The first implication highlights the importance of attitudes in the help-seeking process. Attitudes were significantly related to intentions to seek counseling and strongly increased the likelihood of having sought counseling previously. Altering levels of stigma is often one method suggested for improving attitudes, and in this study reducing public and self-stigma would seem to improve attitudes. Stigma reduction interventions can take many forms, but the most common are contact and education (Corrigan, Morris, Michaels, Rafacz, \& Rüsch, 2012). Contact interventions refer to exposing individuals to others who have experienced a mental illness or previously sought counseling. Education refers to imparting knowledge regarding prevalence of mental health disorders, discussing symptoms, and normalizing the experience. Generally, contact interventions have been found to be more influential in decreasing stigma (Corrigan et al., 2012). Often, these two interventions can be combined in the same workshop or presentation. A presentation could begin with education regarding stigma and mental health, and a speaker could interact with the audience regarding his or her own help-seeking experiences. A similarly formatted program has been pilot tested and found to result in minor reductions in stigma immediately following the presentation (Kern et al., 2017). However, given that only $41 \%$ of the variance in attitudes was accounted for by the various forms of stigma in the current study, it is important to research other factors that could contribute. Additionally, in the current study self-stigma was predictive of previous help-seeking service use, which convolutes the benefits of reducing this form of stigma. However, the potential statistical influence of attitudes in this sample means that more research is needed in this area. 
Another major implication of this study is the importance of having a multidisciplinary team of professionals with different specializations. As the student-athletes in this current study reported an elevated willingness to discuss certain topics in the counseling setting that they did not prefer to discuss with a sport psychology consultant in previous research (Naoi et al., 2011), having professionals on staff who specialize in performance enhancement consulting in addition to mental health concerns could help make sure student-athletes receive holistic care. Recently, the NCAA Division I Power 5 conferences unanimously approved a mandate to require access to mental health services (NCAA, 2019). However, the sample in this study did not consist of Division I athletes, and therefore this guarantee does not exist for them. In most situations, counseling is available for free for students at colleges and universities through the college counseling center, and these are often the resources that Division II and III institutions must rely on to serve their student-athletes. Counseling center directors at these institutions would be wise to hire at least one individual with some training in sport psychology to act as a liaison with athletics while simultaneously being able to help meet the colleges' other counseling needs. This training would promote greater competence in the area, while increasing the likelihood of student-athletes utilizing services, as having a professional who is familiar with their lifestyle and can understand them is an important facilitator of use (López \& Levy, 2013; Moore, 2017).

Additionally, the ranked list of topics can be used to improve outreach efforts with student-athletes. Those topics that are highest ranked are often ones that students recognize as appropriate for counseling, but it is equally important to stress how counseling can be helpful for all of the items present in this study. Underlying a low willingness to seek help for some of the concerns might be a belief that these issues are not severe enough to warrant counseling (Moreland et al., 2018). Therefore, increasing their knowledge regarding counseling services and 
appropriate topics might improve their willingness to seek help. In support of this idea, one recent study of Australian college students found that knowledge of mental health was a significant predictor of previous service use (Li et al., 2018).

\section{Limitations and Future Research}

One limitation of the current study is that due to the makeup of the campuses and teams who participated, the sample predominately consisted of White males. This limits the generalizability to other groups of individuals. Another limitation was the response rate from coaches. Although a very high percentage of athletes who were available participated, a lack of response from numerous coaches meant that many of the student-athletes at the schools were not sampled. It is possible that those coaches who agreed have a vested interest in their studentathlete's mental health and might interact with their athletes differently regarding mental health services compared to those who did not respond. Finally, the number of athletes who had previously sought counseling was relatively small for use in logistic regression. Although the results indicated a good fit to the model, the small cell size means that those results should be interpreted with caution.

Despite these limitations, there are several ways this study adds to the literature. First, it sampled understudied Division II and III student-athletes from three different schools, using a larger sample across more universities than most studies that focus on student-athletes' attitudes toward seeking counseling. Additionally, the method reduced the possibility for self-selection. Previous researchers often emailed athletes to encourage their participation, and those who selfselect may be inherently different than those who decline participation. By collecting data in person with the groups, there was a response rate of $99 \%$, which means that a broad range of 
experiences was likely captured. Finally, the ranked list of help-seeking topics produced in this study can be used to aid practitioners and researchers in the future.

Several avenues for future research arise from this study. First, studies that employ a longitudinal design that examine the various factors in this investigation and their relationship with help-seeking would provide more rigorous evidence for the role of stigma and attitudes with engaging in counseling. Second, the finding that self-stigma was associated with an increased likelihood of previously utilizing mental health services should be replicated with a larger and more diverse sample.

Other factors that might influence help-seeking behavior would shed light on what drives individuals to seek help. One such variable is mental health literacy, or the ability for studentathletes to recognize a mental health concern. Incorporating a solid theoretical framework such as the TRA or extending it to the Theory of Planned Behavior by including perceived behavioral control (Armitage \& Conner, 2001) would strengthen the quality of this research. Additionally, qualitative investigation into the help-seeking experiences of student-athletes is warranted. Although many studies examine help-seeking in a linear fashion, the decision to seek help is often not that simple. The intensity of a current stressor or concern may push someone to seek counseling services even if they tend to stigmatize themselves or others for doing so or hold negative attitudes. Future research could utilize a sample of athletes who have sought services to get an understanding of why they decided to seek services at that time to aid our quantitative knowledge of this process. Some of this research has begun (Bird, Chow, \& Cooper, 2018), but more is needed.

Finally, there are areas to improve measurement. This is the second study where the SSRPH has produced an alpha just below .70 (Hilliard et al., 2018). It is possible that this 
measure is not best suited for use with the student-athlete population, and future research should examine its psychometric properties in this group or work to develop a new measure. Additionally, future studies would be strengthened by gaining more information regarding past help seeking. Age at treatment and whether or not attendance was voluntary might be relevant to the development of their stigma or attitudes and should be taken into consideration. In this study, the researcher predicted previous mental health services use and a closer range in previous helpseeking might be more beneficial for predicting future use.

\section{Conclusion}

The results of this study mostly confirmed previous research, where public stigma was positively associated with self-stigma, which was negatively related with attitudes, and consequently attitudes positively related to intentions. Social network stigma, however, was not directly or indirectly related to help-seeking. The results of the current study indicate that attitudes play a crucial role in determining help-seeking behavior, and researchers should continue working to find empirically validated methods of improving attitudes toward counseling. Likewise, this information can be used by clinicians to guide their group level work with student-athletes. The results from the ranking of topics suggests that student-athletes are not open to discussing all concerns in the counseling context equally, and this information can aid outreach as well. Future research can continue to examine interventions that can be used to reduce various forms of stigma and improve attitudes to seek mental health services. 


\section{References}

Ajzen, L, \& Fishbein, M. (1980). Understanding attitudes and predicting social behavior. Englewood Cliffs, NJ: Prentice-Hall.

Arbuckle, J. L. (2017). Amos (Version 25.0) [Computer Program]. Chicago: IBM SPSS.

Armitage, C. J., \& Conner, M. (2001). Efficacy of the Theory of Planned Behaviour: A metaanalytic review. British Journal of Social Psychology, 40, 471-499. https://doi.org/10.1348/014466601164939

Associated Press. (2018, Jan 17). Washington State quarterback's death permeates NCAA convention discussions. Retrieved from https://www.usatoday.com/story/sports/ncaaf/2018/01/17/washington-state-quarterbackdeath-permeates-ncaa-convention-discussions/109556518/

Biggin, I. J. R., Burns, J., \& Uphill, M. A. (2017). An investigation of athletes' and coaches' perceptions of mental-ill health in elite athletes. Journal of Clinical Sport Psychology, 11, 126-147. https://doi.org/10.1123/jcsp.2016-0017

Bird, M. D., Chow, G. M., \& Cooper, B. T. (2018). Student-athletes' mental health help-seeking experiences: A mixed methodological approach. Journal of College Student Psychotherapy. Advance online publication. https://doi.org/10.1080/87568225.2018.1523699

Bird, M. D., Chow, G. M., Meir, G., \& Freeman, J. (2018). Student-athlete and student nonathletes' stigma and attitudes toward seeking online and face-to-face counseling. Journal of Clinical Sport Psychology, 12, 347-364. https://doi.org/10.1123/jcsp.2017-0010

Brewer, B. W., \& Cornelius, A. E. (2001). Norms and factorial invariance of the Athletic Identity Measurement Scale. Academic Athletic Journal, 15, 103-113. 
Byrne, B. M. (2016). Structural equation modeling with Amos: Basic concepts, applications, and programming ( $3^{\text {rd }}$ ed.). New York: Routledge.

Cash, T. E., Begley, P. J., McCown, D. A., \& Weise, B. C. (1975). When counselors are heard but not seen: Initial impact of physical attractiveness. Journal of Counseling Psychology, $22,273-279$.

Cepeda-Benito, A., \& Short, P. (1998). Self-concealment, avoidance of psychological services, and perceived likelihood of seeking professional help. Journal of Counseling Psychology, 45, 58-64. http://dx.doi.org/10.1037/0022-0167.45.1.58

Corrigan, P. (2004). How stigma interferes with mental health care. American Psychologist, 59, 614-625. http://dx.doi.org/10.1037/0003-066X.59.7.614

Corrigan, P. W., Morris, S. B., Michaels, P. J., Rafacz, J. D., \& Rüsch, N. (2012). Challenging the public stigma of mental illness: A meta-analysis of outcome studies. Psychiatric Services, 63, 963-973. https://doi.org/10.1176/appi.ps.201100529

Corrigan, P. W., \& Watson, A. C. (2002). The paradox of self-stigma and mental illness. Clinical Psychology: Science and Practice, 9, 35-53. https://doi.org/10.1093/clipsy.9.1.35

DeFeciani, L. (2016). Eating disorders and body image concerns among male athletes. Clinical Social Work Journal, 44, 114-123. doi: 10.1007/s10615-015-0567-9

DeLenardo, S., \& Lennox Terrion, J. (2014). Suck it up: Opinions and attitudes about mental illness stigma and help-seeking behavior of male varsity football players. Canadian Journal of Community Mental Health, 33, 43-56. doi:10.7870/cjcmh-2014-023

Drew, B., \& Matthews, J. (2018). The prevalence of depressive and anxiety symptoms in student-athletes and the relationship with resilience and help-seeking behavior. Journal of 
Clinical Sport Psychology. Advance online publication. https://doi.org/10.1123/jcsp.2017-0043

Etzel, E. F., Watson, J. C., Visek, A. J., \& Maniar, S. D. (2006). Understanding and promoting college student-athlete health: essential issues for student affairs professionals. Journal of Student Affairs Research and Practice, 43, 518-546. doi: 10.2202/1949-6605.1685

Fischer, E. H., \& Farina, A. (1995). Attitudes toward seeking professional psychological help: A shortened form and considerations for research. Journal of College Student Development, $36,368-373$.

Garriott, P. O., Raque-Bogdan, T. L., Yalango, K., Schaefer Ziemer, K., \& Utley, J. (2017). Intentions to seek counseling in first-generation and continuing-generation college students. Journal of Counseling Psychology, 64, 432-442. http://dx.doi.org/10.1037/cou0000210

Gavrilova, Y., \& Donohue, B. (2018). Sport-specific mental health interventions in athletes: A call for optimization models sensitive to sport culture. Journal of Sport Behavior, 41, 283-304.

Gucciardi, D. F., Hanton, S., \& Fleming, S. (2017). Are mental health and mental toughness contradictory concepts in elite sport? A narrative review of theory and evidence. Journal of Science and Medicine in Sport, 20, 307-311.

https://doi.org/10.1016/j.jsams.2016.08.006

Hammer, J. H., \& Spiker, D. A. (2018). Dimensionality, reliability, and predictive evidence of validity for three help seeking intention instruments: ISCI, GHSQ, and MHSIS. Journal of Counseling Psychology, 65, 394-401. http://dx.doi.org/10.1037/cou0000256 
Hilliard, R. C., Redmond, L. A., \& Watson II, J. C. (2018). The relationships among selfcompassion, stigma, and attitudes toward counseling in student-athletes. Journal of Clinical Sport Psychology. Advance online publication. https://doi.org/10.1123/jcsp.2018-0027

Jolly, J. C. (2008). Raising the question \#9 Is the student-athlete population unique? And why should we care? Communication Education, 57, 145-151. http://dx.doi.org/10.1080/03634520701613676

Jones, N., Keeling, M., Thandi, G., \& Greenberg, N. (2015). Stigmatisation, perceived barriers to care, help seeking and the mental health of British Military personnel. Social Psychiatry and Psychiatric Epidemiology, 50, 1873-1883. doi: 10.1007/s00127-015-1118-y

Kern, A., Heininger, W., Klueh, E., Salazar, S., Hansen, B., Meyer, T., \& Eisenberg, D. (2017). Athletes Connected: Results from a pilot project to address knowledge and attitudes about mental health among college student-athletes. Journal of Clinical Sport Psychology, 11, 324-336. https://doi.org/10.1123/JCSP.2016-0028

Kline, R. B. (2016). Principles and practice of structural equation modeling (4th ed.). New York, NY: Guilford Press.

Komiya, N., Good, G.E., \& Sherrod, N. B. (2000). Emotional openness as a predictor of college students' attitudes toward seeking psychological help. Journal of Counseling Psychology, 47, 138-143. doi: 10.1037/AJ022-0167,47.1.138

Li, W., Denson, L. A., \& Dorstyn, D. S. (2018). Understanding Australian university students' mental health help-seeking: An empirical and theoretical investigation. Australian Journal of Psychology, 70, 30-40. doi: 10.1111/ajpy.12157 
López, R., L., \& Levy, J., J. (2013). Student athletes' perceived barriers to and preferences for seeking counseling. Journal of College Counseling, 16, 19-31. doi: 10.1002/j.2161$\underline{1882.2013 .00024 . x}$

Maniar, S. D., Curry, L. A., Sommers-Flanagan, J., \& Walsh, J. A. (2001). Student-athlete preferences in seeking help when confronted with sport performance problems. The Sport Psychologist, 15, 205-223. https://doi.org/10.1123/tsp.15.2.205

Moore, M. (2017). Stepping outside of their comfort zone: Perceptions of seeking behavioral health services amongst college athletes. Journal of Issues in Intercollegiate Athletics, 2017 special issue, 130-144.

Moreland, J. J., Coxe, K. A., \& Yang, J. (2018). Collegiate athletes' mental health services utilization: A systematic review of conceptualizations, operationalizations, facilitators, and barriers. Journal of Sport and Health Science, 7, 58-69. http://dx.doi.org/doi: 10.1016/j.jshs.2017.04.009

Naoi, A., Watson, J., Deaner, H., \& Sato, M. (2011). Multicultural issues in sport psychology and consultation. International Journal of Sport \& Exercise Psychology, 9, 110-125. http://dx.doi.org/10.1080/1612197X.2011.567101

National Collegiate Athletic Association. (2016a). NCAA GOALS study of the student-athlete experience: Initial summary of findings January 2016. Retrieved from http://www.ncaa.org/sites/default/files/GOALS_2015_summary_jan2016_final_2016062 7.pdf

National Collegiate Athletic Association Mental Health Task Force. (2016b). Mental health best practices: Inter-association consensus document: Best practices for understanding and supporting student-athlete mental wellness. Indianapolis, IN: Author. 
National Collegiate Athletic Association. (2019, January 24). Access to mental health services guaranteed by autonomy conferences. Retrieved from http://www.ncaa.org/about/resources/media-center/news/access-mental-health-servicesguaranteed-autonomy-conferences

Parent, M. C. (2013). Handling item-level missing data: Simpler is just as good. The Counseling Psychologist, 41, 568-600. https://doi.org/10.1177/0011000012445176

Pérez-Rojas, A. E., Lockard, A. J., Bartholomew, T. T., Janis, R. A., Carney, D. M., Xiao, H., . . . Hayes, J. A. (2017). Presenting concerns in counseling centers: The view from clinicians on the ground. Psychological Services, 14, 416-427. http://dx.doi.org/10.1037/ser0000122

Pinkerton, R. S., Hinz, L. D., \& Barrow, J. C. (1989). The college student-athlete: Psychological considerations and interventions. Journal of American College Health, 37, 218-226. doi: $10.1080 / 07448481.1989 .993906$

Preacher, K. J., \& Hayes, A. F. (2008). Asymptotic and resampling strategies for assessing and comparing indirect effects in multiple mediator models. Behavior Research Methods, 40, 879-891. doi: 10.3758/BRM.40.3.879

Ramaeker, J., \& Petrie, T. A. (2019). “Man up!”: Exploring intersections of sport participation, masculinity, psychological distress, and help-seeking attitudes and intentions. Psychology of Men \& Masculinities. Advance online publication. http://dx.doi.org/10.1037/men0000198

Rankin, S., \& Merson, D. (2012). LGBTQ national college athlete report. Charlotte, NC: Campus Pride. Available from https://www.campuspride.org/wpcontent/uploads/CampusPride-Athlete-Report-Exec-Summary.pdf 
Russell, D. W., Kahn, J. H., Spoth, R., \& Almaier, E. M. (1998). Analyzing data from experimental studies: a latent variable structural equation modeling approach. Journal of Counseling Psychology, 45, 18-29. http://dx.doi.org/10.1037/0022-0167.45.1.18

Sarac, N., Sarac, B., Pedroza, A., \& Borchers, J. (2018). Epidemiology of mental health conditions in incoming division I collegiate athletes. The Physician and Sportsmedicine, 46, 242-248. https://doi.org/10.1080/00913847.2018.1427412

Schinke, R. J., Stambulova, N. B., Si, G., \& Moore, Z. (2018). International Society of Sport Psychology position stand: Athletes' mental health, performance, and development. International Journal of Sport and Exercise Psychology, 16, 622-639. http://dx.doi.org/10.1080/1612197X.2017.1295557

Schlomer, G. L., Bauman, S., \& Card, N. A. (2010). Best practices for missing data management in counseling psychology. Journal of Counseling Psychology, 57, 1-10. http://dx.doi.org/10.1037/a0018082

Schomerus, G., \& Angermeyer, M. C. (2008). Stigma and its impact on help-seeking for mental disorders: What do we know? Epidemiology and Psychiatric Sciences, 17, 31-37. https://doi.org/10.1017/S1121189X00002669

Scott, J. (2018, April). Focusing on student-athletes' mental health. Retrieved from https://www.athleticbusiness.com/health-fitness/focusing-on-student-athletes-mentalhealth.html?eid=61611281\&bid=2055406

Sheppard, B. H., Hartwick, J., \& Warshaw, P. R. (1988). The Theory of Reasoned Action: A meta-analysis of past research with recommendations for modifications and future research. Journal of Consumer Research, 15, 325-343. https://doi.org/10.1086/209170 
Shrout, P. E., \& Bolger, N. (2002). Mediation in experimental and nonexperimental studies: New procedures and recommendations. Psychological Methods, 7, 422-445. doi:10.1037/1082-989X.7.4.422

Soper, D. (2013). A-priori sample size calculator for structural equation models [Computer software]. Retrieved from https://www.danielsoper.com/statcalc/calculator.aspx ?id=89

Tabachnick, B. G., \& Fidell, L. S. (2013).Using multivariate statistics (6th ed.). Boston: Pearson Education.

Tahtinen, R. E., \& Kristjansdottir, H. (2018). The influence of anxiety and depression symptoms on help-seeking intentions in individual sport athletes and non-athletes: The role of gender and athlete status. Journal of Clinical Sport Psychology, 13, 134-151. https://doi.org/10.1123/jcsp.2017-0028

ten Have, M., de Graaf, R., Ormel, J., Vilagut, G., Kovess, V., Alonso, J., \& the ESEMeD/MHEDEA 2000 investigators. (2010). Are attitudes towards mental health help-seeking associated with service use? Results from the European Study of Epidemiology of Mental Disorders. Social Psychiatry and Psychiatric Epidemiology, 45, 153-163. doi:10.1007/s00127-009-0050-4

Topkaya, N., Vogel, D. L., \& Brenner, R. E. (2017). Examination of the stigmas toward help seeking among Turkish college students. Journal of Counseling \& Development, 95, 213 225. https://doi.org/10.1002/jcad.12133

Varnes, J. R., Stellefson, M. L., Janelle, C. M., Dorman, S. M., Dodd, D., \& Miller, M. D. (2013). A systematic review of studies comparing body image concerns among female college athletes and non-athletes, 1997-2012. Body Image, 10, 421-432. https://doi.org/10.1016/j.bodyim.2013.06.001 
Vogel, D. L., Wade, N. G., \& Ascheman, P. L. (2009). Measuring perceptions of stigmatization by others for seeking psychological help: Reliability and validity of a new stigma scale with college students. Journal of Counseling Psychology, 56, 301-308. http://dx.doi.org/10.1037/a0014903

Vogel, D. L., Wade, N. G., \& Haake, S. (2006). Measuring the self-stigma associated with seeking psychological help. Journal of Counseling Psychology, 53, 325-337. http://dx.doi.org/10.1037/0022-0167.53.3.325

Wahto, R. S., Swift, J. S., \& Whipple, J. L. (2016). The role of stigma and referral source in predicting college student-athletes' attitudes toward psychological help-seeking. Journal of Clinical Sport Psychology, 10, 85-98. http://dx.doi.org/10.1123/JCSP.2015-0025

Watson, J. C. (2006). Student-athletes and counseling: Factors influencing the decision to seek counseling services. College Student Journal, 40, 35-42.

Wolanin, A., Hong, E., Marks, D., Panchoo, K., \& Gross, M. (2016). Prevalence of clinically elevated depressive symptoms in college athletes and differences by gender and sport. British Journal of Sports Medicine, 50, 167-171. doi:10.1136/bjsports-2015-095756 


\section{Appendix A: Figure and Tables}

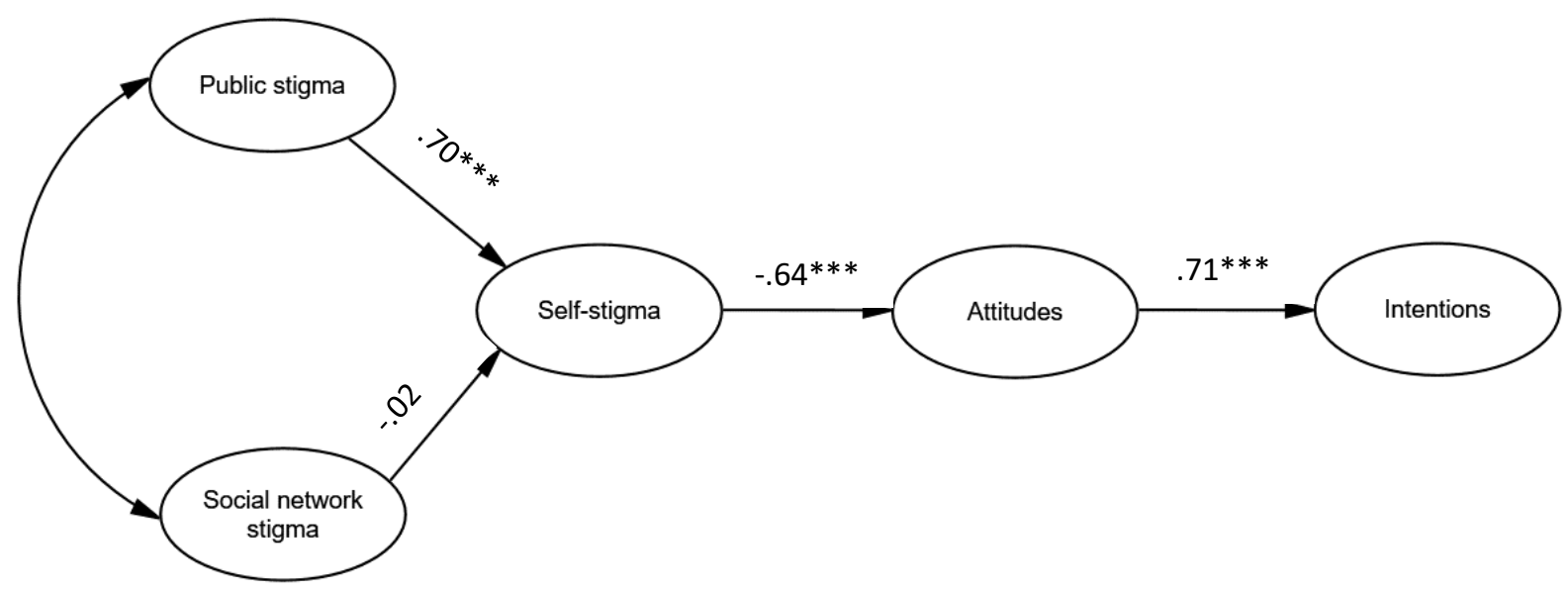

Figure 1. Final mediated model. $* * * p<.001$ 
Table 1

Sport participation for the sample

\begin{tabular}{llll}
\hline Sport & Total & Division II & Division III \\
\hline Baseball & 63 & 37 & 26 \\
Basketball & 22 & 0 & 22 \\
Cross country & 46 & 8 & 38 \\
Football & 78 & 0 & 78 \\
Golf & 1 & 0 & 1 \\
Soccer & 56 & 0 & 56 \\
Softball & 3 & 1 & 2 \\
Swimming & 20 & 20 & 0 \\
Track and field & 63 & 12 & 51 \\
Volleyball & 32 & 14 & 18 \\
Wrestling & 5 & 0 & 5 \\
\hline
\end{tabular}

Note: Totals do not add up to the sample $\mathrm{N}$ because several participants competed in more than one sport 
Table 2

Correlations for the instruments

\begin{tabular}{llllll}
\hline Variable & 1 & 2 & 3 & 4 & 5 \\
\hline 1.Social network stigma & - & & & & \\
2.Public stigma & $.45^{* *}$ & - & & & \\
3.Self-stigma & $.35^{* *}$ & $.49 * *$ & - & & \\
4.Attitudes & $-.19 * *$ & $-.27 * *$ & $-.49 * *$ & - & \\
5.Intentions & $-.12^{*}$ & $-.21 * *$ & $-.49 * *$ & $.61 * *$ & - \\
Mean & 1.73 & 1.07 & 2.56 & 1.55 & 4.08 \\
SD & 0.68 & 0.50 & 0.64 & 0.54 & 1.53 \\
\hline
\end{tabular}

$* \mathrm{p}<.05, * * \mathrm{p}<.001$

Note: $\mathrm{N}=312$; Social network stigma = Perceptions of Stigmatization by Others for Seeking Help scale; Public stigma = Stigma Scale for Receiving Psychological Help; Self-stigma = SelfStigma of Seeking Help; Attitudes = Attitudes Toward Seeking Professional Psychological HelpShort Form; Intentions = Mental Help-Seeking Intention Scale. 
Table 3

Factor loadings for the measurement model

\begin{tabular}{lllll}
\hline Variable & $\begin{array}{l}\text { Unstandardized } \\
\text { factor loading }\end{array}$ & $S E$ & $Z$ & $\begin{array}{l}\text { Standardized factor } \\
\text { loading }\end{array}$ \\
\hline Public stigma & & & & \\
$\quad$ Public stigma parcel 1 & .38 & .04 & 9.10 & $.56^{* * *}$ \\
$\quad$ Public stigma parcel 2 & .40 & .04 & 11.43 & $.75^{* * *}$ \\
Social network stigma & & & & \\
$\quad$ Social network stigma parcel 1 & .65 & .04 & 15.99 & $.92^{* * *}$ \\
$\quad$ Social network stigma parcel 2 & .62 & .04 & 14.22 & $.82^{* * *}$ \\
Self-stigma & & & & \\
Self-stigma parcel 1 & .53 & .03 & 16.36 & $.82^{* * *}$ \\
Self-stigma parcel 2 & .59 & .04 & 13.99 & $.73 * * *$ \\
$\quad$ Self-stigma parcel 3 & .64 & .04 & 16.97 & $.84 * * *$ \\
Attitudes & & & & \\
Attitude parcel 1 & .49 & .03 & 15.05 & $.78^{* * *}$ \\
Attitude parcel 2 & .43 & .04 & 12.26 & $.67 * * *$ \\
Attitude parcel 3 & .52 & .03 & 15.87 & $.81^{* * *}$ \\
Intentions & & & & \\
Intentions 1 & 1.40 & .07 & 20.34 & $.90^{* * *}$ \\
Intentions 2 & 1.53 & .07 & 23.37 & $.97 * * *$ \\
Intentions 3 & 1.56 & .07 & 21.76 & $.94 * * *$ \\
\hline
\end{tabular}

Note: Because the Intentions scale only consisted of three items, each item was used in the measurement model, rather than creating parcels. $* * * p<.001$ 
Table 4

Bias-corrected bootstrap analyses of the significant indirect effects of the variables

\begin{tabular}{llll}
\hline Path & $\beta$ & SE & $95 \%$ CI \\
\hline Public stigma $\rightarrow$ Self-stigma $\rightarrow$ Attitudes & -.45 & .08 & {$[-.64,-.32]$} \\
Public stigma $\rightarrow$ Self-stigma $\rightarrow$ Attitudes $\rightarrow$ Intentions & -.32 & .06 & {$[-.47,-.22]$} \\
Self-stigma $\rightarrow$ Attitudes $\rightarrow$ Intentions & -.46 & .05 & {$[-.55,-.35]$} \\
\hline
\end{tabular}

Note: $\mathrm{CI}=$ Confidence interval. All pathways including social network stigma were not significant and were not included. All pathways in the table were significant at $p<.001$. 
Table 5

Logistic regression results for previous help-seeking

\begin{tabular}{llllll}
\hline & $\beta$ & SE & Wald & OR & 95\% CI (OR) \\
\hline $\begin{array}{l}\text { Step 1 } \\
\quad \text { Gender }\end{array}$ & -0.44 & .30 & 2.17 & .14 & {$[.36,1.16]$} \\
Step 2 & & & & & \\
$\quad$ Gender & -0.27 & .32 & 0.72 & .76 & {$[.41,1.43]$} \\
$\quad$ Public stigma & 0.35 & .37 & 0.87 & 1.41 & {$[.68,2.93]$} \\
$\quad$ Social network stigma & 0.21 & .24 & 0.72 & 1.23 & {$[.77,1.97]$} \\
Self-stigma & 0.83 & .33 & 6.31 & $2.28^{*}$ & {$[1.19,4.34]$} \\
Attitudes & 1.33 & .40 & 10.80 & $3.76^{* *}$ & {$[1.71,8.29]$} \\
$\quad$ Intentions & 0.16 & .13 & 1.52 & 1.18 & {$[.91,1.53]$} \\
\hline
\end{tabular}

Note: $\mathrm{OR}=$ Odds ratio, $\mathrm{CI}=$ Confidence interval. Step 2 model fit, $-2 \log$ likelihood $=273.55$, Cox \& Snell $\mathrm{R}^{2}=.09$, Nagelkerke $\mathrm{R}^{2}=.14$.

$* p<.01, * * p<.001$ 
Table 6

Means and standard deviations for help-seeking topics in the sample

\begin{tabular}{|c|c|c|c|c|}
\hline & & Total & Male & Female \\
\hline Item & $N$ & $M(S D)$ & $M(S D)$ & $M(S D)$ \\
\hline Disordered eating & 324 & $2.19(0.98)$ & $2.09(0.97)$ & $2.40(0.96)$ \\
\hline Excessive alcohol use & 324 & $2.46(1.08)$ & $2.43(1.08)$ & $2.52(1.07)$ \\
\hline Relationship difficulties & 324 & $1.95(0.88)$ & $1.93(0.85)$ & $2.00(0.96)$ \\
\hline Concerns about sexuality & 322 & $1.58(0.79)$ & $1.51(0.77)$ & $1.73(0.82)$ \\
\hline Depression & 325 & $2.59(1.03)$ & $2.54(1.04)$ & $2.67(0.99)$ \\
\hline Family conflict & 324 & $2.16(0.99)$ & $2.14(0.97)$ & $2.20(1.04)$ \\
\hline Anxiety & 325 & $2.40(0.99)$ & $2.26(0.98)$ & $2.68(0.94)$ \\
\hline Choosing a major & 325 & $1.93(1.04)$ & $1.88(1.00)$ & $2.04(1.11)$ \\
\hline Dealing with injury & 325 & $2.15(1.06)$ & $2.13(1.04)$ & $2.20(1.10)$ \\
\hline Difficulty in sleeping & 325 & $1.94(0.85)$ & $1.92(0.84)$ & $1.96(0.89)$ \\
\hline Drug problems & 323 & $2.65(1.18)$ & $2.64(1.22)$ & $2.66(1.09)$ \\
\hline Self-esteem/confidence & 325 & $1.93(0.88)$ & $1.87(0.89)$ & $2.06(0.85)$ \\
\hline Test anxiety & 325 & $1.98(0.94)$ & $1.88(0.89)$ & $2.21(0.99)$ \\
\hline Difficulty with friends & 324 & $1.69(0.77)$ & $1.61(.72)$ & $1.87(0.86)$ \\
\hline Academic performance & 324 & $2.23(0.91)$ & $2.26(0.92)$ & $2.19(0.91)$ \\
\hline Self-understanding & 324 & $1.92(0.90)$ & $1.89(0.89)$ & $2.00(0.91)$ \\
\hline Loneliness & 325 & $1.91(0.93)$ & $1.89(0.92)$ & $1.96(0.96)$ \\
\hline Body image concerns & 324 & $1.71(0.80)$ & $1.60(0.76)$ & $1.97(0.83)$ \\
\hline Stress & 325 & $2.28(0.99)$ & $2.16(1.00)$ & $2.52(0.93)$ \\
\hline Athletic performance & 325 & $2.18(1.02)$ & $2.09(0.99)$ & $2.40(1.04)$ \\
\hline
\end{tabular}

Note: $\mathrm{N}$ differs for the items because some respondents skipped questions and this data did not need to be imputed. 


\section{Appendix B: Extended Review of Literature}

There are currently over 490,000 National Collegiate Athletic Association (NCAA) student-athletes participating in sanctioned sports (NCAA, 2017). Many authors consider this group a special population because of their unique position within the collegiate landscape (e.g., Loughran \& Etzel, 2008; Jolly, 2008; Pinkerton, Hinz, \& Barrow, 1989). Researchers have generally found that college student-athletes experience mental health issues at rates that are comparable to their nonathlete peers (e.g., Etzel, Watson, Visek, \& Maniar, 2006; Gill, 2008; Wolanin, Hong, Marks, Panchoo, \& Gross, 2016). In fact, a recent study of athletes at a single university revealed that $62.6 \%$ reported mental health issues had impacted their athletic performance in the month prior to study (Kern et al., 2017) and in a more representative sample, $30 \%$ of student-athletes reported feeling overwhelmed in the last month (NCAA, 2016). A myriad of reasons could contribute to increased levels of stress and psychopathology amongst student-athletes, such as highly regimented schedules, time demands, and pressures to be successful academically and athletically (Jolly, 2008). The purpose of this review of literature is to describe the influence of stigma on attitudes and intentions to seek help in college studentathletes. It will begin with a discussion of issues facing the college population and studentathletes in particular. Next, concepts will be defined and issues surrounding their measurement will be examined. The role of stigma and other factors that influence attitudes, intentions, and help-seeking behavior in the general population will be reviewed and then followed by an analysis of those same topics specifically within college student-athletes. The review will end by summarizing the content and suggesting future research directions. 


\section{The College Population}

The college population in general has seen an increase in mental health issues and visits to counseling centers (Pérez-Rojas et al., 2017). One of the most recent estimates of college students found that the most prevalent presenting concerns at college counseling centers included anxiety (54\%), depression (46\%), and stress (45\%). Suicidality was reported in $8.4 \%$ of cases (Pérez-Rojas et al.). These presenting concerns tend to align with reports from literature investigating student-athlete mental health concerns. In their brief review, Gavrilova and Donohue (2018) listed stress, anxiety, depression, relationships, substance use, and eating disorders as the top concerns for student-athletes. Further, between 2003-2004 and 2011-2012, a minimum of $7 \%$ of student-athlete deaths per year were from suicide (Rao, Asif, Drezner, Toresdahl, \& Harmon, 2015). The results from previous studies clearly suggest that there is a need for counseling services amongst college student-athletes. However, there is still extensive variability in the rates of mental health conditions reported across different samples. For example, the results from a recent study that examined 1,118 incoming student-athletes at Ohio State University between 2011-2017 indicated that only $14.0 \%$ reported any history of a mental health condition (Sarac, Sarac, Pedroza, \& Borchers, 2018). This number is only slightly lower than a recent report of college students worldwide, where $20.3 \%$ had any mental health condition (Auerbach et al., 2016) but is much lower than another study where $34.4 \%$ reported a history of a mental health condition (Ketchen Lipson, Gaddis, Heinze, Beck, \& Eisenberg, 2015). The study methodologies may partially account for these discrepancies. Auerbach et al. (2016) used a 12month timespan for their diagnostic interviews, whereas the questions in Ketchen Lipson et al. (2015) ranged from two weeks to the past year. Sarac et al. (2018) simply asked if participants had ever been diagnosed with a mental health condition and was not time limited. Regardless of 
the actual prevalence, the data suggest that a considerable number of student-athletes experience mental health concerns. The treatment utilization identified in the previous studies ranged from $16.4 \%$ of the students with a condition (Auerbach et al., 2016) to 39.4\% (Ketchen Lipson et al., 2015). In conjunction with this utilization data, many researchers have continued to suggest that counseling services are still being underutilized by college student-athletes (López \& Levy, 2013; Moreland, Coxe, \& Yang, 2018).

\section{Stigma: An Important Construct Related to Attitudes Toward Help-Seeking}

One variable that researchers have found to have a strong relationship with help-seeking is stigma. Some authors have argued that because of the role it plays as a barrier to seeking or adhering to treatment, stigma is an important public health concern (Abdullah \& Brown, 2011; Corrigan, 2007). Stigma toward mental illness has a long history in psychological research as studies in various areas have found stigma effects on multiple aspects of an individual's identity and self-concept (Abdullah \& Brown, 2011). These stigmas have arisen throughout the history of the counseling profession when those who were institutionalized were perceived as "crazy." As a profession, it has been difficult to distance contemporary counseling from treatments of the past, and as a result there are still numerous stigmas attached to seeking mental health care, as well as to individuals with mental illness. The importance of stigma was demonstrated in a recent meta-analysis (Clement et al., 2015). That study found that stigma had a near moderate sized negative relationship ( $\mathrm{Md} d=-0.41)$ with help-seeking. Treatment stigma, or stigma associated with receiving or seeking mental health services, had the strongest negative relationships with help-seeking attitudes and behaviors. Although attitudes toward help-seeking was the outcome variable in a majority the studies in this analysis, there was a relationship with actual helpseeking behaviors. Additionally, other studies have found a relationship between attitudes and 
actual help-seeking behaviors (Elhai et al., 2008; ten Have et al., 2010). Thus, it appears that improving positive attitudes could lead to increases in service use. In order for this to occur, levels of stigma must be reduced.

Corrigan (2004) posited that there were four processes that contributed to the stigma construct: cues, stereotypes, prejudice, and discrimination. To help explain these concepts, the general situation of a student-athlete will be used. Cues refer to characteristics that indicate someone may have a mental illness. In the current example, this could be that a coach sees an individual walk into the office of the university athletic department's sport psychologist. However, there are other possible cues that society might use to assume mental illness. These could include physical appearances, labels, social-skills deficits, and psychiatric symptoms (Corrigan, 2004). For example, an individual seen on the street who looks disheveled might be assumed to have a mental illness. Corrigan (2004) is sure to point out that mental illness can be inaccurately attributed to individuals who may possess cues. After a cue, the stereotype is elicited. A common stereotype for the mentally ill is that the person is violent (Chan \& Yanos, 2017; Corrigan, 2004). In the student-athlete example, the stereotype might be that someone who has a mental illness is weak and incompetent and cannot handle performance pressure. These stereotypes are often inaccurate but act to create a stigmatizing belief in the individual. This leads to the third process, which is the prejudice, or stigmatizing attitude. Prejudice extends beyond beliefs because prejudicial beliefs often have an evaluative component associated with them (Corrigan, 2004). In essence, the individual makes a judgment about the stigmatized other based upon the belief that is held. For example, the previously stigmatized stereotype may be believed by a coach who believes that individuals with mental illness will not be capable players. Thus, there is an evaluative component to this stereotype: having the mental illness means that 
the player will be incapable of performing well. Finally, this leads to the final process, discrimination, which is behavioral in nature (Corrigan, 2004). Discrimination often takes the form of a negative reaction to the stigmatized group or individual, which often includes avoidance (Corrigan, 2004). A coach may not give a player any playing time because of the associations with mental illness. This is classified as discrimination because it represents an action committed by an individual because of stigmatized beliefs that person holds. Further, Corrigan notes that these processes can be manifested through two different forms of stigma: public and self-stigma.

Public stigma has been defined as "what a naïve public does to a stigmatized group when they endorse the prejudice about that group" (Corrigan, 2004, p. 616). Essentially, this stigma represents beliefs on a societal level. Corrigan notes that there are real world impacts to widespread public stigma, such as more difficulty obtaining jobs, having safe housing, and being imprisoned. Self-stigma, on the other hand, represents the internalization of this public stigma and often results in decreased self-esteem (Corrigan, 2004). This construct is internalized and individualized and can manifest itself in one's belief that he or she is viewed as unacceptable (Vogel, Wade, \& Haake, 2006). The four processes previously described for the construction of stigma apply to both forms of stigma. The example previously given was geared more at public stigma. For those processes to unfold for the creation of self-stigma, the prejudice and discrimination comes from within. In the student-athlete example, the individual may believe that having mental health issues will in fact deem them to be incapable of playing well (prejudice) and consequently stop putting forth effort or quit the team (discrimination). Therefore, although the two different types of stigma are similar, it is important to distinguish between both of them. Someone may be aware of public stigmas and stereotypes associated with 
mental illness or with seeking help for mental health issues, but may not internalize them. In fact, several studies have found that self-stigma likely plays a stronger role than public stigma in the relationship with attitudes toward counseling (e.g., Lally, O'Conghaile, Quigley, Bainbridge, \& McDonald, 2013; Lannin, Vogel, Brenner, \& Tucker, 2015; Nam et al., 2013; Shechtman, Vogel, \& Maman, 2010). In fact, higher levels of self-stigma may reduce the likelihood that individuals even seek out information related to mental health, let alone seek actual counseling services (Lannin, Vogel, Brenner, Abraham, \& Heath, 2016). In this study, participants completed measures related to self-stigma, attitudes, and psychological distress before being asked if they would like to seek information on the counseling center or general mental health concerns. The participants could select one, both, or neither of the options. Self-stigma was significantly associated with a decrease in seeking mental health information $(\beta=-.33)$ but not with information about the counseling center $(\beta=-.23)$. Additionally, increased self-stigma was associated with less positive attitudes $(\beta=-.60)$, which was then related to less help seeking behaviors. Greater distress was also associated with help-seeking behaviors, but even those with higher distress sought less information with higher levels of stigma. Seeking information about mental health is a minor first step in actual help-seeking. Although there are factors that could have contributed to participants deciding not to seek further information such as time, it appears that increased levels of self-stigma may reduce the chances of taking this first step toward developing mental health literacy and seeking help.

\section{Media Influences on Public Stigma}

One of the major issues with combating the stigma connected with mental illness and help-seeking is the ubiquitous nature of the media. The media often inaccurately portrays mental illness, and because many people, especially college students, have traditionally only received 
their knowledge of mental illness through electronic media (Granello, Pauley, \& Carmichael, 1999), this promulgation of myths through the media is problematic. People suffering from mental illness are often portrayed as violent in film and media (Chan \& Yanos, 2018; March, 1999) and this has not gone unnoticed by society. Numerous studies have found that the most frequently endorsed stereotypes associated with mental illness is violent behavior (e.g., Angermeyer \& Dietrich, 2006; Corrigan, 2004; Schomerus et al., 2012). If media information is one's only source of knowledge about mental illness, it is clear how this link is established.

However, an association with violent stereotypes is not the only detrimental effect of media depictions of mental illness. More recent research has suggested that media portrayals can influence attitudes and willingness to seek psychological help (e.g., Maier, Gentile, Vogel, \& Kaplan, 2014; Vogel, Gentile, \& Kaplan, 2008). In one study, exposure to television comedy and dramas was associated with increased perceptions of stigma. In turn, these increased perceptions were associated with more negative attitudes and lower intentions to seek help (Vogel et al., 2008). Comedy and drama genres were selected because they tend to portray more mental health professionals, but the authors noted that a direct measure of exposure to these individuals was not included. Another study found the perceptions of those with mental illness, others who seek help, and of psychologists as portrayed in movies and television influenced selfstigma in college students (Maier et al., 2014). Further, the authors found that the more likely participants were to seek help from a psychologist character, the more positive attitudes they had toward real life psychologists. In essence, the perceptions they had of media characters was connected to their self-stigma for seeking help. These studies suggest that although strides have been made in the discussion of mental health issues, media influences still help to shape beliefs and stigma surrounding mental health help-seeking. 


\section{Stigma and Help-Seeking Theories}

The Theory of Reasoned Action (TRA) is a useful framework for understanding ways to influence help-seeking behavior. Many studies in the counseling literature have adopted parts of the TRA to study counseling intentions and help-seeking behavior. The TRA posits that subjective norms and attitudes interact to influence intentions and ultimately behavior. With regard to counseling specifically, this would refer to actually seeking help for mental health services. Much of the research examining attitudes toward counseling is atheoretical and simply examines factors that might influence behavior. However, a large body of literature utilizes aspects of the TRA. Few studies have used the full model, as most center around the framework of attitudes and how they can influence intentions. This is likely because attitudes toward a behavior are relatively more malleable than subjective norms. There is substantial research evidence within the counseling literature to support this theory. A meta-analysis that examined factors influencing help-seeking intentions found that attitudes was the strongest predictor of intentions $(r=.46)$ in college students (Li, Dorstyn, \& Denson, 2014). Therefore, examining elements that influence attitudes is an important inquiry of study for counseling research. One of these factors that influences attitudes is stigma.

One theory that has empirical support as to why public stigma might be manifested with increased self-stigma is the Modified Labeling Theory (Link, Cullen, Struening, Shrout, \& Dohrenwend, 1989). The tenets of this theory are that negative external perceptions or beliefs can influence one's internal sense of self. In essence, this would mean public stigma or perceptions of others gets internalized as self-stigma. There is evidence to support this theory. Vogel, Bitman, Hammer, and Wade (2013) examined the temporal relationship between selfstigma and public stigma in a sample of 448 college students. Using cross lagged structural 
equation modeling, the authors found that over a three month span, those with higher public stigma had increased self-stigma. When they examined the relationship in reverse, the same pattern was not true. In other words, there was evidence that elevated levels of public stigma was associated with higher levels of self-stigma after three months, but levels of self-stigma did not lead to increased public stigma. Changing the views of society can be a difficult undertaking, and gearing interventions toward reducing self-stigma could yield more positive results.

Although these linear stage models are useful for helping to predict help-seeking behavior, they come with a major caveat. That major caveat is that life is not always linear and occasionally significant events happen in an individual's life that might push them in a certain direction. This is essentially the premise of chaos theory, which could be an alternative conceptualization of help-seeking behavior. At this point, chaos theory does not seem to have a place in the science of help-seeking behavior as it relates to counseling. However, crisis situations occur that might put someone's life into a state of chaos and push them in a direction of seeking counseling even if under normal circumstances they would not entertain the idea. There are articles discussing the value of chaos theory as a practitioner and for counselor training (e.g., Wilbur, Kulikowich, Roberts-Wilbur, \& Torres-Rivera, 1995; Wilbur, Roberts-Wilbur, Torres-Rivera, \& Kulikowich, 1995), but that is the extent of the literature. In these articles, the authors urge counselors to consider the initial conditions upon which a client enters counseling, and how minor variations in the context may have influenced help-seeking. However, researchers have not examined the ways in which chaos might push clients into counseling. Chaos theory has more of a hold within career counseling (e.g., Bright \& Pryor, 2005; Pryor, Amundson, \& Bright, 2008), where theorists recognize that a wide variety of influences and circumstances can lead to vocational selection. 


\section{Measurement of Stigma, Attitudes, and Intentions}

This section will detail the measurement of stigma, attitudes, and intentions to seek counseling. The stigma section will briefly delineate between measuring mental illness stigma and treatment stigma, then focus on the measurement of public stigma, social network stigma, and self-stigma. A brief review of various attitude measures will then follow, but the focus will be on the measures used in the current study. Finally, a brief review of intentions measures will be provided with an emphasis on the ones to be used in this study. For a full review on different measures related to stigma, attitudes, and intentions to seek counseling, see Wei, McGrath, Hayden, \& Kutcher (2015).

Measurement of stigma. Stigma is a broad concept that has been measured using myriad methods. One issue associated with the measurement of stigma common to the research is that authors often describe stigma broadly but do not always specify if they are attempting to measure stigma related to mental illness or related to help-seeking. In many cases, researchers specify that the goal of the study is to measure mental illness stigma, but other times researchers describe the influence of stigma on treatment seeking when they have used measures that actually measure mental illness. Recently, authors have argued that measuring stigma related to the treatment of mental health issues is different than stigma toward people with mental illness, and the two should not be confused (Fox, Earnshaw, Taverna, \& Vogt, 2018). There is also empirical evidence to support this claim, as one group of researchers found that stigma associated with actual mental illness was conceptually different than stigma related to helpseeking (Tucker et al., 2013). Therefore, it is imperative that researchers use instruments that measure the actual construct in question. 
Given the aforementioned considerations, the measure that will be used in the current study to explore the self-stigma of seeking help is the Self-Stigma of Seeking Help Scale (SSOSH; Vogel et al., 2006). This instrument was validated through numerous samples of college students. The initial developers of the scale found it to possess strong psychometric qualities (Vogel et al., 2006). These include a test-retest reliability score of .72 over a twomonth period, construct validity present through positive associations with anticipated risks, selfconcealment, and public stigma, criterion validity evident through negative associations with attitudes toward and intentions to seek counseling, and good internal consistency ( $\alpha$ between .86.91). Factor analysis revealed a unidimensional structure. The total sample in this initial validation study consisted of well over 1,000 undergraduate students. The stability within the college population makes it an excellent measure for this current dissertation, as the focus will be on the college athlete population. There is also evidence of cross-cultural validity for the scale. Vogel, Armstrong, et al. (2013) examined data from six different countries using the SSOSH. The sample for each country ranged from 299-1,376. This sample was not limited to college students but had a wide range in ages, from 18 to 64 . They used factor analysis to examine measurement invariance and latent mean comparisons across the countries. The authors found a unidimensional structure across all six samples and was sufficiently invariant. This suggests that it is a good scale to use in samples of college students that contain diversity. Finally, a negative relationship with counseling attitudes provided evidence for construct validity. The internal consistency in this initial study was .72. Further, the scale was found to be acceptable within a Greek population as well (Efstathiou, Kouvaraki, Ploubidis, \& Kalantzi-Azizi, 2018).

Public stigma will be measured in the current study with the Stigma Scale for Receiving Psychological Help (SSRPH; Komiya, Good, \& Sherrod, 2000). Although the initial creation of 
the scale was somewhat less rigorous than more recent questionnaires, the psychometrics for the SSRPH have consistently held up. After the initial five items for the scale were developed, they were subject to analysis by counseling psychologists who agreed that the items measured stigma, providing evidence for face validity. Next, the authors used a maximum likelihood factor analysis and discovered a unidimensional factor structure. Studies using the scale since its creation have confirmed a unidimensional structure, but sometimes find an internal consistency that falls below .70. For example, in a study across ten nations, the reliability estimates ranged from .61 to .76 (Vogel et al., 2017). In another recent sample of collegiate athletes, the reliability coefficient was .66 (Hilliard, Redmond, \& Watson, 2018a). However, a majority of public stigma measures examine stigma toward mental illness (Wei et al., 2017), so the SSRPH is best suited for measuring stigma toward seeking treatment. In addition to the evidence from Vogel et al. (2017) regarding cross-cultural applicability, Efstathiou et al. (2018) also found the scale to be reliable and valid in Greek university students.

Social network stigma is most accurately measured by the Perceptions of Stigmatization by Others for Seeking Help scale (PSOSH; Vogel, Wade, \& Ascheman, 2009). This scale measures perceptions of being stigmatized by those who are close to the respondent. This differs from measures such as the SSRPH because those other public stigma measures examine stigma more broadly. These other measures allow the individual to step outside of their own social network, which could have a different impact on the influence of the stigma on their sense of self. Through factor analyses, Vogel et al. (2009) found a one-factor solution for the PSOSH. Its status as a unique stigma construct was demonstrated through factor analysis by combining its scores with other related stigma scales such as the SSRPH and one that measures stigma toward mental illness. The results of that factor analysis found that the items on the PSOSH all loaded 
strongly on one factor (above .6) and had a loading lower than .1 for all other factors. No other items loaded stronger than .1 on the PSOSH subscale, suggesting it was unique, although related, to other types of public stigma. The PSOSH also predicted self-stigma above other public stigma measures. It had a three-week test-retest reliability of .77. Internal consistency across the five samples ranged from .78 to .89 . This sample was also validated in college students. Like the SSOSH, the PSOSH has also demonstrated adequate cross cultural utility in a sample of 3,440 participants from 11 different countries (Vogel et al., 2019). In this large multi-nation study, all reliabilities were above .85 and there was good metric equivalence/invariance across the 11 countries.

Measurement of attitudes. Several measures have been used to examine attitudes toward help-seeking (see Wei et al., 2015). These instruments have been created from different theoretical backgrounds but have been designed to elicit beliefs related to seeking psychological treatment. They vary in that some scales measure attitudes toward specific mental illnesses or mental health service providers, whereas others take a broader approach. A major limitation of previous attitudes measures is that they often incidentally measure multiple constructs, a concept referred to as construct-irrelevant variance (Hammer, Parent, \& Spiker, 2018). Additionally, construct underrepresentation is present in some measures (Hammer et al.), as the questions may not adequately measure attitudes. For further elaboration on some limitations of attitudes toward help-seeking measures, see Hammer et al.

The current study will utilize the Attitudes Towards Seeking Professional Psychological Help Scale-Short Form (ATSPPH-SF; Fischer \& Farina, 1995). This scale is a ten-item shortened version of the Attitudes Toward Seeking Professional Psychological Help Scale, which contains 29 items. Factor analysis was used in the validation of this shortened scale and revealed 
a unidimensional structure. It also correlated highly with the full version, $r=.87$. The internal consistency in this initial study was .84 , and this adequate reliability was confirmed in several samples. The researchers also found a test-retest reliability of .80 over one month. Some studies have found evidence of a two-factor structure (e.g., Elhai, Schweinle, \& Anderson, 2008), but even then, the scale demonstrated adequate psychometrics if just a total score was used. Despite the inconsistency in factor structure, the authors found support for multiple forms of validity and found a relationship with service use. The authors concluded that "future mental health services research should incorporate this type of instrument into models predicting treatment use" (Elhai et al., 2008, p.328). Additionally, this scale is the most commonly used measure for assessing attitudes toward psychological help-seeking and has meta-analytic support for its use in college students for predicting intentions to seek help (Li et al., 2014).

Measurement of intentions. Measuring actual mental health service use is time and resource intensive, so researchers will often use the closest proxy to actual behavior, intentions. Using the TRA, intentions is the final step in the prediction of behavior. When examining intentions to seek mental health services, two instruments have typically been used: the Intentions to Seek Counseling Inventory (ISCI; Cash, Begley, McCown, \& Weise, 1975) and the General Help-Seeking Questionnaire (GHSQ; Deane, Wilson, \& Ciarrochi, 2001). Although this scale demonstrates adequate psychometrics (Hammer \& Spiker, 2018), the GHSQ measures help-seeking intention from six sources. This includes a variety of informal sources such as family or friend in addition to professional help. The focus of the current dissertation is on professional psychological help, which aligns with the attitudes measures being used in the study. Therefore, the GHSQ will not be used or described further. 
There will be two separate measures for intentions used in the current study. One measure will be used directly as the measure of intentions while another will be used to measure topics for which student-athletes would be likely to seek counseling. The intentions measure that will be used to measure actual intentions to seek help is the new Mental Help-Seeking Intention Scale (MHSIS; Hammer \& Spiker, 2018). This is a three-item measure that was recently evaluated in comparison to other intentions measures. The MHSIS was designed specifically using the tenets of TPB and was created with a guide from Ajzen on making TPB scales. It is a unidimensional scale with strong internal consistency $(\alpha=.94)$. The authors also found that the MHSIS most accurately predicted actual help-seeking behavior when compared with two other intentions measures, one of which was the ISCI. The MHSIS was developed in a sample of community adults (Hammer \& Spiker, 2018) and has yet to be used outside of the validation study. There are two significant limitations regarding the MHSIS. The first is that the sample was recruited using ResearchMatch, a website specifically created by volunteers interested in completing health based surveys (Hammer \& Spiker, 2018). This limits the generalizability of the results to a sample of individuals who may have greater intentions to seek counseling and may already be more interested in the topic. A second limitation is that the sample was $84 \%$ female, which could have affected the results because of known gender differences on mental health service utilization between males and females. Despite these limitations, the sound theoretical foundation, the predictive validity, and brevity of the survey make it appropriate for use in the current study.

A modified version of the ISCI (Cash et al., 1975) will be used to measure willingness to seek counseling for a variety of issues. The ISCI is commonly used in research as a measure of intentions. However, in a study measuring predictive validity of actual help-seeking behavior, 
the ISCI fared the worst (Hammer \& Spiker, 2018). The creation of the ISCI by Cash et al. (1975) is unclear, as the authors originally used it to measure expectations of counselor helpfulness for a variety of issues. Researchers later examined its factor structure and discovered three scales: drug use concerns, academic concerns, and psychological and interpersonal concerns (Cepeda-Benito \& Short, 1998). However, not all research has confirmed this structure (e.g., Pheko, Chilisa, Balogun, \& Kgathi, 2013). Additionally, although good reliability has been found in most cases, some authors have reported reliabilities below .70 (e.g., Vogel, Wester, Wey, \& Boysen, 2005). Therefore, because the MHSIS (Hammer \& Spiker, 2018) demonstrates better utility as a measure of actual intentions to seek help overall, it will be used. Items on the ISCI might not fully encapsulate the range of issues that would be relevant for student-athletes. Therefore, some items will be modified to reflect the most common presenting problems in college centers (Pérez-Rojas et al., 2017) as well as concerns relevant to student-athletes (Gavrilova \& Donohue, 2018; Maniar, Curry, Sommers-Flanagan, \& Walsh, 2001), such as injury. This modified form of the ISCI will then be used to establish a rank order of topics for which student-athletes will be interested in seeking.

\section{Attitudes and Intentions to Seek Help in the General Population}

Attitudes toward help-seeking are generally considered to be an important proxy of actual service use. Although attitudes do not necessarily indicate if someone will seek counseling, the results of studies suggest that attitudes are related with actual help-seeking behaviors (Elhai et al., 2008; ten Have et al., 2010). Unfortunately, a recent meta-analysis suggests that attitudes grew increasingly negative in college students between 1968-2008 (Mackenzie, Erickson, Deane, \& Wright, 2014). This study exclusively examined articles that had used the ATSPPH(-SF) because of its pervasive use in the literature and psychometric reliability. However, as 
discussion of mental health becomes more commonplace, it is possible the results since 2008 would show a different trend. There are numerous factors that influence attitudes and helpseeking intentions. This section will briefly outline non-stigma related issues that influence attitudes towards help seeking before discussing the role of stigma in influencing attitudes. The section will end with a discussion of variables that influence intentions to seek counseling.

Although stigma is an important variable in examining attitudes toward help-seeking, it is not the only predictor. A recent meta-analysis examined several variables that might contribute to attitudes (Nam et al., 2013). The authors examined 19 studies containing 7,396 participants that used the ATSPPH or its short form as the outcome variable. Overall, self-stigma had the strongest relationship with attitudes $(r=-.63)$, followed by anticipated benefits $(r=.52)$. Remaining significant predictors in the meta-analysis included self-disclosure $(r=.34)$, anticipated risk $(r=-.26)$, public stigma $(r=-.24)$, self-concealment $(r=-.17)$, social support $(r$ $=.13)$, and depression $(r=-.07)$. Excluding stigma, anticipated benefits, self-disclosure, and anticipated risk will be briefly discussed with regard to their relation to attitudes. Additionally, four other variables will be mentioned as they relate to attitudes toward counseling: gender, ethnicity, previous help-seeking experience, and gender role conflict. Gender was examined with more depth in a previous meta-analysis (Nam et al., 2010) and thus was not included in the previously described meta-analysis. The other three variables have also consistently been found to relate to attitudes. An extensive description of all the variables impacting attitudes is beyond the scope of this review, however, other variables influence attitudes toward seeking help as well.

Anticipated benefits are the perceived value one attributes to seeking counseling (Nam et al., 2013). If an individual believes seeking counseling will have positive effects in their life, 
that individual is more likely to hold better attitudes toward counseling. This relationship was initially studied by Vogel and Webster (2003) when they found that benefits positively predicted attitudes in two samples of college students. This has continued to be confirmed in other samples of college students (e.g., Li, Denson, \& Dorstyn, 2017; Shaffer, Vogel, \& Wei, 2006).

The antithesis to anticipated benefits is the anticipated risk associated with seeking counseling. This can be described as the perceived danger of being open with someone and seeking counseling (Vogel \& Webster, 2003). The trend in the data is that counseling attitudes are worse with higher anticipated risk (e.g., Li et al., 2017; Shaffer et al., 2006; Vogel \& Webster, 2003). Because benefits and risks are often measured using the same scale created by Vogel and Webster (2003), most studies examine the two constructs together.

Self-disclosure is defined as a "process whereby a person verbally reveals private feelings, thoughts, beliefs, or attitudes to another person" (Nam et al., 2013, p. 40). As a positive predictor in the meta-analysis by Nam et al., elevated levels of self-disclosure relate to more positive counseling attitudes. In an early study, self-disclosure predicted attitudes and intentions (Vogel \& Webster, 2003) and this association has since been reconfirmed (e.g., Vogel et al., 2005).

Other variables not included in the meta-analysis by Nam et al. (2013) may be important when considering attitudes. Two of these variables are the specific demographic characteristics of gender and race. The results of most studies indicate that women tend to have more positive attitudes toward counseling, but there have been studies that have found either no differences or more favorable attitudes towards counseling for men (e.g., Ballesteros \& Hilliard, 2016; Kroshus, 2017). However, women had significantly higher attitudes in a recent meta-analysis (Nam et al., 2010). 
Race has also been consistently found to relate to attitudes. In the same meta-analysis describing gender differences, racial differences were also examined (Nam et al., 2010). Caucasian American college students had more positive attitudes toward counseling than Asian and Asian American college students. Several other researchers have also noted that racial and ethnic minority college students tend to have less favorable attitudes toward counseling (e.g., Cheng, Kwan, \& Sevig, 2013; Masuda et al., 2009).

Prior counseling history has also been found to strongly relate to attitudes towards counseling (e.g., Ballesteros \& Hilliard, 2016; Cheng, Wang, McDermott, Kridel, \& Rislin, 2018; ten Have et al., 2010; Vogel et al., 2007). In these studies, those who had sought counseling in their lifetime tended to have more favorable attitudes toward counseling. As a result of this positive association with attitudes, most studies using hierarchical multiple regression have used previous experience as a control variable when exploring factors that predict attitudes.

Gender role conflict has been consistently identified as having an association with more negative attitudes toward counseling (e.g., Pederson \& Vogel, 2007; Shepherd \& Rickard, 2012; Wester, Arndt, Sedivy, \& Arndt, 2010). This issue has been studied almost exclusively in men as a method of further exploring how masculine norms might influence attitudes. The association of gender role conflict has been found within college student populations (Pederson \& Vogel, 2007; Shepherd \& Rickard, 2012) as well as in police officers (Wester et al., 2010). Further, in these studies, the relationship between gender role conflict and self-stigma was such that more gender role conflict related to higher self-stigma and ultimately worse attitudes towards counseling. Additionally, in the sample of police officers, those with higher gender role conflict scores also saw more risk and less benefits associated with seeking counseling (Wester 
et al., 2010). Therefore, reducing gender role conflict could be an important step to help males improve their attitudes toward counseling.

\section{Stigma, Attitudes, and Intentions Toward Help-Seeking in the General Population}

In addition to the variables mentioned previously, stigma has been found to have a large influence on counseling attitudes. Specifically, a large relationship with help-seeking was recently found for self-stigma $(r=-.63)$, which was the strongest of all variables included in the study (Nam et al., 2013). Although significant, public stigma's association was small $(r=-.11)$. As previously described, public stigma often manifests itself as self-stigma, and is closer to attitudes as self-stigma is an individual's own personal beliefs. Research on the relationship between stigma and attitudes has dated back for decades, such as one early study which found that stigma concerns negatively predicted attitudes toward help-seeking behavior (Deane \& Chamberlain, 1994). This study did not distinguish between self and public stigma, as the stigma questions conceptually contained items from both. Since this study, a significant body of literature has accrued that has examined the role of self-stigma and public stigma separately or in conjunction with attitudes. The influence of stigma has been found in multiple populations including youth (e.g., Gulliver, Griffiths, \& Christensen, 2010; Shechtman et al., 2010) college students (e.g., Garriott et al., 2017; Vogel, Wade, \& Hackler, 2007), adults (e.g., Jung, von Sternberg, \& Davis, 2017; Stewart, Jameson, \& Curtin, 2015), and members of the military (Currier, McDermott, \& McCormick, 2017; Wade et al., 2015).

The earliest study to test the hypothesized relationship of self and public stigma on attitudes and intentions to seek counseling was conducted by Vogel et al. (2007). In their study, an even split of 676 male and female college students recruited from psychology courses completed the Perceived Devaluation-Discrimination scale (PDD; Link, Cullen, Frank, \& 
Wozniak, 1987), the SSOSH (Vogel et al., 2006), the ATSPPH-SF (Fischer \& Farina, 1995), ISCI (Cash et al., 1975). The authors tested a mediation relationship from public stigma to intentions using structural equation modeling (SEM). They believed this relationship would be fully mediated through self-stigma and attitudes. Their hypothesized model was confirmed, as the structural model provided an excellent fit to the data. They also tested an alternative partially mediated model that contained direct paths from public stigma to attitudes, public stigma to intentions, and self-stigma to intentions. This model also demonstrated excellent fit, but the scaled chi-square difference test revealed no differences between the two models. Thus, they retained the original model for the bootstrapping analysis. The path coefficients in the model were all significant at $p<.001$. The path coefficient from public to self-stigma was .26 , from self-stigma to attitudes was -.76, and .59 between attitudes and intentions. In this model, $57 \%$ of the variance in the model was accounted for through public stigma and self-stigma, whereas $34 \%$ of the variance for intentions was accounted for through public stigma, self-stigma, and attitudes.

The results of this study set the stage for future inquiry into the relationships between stigma toward help-seeking and attitudes. The authors reported that in their model, more variance was accounted for than in previous studies examining the influence of public stigma, where only $25 \%$ was accounted for (Komiya et al., 2000). The authors attributed this effect to the importance of self-stigma, as Komiya et al. did not investigate self-stigma toward helpseeking. Although there were several strengths to the Vogel et al. (2007) study, the authors still reported some important limitations. The sample identified as $90 \%$ Caucasian, which would limit the results to other cultural groups and ethnic backgrounds. Additionally, the measure they used for public stigma measures the stigma of being a former mental patient. Thus, it more 
directly measures public stigma associated with having a mental illness as opposed to seeking help for mental health concerns.

Since the publication of Vogel et al. (2007), many researchers have examined the link between these two stigmas and counseling attitudes. One issue in directly comparing these results, even for those using SEM, is that public stigma has often been measured in different ways. As previously stated, Vogel et al. (2007) used a measure that examined stigma toward those with a mental illness. Therefore, studies using the PDD as their measure of public treatment stigma are measuring a different construct (Fox et al., 2018; Tucker et al., 2013). In addition, it is possible that a slightly different form of public stigma that is similar to, yet slightly different from the type of general public stigma defined by Corrigan (2004).

Some studies in this area use the PSOSH (Vogel et al., 2009) to measure public stigma. However, this measure could be examining a slightly nuanced version of public stigma, as the PSOSH focuses more directly on the stigma of others who are directly within one's social network. Therefore, I will refer to this type of stigma as social network stigma. This measure instructs individuals to answer questions based upon their perception of how the people they interact with would perceive them if they were to seek help. Although I have not found any studies that have empirically investigated the differences in the constructs in the way that Tucker et al. (2013) examined differences between stigma toward individuals with mental illness and stigma toward help-seeking, it is possible that there are differences. One study measured social network stigma and public stigma (Topkaya et al., 2017). The SSRPH (Komiya et al., 2000) was used to measure public stigma. Using SEM, they found that public stigma had a structural coefficient of .57 with self-stigma and social network stigma had one of .17 . The large differences in the strength of those coefficients suggests that there could potentially be 
something different being measured by each scale. In some instances, it might be important for the researchers to determine which type of public stigma, general or from close others, is most relevant to study.

Stigma in the college population. As previously described, stigma affects individuals across all stages of life from youth to late adulthood (e.g., Gulliver et al., 2010; Jung et al., 2017). However, most of the research has focused on stigma amongst college students. Since that is the emphasis of this dissertation, more discussion will be spent on this population (see Corrigan, Druss, \& Perlick, 2014 for a broad review on the impact of stigma across populations). The previously described meta-analysis of variables associated with help-seeking attitudes was conducted on studies of college students (Nam et al., 2013) and is therefore extremely relevant here. Although public stigma was much smaller on its own, previous studies suggest that higher public stigma leads to higher self-stigma, so it still remains an important variable (e.g., Vogel et al., 2013). In fact, stigma continues to be a pervasive barrier to counseling in studies using different methodological approaches. For example, in two separate qualitative studies, college students mentioned that the stigma connected to seeking mental health services played a major role in preventing students from seeking help (Quinn, Wilson, MacIntyre, \& Tinklin, 2009; Seamark \& Gabriel, 2018). This was a concern even for those who did ultimately seek help, as those students still mentioned that they were afraid of being perceived as weak for seeking services (Quinn et al., 2009). In another study that contained a mix of individuals who had and had not sought help, one of the major themes that arose related to stigma, and how students would feel more comfortable seeking help if the process was normalized (Seamark \& Gabriel, 2018). 
Numerous quantitative studies also support the findings relative to the relationship between stigma and help-seeking behaviors. One study examined the cluster profiles of college students to see how those profiles influenced whether or not they had previously gone to counseling in the past year (Wu et al., 2017). Cluster analysis revealed three distinct profiles of students: 1) low self-stigma, low public stigma; 2) average self-stigma, high public stigma; and 3) high self-stigma, high public stigma. The results indicated that those who were in the high self-stigma, high public stigma group were least likely to have sought services in the previous year. On the other hand, the individuals in the low self-stigma, low public stigma profile were most likely to seek help. The authors suggested that the findings provided more evidence that self-stigma plays a stronger role in help-seeking than does public stigma. Interestingly, students in the high self-stigma, high public stigma group also had lower perceived need for seeking help. Therefore, the results of this study imply that elevated levels of stigma could potentially play a significant role in reducing mental health literacy and minimizing the presence of a mental health condition, further decreasing the likelihood of someone seeking help. Some evidence for this idea comes from a recent publication by Jennings et al. (2017). Although those authors did not measure perceived need, they did measure whether participants were currently experiencing distress. In the study, 115 out of 263 of the participants reported currently experiencing an emotional, stress, family, or alcohol/drug related problem. Public, self-stigma, and more negative attitudes toward counseling all predicted that these participants would be less likely to have sought counseling in the past six months. Thus, although they were experiencing a need in that moment, those with higher stigma were less likely to seek the help they needed.

Although a similar construct to attitudes, intentions is a further step in examining the willingness of individuals to seek help. In the TRA, intentions are the closest proxy of help- 
seeking behavior and are distinct from attitudes (Azjen \& Fishbein, 1980). Therefore, it is important to examine them in addition to attitudes. The research examining intentions in the college population has found that attitudes play a significant role in influencing intentions (e.g., Fripp \& Carlson, 2017; Garriott et al., 2017). A recent meta-analysis examined variables related with intentions to seek counseling in college students (Li et al., 2014). The authors examined 18 studies that contained 6,839 participants. Variables were only included if they had been investigated in at least three studies. Not surprisingly, attitudes was found to have the strongest relationship with intentions $(r=.46)$, which was a large effect size. Anticipated utility was close behind $(r=.42)$. Adherence to Asian values $(r=-.15)$, public stigma $(r=-.11)$, and anticipated risk $(r=-.10)$ were significant but had small effect sizes. Social support, self-concealment, psychological distress, and self-disclosure were not significant. It is unclear why public stigma was included whereas self-stigma was not, given that most studies that examine public stigma also include self-stigma. Regardless, the results of this meta-analysis support the TRA (Ajzen, 1991; Ajzen \& Fishbein, 1980), as attitude is most proximal to intentions and played the strongest role in predicting those intentions.

Stigma is another variable that has been studied in direct relation to intention. Although many studies examine the impact of stigma through attitudes (e.g., Garriott et al., 2017; Wade et al., 2015), several studies have left out the attitude link. These studies have typically found that self-stigma significantly predicts help-seeking intentions (e.g., Andoh-Arthur, Asante, \& Osafo, 2015; Currier et al., 2017; Lally et al., 2013; Lannin et al., 2015). Once more, public stigma has typically not shown a direct association with help-seeking intentions (e.g., Andoh-Arthur et al., 2015; Lally et al., 2013). However, in a study of Turkish college students, a SEM analysis helped to show that public stigma had a direct association with intentions (Topkaya et al., 2017). 
A recent study of college-aged men also sheds more light on the role of stigma regarding intentions (DeBate, Gatto, \& Rafal, 2018). In that study, the authors used several measures related to the TRA framework (i.e., subjective norms and attitudes) to measure intentions. The authors found that stigma mediated the relationship with intentions and that the relationships between the variables with intentions was stronger after controlling and eliminating the effect of stigma. Therefore, it is clear that stigma also plays a role in determining help-seeking intentions, even if indirectly. Although public stigma may not always play a direct role, the internalization of the construct into self-stigma (Vogel et al., 2013) and the established pathway between selfstigma, attitudes, and intentions renders public stigma as a relevant variable for intentions. Additionally, public stigma did have a significant, albeit small, association with intentions in a recent meta-analysis ( $\mathrm{Li}$ et al., 2014). Therefore, all forms of stigma are important pieces of the help-seeking puzzle.

Stigma and culture. It is also important to study the cross cultural validity of stigma in its relation to counseling attitudes. The current literature suggests that stigma toward mental health help-seeking is associated with worse attitudes across numerous cultures (e.g., Cheng et al., 2018; Masuda, Anderson, \& Edmonds, 2012; Vogel et al., 2017). However, there is a difference in the role that public stigma plays across these cultures. In one of the exemplary cross-cultural examinations of this topic, Vogel et al. (2017) analyzed data from 3,276 college students from ten different countries. In the study, the authors examined how public and selfstigma influence attitudes. Public stigma was measured using the SSRPH, an appropriate public stigma measure for help-seeking stigma. Overall, public stigma was associated with greater selfstigma, which related to more negative attitudes toward counseling. The path from public to self-stigma varied across countries, and did not show an association in Portugal. This suggests 
that the cultural context is important for determining how strong of an influence public stigma might have on an individual's self-stigma.

More evidence for the cultural context comes from studies conducted in several other countries. A set of studies has failed to find an association between public stigma and selfstigma in Israeli students (e.g., Shechtman et al., 2010; Shechtman, Vogel, Strass, \& Heath, 2018). The association was not present for college students and their attitudes toward group or individual therapy (Schechtman et al., 2010), and was not present for adolescents (Shechtman et al., 2018). Further, in a sample of Irish college students, self-stigma predicted non-help seeking intentions, whereas public stigma did not (Lally, O'Conghaile, Quigley, Bainbridge, \& McDonald, 2013). Public stigma also did not predict help-seeking attitudes or intentions in Ghanaian college students (Andoh-Arthur et al., 2015) and in one study of Turkish college students (Topkaya, 2014). However, self-stigma was a significant predictor of help seeking behaviors with the Ghanaian and Turkish samples. Opposingly, in Botswanian university students, public stigma and not self-stigma was a significant predictor of help-seeking intentions (Pheko et al., 2013). Therefore, it becomes readily apparent that cultural forces likely help explain why public stigma may have an influence in many countries (e.g., Vogel et al., 2017) but not in others. For example, diverse cultural makeup and beliefs of the citizens in that particular country might be responsible for diminished associations of public stigma with other variables (e.g, Shechtman et al., 2010). However, reasons why public stigma is not as important a factor in some countries should be further explored. Within the United States, Abdullah and Brown (2011) state that the role cultural values play for Asians and African Americans is clearer than for other groups. 
Stigma has been found to play one of the strongest roles in influencing attitudes in Asian culture. Across numerous studies, levels of stigma have been found to be associated with more negative attitudes toward help-seeking within those from Asian descent (e.g., Arora, Metz, \& Carlson, 2016; Cheng et al., 2018; Choi \& Miller, 2014; Masuda et al., 2009). In one study, those who identified as Asian American or Asian were more likely to be in the cluster profile of individuals with high self and public stigma (Wu et al., 2017). Additionally, being Asian was found to be a predictor of more negative attitudes in studies containing multiple ethnic groups (Cheng et al., 2018; Eisenberg, Downs, Golberstein, \& Zivin, 2009). In studies that have compared treatment utilization and attitudes of Asian college students with White college students, the Asian college students show more stigma and less utilization (e.g., Loya, Reddy, \& Hinshaw, 2010; Masuda et al., 2009; Rafal, Gatto, \& DeBate, 2018). Treatment rates for Asian American students was only $8.5 \%$ compared to $50.4 \%$ of the White students in one study (Masuda et al., 2009). Further, these results have been found in studies of Asians within (e.g., Arora et al., 2016; Cheng et al., 2018; Choi \& Miller, 2014) and outside of the United States (e.g., Bathje, Kim, Rau, Bassiouny, \& Kim, 2014). As with other research, self-stigma more strongly predicted attitudes. In South Asians in particular, self-stigma has been found to play a more significant role than public stigma (e.g., Arora et al., 2016; Loya et al., 2010).

Stigma has also been found to be influential in populations of African descent (e.g., Fripp \& Carlson, 2017; Masuda et al., 2012). Quantitative studies have found that stigma is associated with reduced attitudes toward help-seeking (Fripp \& Carlson, 2017; Masuda et al., 2009; Masuda et al., 2012). Qualitative studies have also provided evidence to suggest that stigma is a barrier to help-seeking. In one study of African American women, the participants reported stigma as a barrier to seeking help care (Ward, Clark, \& Heidrich, 2009). However, a study with 17 men 
reported no issues with stigma and those adults believed mental illness to be commonplace (Ward \& Besson, 2013). The small sample and qualitative approach does not make the results generalizable, and the population range of 25-74 further restricts transferring these results to college students. Therefore, the available data suggests that stigma influences attitudes toward help-seeking in a negative way. However, as with all cultures, values may play an important role. Support for this comes from a study that found greater levels of Africentric values were associated with more public stigma toward counseling in college students (Wallace \& Constantine, 2005).

Finally, those of Latin decent are a third group for which consistent results have been found (e.g., Ballesteros \& Hilliard, 2016; Mendoza, Masuda, \& Swartout, 2015; Fripp \& Carlson, 2017). Similar to the general trend, self-stigma has been found to have a stronger relationship with counseling attitudes than public stigma. This relationship has also been extended to online counseling (Ballesteros \& Hilliard, 2016).

This section reviewed the evidence that stigma toward mental health counseling is a universal phenomenon that impacts individuals across cultures. However, it should be noted that research conclusions should not be drawn across all individuals from a cultural group. Individuals from different Asian or Latin cultures, for example, are likely to have different values. Even in the section describing Asian values, there was little attention paid to differences between different Asian groups. Two of the studies specified that South Asian college students were directly examined (Arora et al., 2016; Loya et al., 2010). This will take a deliberate effort by researchers to obtain subsamples large enough for comparison. Ballesteros and Hilliard (2016) reported the different Latin ethnicities present in their sample, but the numbers were not large enough to make comparisons between individuals from different Latin backgrounds. 
Therefore, research should use a culturally sensitive lens when applying conclusions and prior to making overarching generalizations. Otherwise, further stereotypes could be created (Corrigan et al., 2014).

Mental health interventions to reduce stigma in the general population. There have been hundreds of studies that have examined interventions to reduce stigma in the general population. The purpose of this section is not to exhaustively review those interventions, but rather to acknowledge their prominence. It is important that these interventions be at least briefly described because the positive effects of interventions on reducing stigma suggest that stigma can be altered. This is essential if stigma is a factor that influences attitudes and ultimately intentions for help-seeking behavior. For a more thorough explication of stigma interventions, see Thornicroft et al. (2016) or Yanos, Lucksted, Drapalski, Roe, \& Lysaker (2015) for reducing self-stigma specifically.

Stigma reduction interventions are commonly conducted using contact and education methods (Corrigan et al., 2014). Contact interventions are intentionally structured so that participants communicate with individuals who describe their experience with mental illness. This approach has been found to have slightly stronger effects than using an education intervention (Corrigan, Morris, Michaels, Rafacz, \& Rüsch, 2012). The format of these contact interventions vary. It could simply be a presentation from the speaker to the audience or it could take the form of a more interactive discussion between the speaker with mental illness and the audience. Although this approach often occurs through live in-person interactions, many studies have utilized a video-based approach. Researchers in one study showed college students one of three videos: an individual talking about their own experience with mental illness, an individual talking about a friend or family member's experience with mental illness, or a control video 
about the loss of the Cherokee language in youth (Hackler, Cornish, \& Vogel, 2016).

Participants completed pre, post, and one-week follow-up measures on instruments measuring mental illness. Results found that both treatment videos were effective at reducing stigma.

Educational interventions inform the audience about various aspects of mental health. There are a variety of approaches that can be taken, but education often involves some aspect of dispelling myths related to mental illness and mental health help-seeking, describing prevalence and symptoms of various mental health conditions, barriers to seeking treatment, and local resources that are available. If the presentation is being given to a specific demographic group, statistics and information tailored to that group will be included as well. Education interventions are used for public and self-stigma, and a recent review found psychoeducation to be the most commonly used intervention strategy for self-stigma (Mittal, Sullivan, Chekuri, Allee, \& Corrigan, 2012).

These are not the only methods used to reduce stigma, however. For example, an interesting study found that participants had lower perceptions of stigma when psychotherapy was advertised as focusing on the alliance rather than diagnosis and treatment (Swan, Heesacker, \& King, 2016). The reason why is unknown. However, if future research confirms this finding, it could be an easy way to manipulate individuals' perceptions of the counseling process and potentially improve attitudes toward counseling. This is important as some of the strategies for reducing stigma require interventions that are conducted while in therapy (Mittal et al., 2012). However, if the goal is reducing stigma to get individuals to seek help, then other strategies must be utilized.

There is one major limitation that arises from various reviews of interventions to reduce stigma: the need to include long-term follow up to examine lasting impact (Thornicroft et 
al., 2016). In that same review, Thornicroft et al. (2016) found that in college students, social contact tends to result in short term gains, but less is known about long-term gains because of the aforementioned limitation of minimal follow-up. As another example, the authors in the previously described video-based study only included follow-up one week after the viewing (Hackler et al., 2016). It is therefore unknown if their results were maintained over time and what type of impact that might have on an individual.

In summary, there are a variety of interventions to reduce stigma and improve counseling attitudes. It is beyond the scope of this review to cover them all in detail. However, results suggest that these interventions can effectively reduce stigma toward mental illness and mental health treatment (Thornicroft et al., 2016; Yanos et al., 2015) and therefore studies should continue to examine unique interventions with the college population that aim to reduce stigma, while including longer periods of follow up.

\section{Summary of Stigma and Help-Seeking in the General Population}

This section provided a review of the literature on stigma, attitudes, and intentions to seek help in the general population, with a more focused review of the impact of these factors within the college population. Across the lifespan, stigma has been found to be an influential factor in determining individuals' attitudes toward seeking help. Specifically, the results from several studies suggest that self-stigma plays a more important role in the formation of attitudes and intentions toward help-seeking compared to public stigma or social network stigma (e.g., Lally et al., 2013; Lannin et al., 2015). Further, the link between attitudes and intentions to seek counseling supports the TRA (Ajzen \& Fishbein, 1980), which posits that attitudes influence intentions to engage in a particular behavior. One limitation of this research is that most studies examine attitudes or intentions, but rarely investigate actual help-seeking behavior. Although 
attitudes and intentions have been associated with actual help-seeking behavior (e.g., Elhai et al., 2008; Nagai, 2015; ten Have et al., 2015), those concepts cannot always be used as a proxy for actual help-seeking. Most studies have the potential to study actual behavior as part of their analyses because they report the percentage of individuals who have received prior treatment. Thus, they have a measure of actual help-seeking behavior. Future research could use that information as an outcome variable in the analyses rather than as a control to give a more accurate representation of how stigma influences help-seeking. Jennings et al. (2017) used logistic regression to determine if individuals who were experiencing current distress reported help-seeking behavior. This is only one type of statistical method that could be adopted in future studies to get a more nuanced understanding of factors that influence actual help-seeking behavior. Given that treatment utilization rates have a wide range and have been found to be as low as $16 \%$ (Auerbach et al., 2016) or as high as 39\% (Ketchen Lipson et al., 2015) and that approximately one-third of individuals who require treatment do not seek it (Wang et al., 2007), expanding research to focus on facilitators and barriers to actual help-seeking and not simply factors that influence attitudes or intentions would provide more clarity on the topic.

\section{Student-Athlete Help-Seeking}

Compared to the literature in the general population on attitudes toward counseling and mental illness, there has been relatively little research conducted on student-athletes. This is unfortunate because contrary to what some authors have argued, student-athletes are not exempt from experiencing mental health challenges (Wolanin et al., 2016). As described in the introduction to this literature review, the prevalence of mental health concerns amongst studentathletes are comparable to their nonathlete peers (e.g., Etzel et al., 2006; Gill, 2008; Wolanin et al., 2016). Additionally, studies have been inconsistent regarding differences between student- 
athletes and nonathletes regarding their attitudes toward counseling. One of the earliest studies comparing the two groups found that nonathletes had more positive attitudes toward counseling compared with student-athletes (Watson, 2005) and a more recent study found that studentathletes had lower overall scores on attitudes compared to nonathletes, but only had significant differences on two of the four subscales of the ATSPPH (Leimer, Leon, \& Shelley, 2014). However, Barnard (2016) did not find differences in attitudes between student-athletes and nonathletes. Student-athletes have been found to possess more stigma than nonathletes in at least one recent study (Kaier, DeMarni Cromer, Johnson, Strunk, \& Davis, 2015). However, the authors used the PDD, which measures stigma toward individuals with mental illness and not treatment seeking. Bird et al. (2018) measured stigma and attitudes toward help-seeking in both groups and did not find any differences, and a recent study did not find differences between groups after controlling for previous therapy history and gender (Hilliard, Redmond, \& Watson, 2018b). Therefore, it remains unclear if stigma and attitudes amongst college athletes differ from nonathlete college students. Further clouding the picture is the lack of consistency in measures across studies. Although most studies use the ATSPPH or its short form to measure attitudes (e.g., Barnard, 2016; Leimer et al., 2014; Watson, 2005), the stigma measures have varied greatly. The two studies measuring stigma differences discussed in this section used very different measures. Kaier et al. (2015) the PDD, which is problematic because they stated the purpose of their study was to examine "PPS [perceived public stigma] and personal stigma about mental health help-seeking..." (p. 736). Although the PDD does contain items that refer to helpseeking, Tucker et al. (2013) reported that measures such as the PDD that contain elements related to help-seeking and mental illness stigma can cloud the nuances of stigma toward helpseeking behavior and are conceptually distinct. Contrarily, Bird et al. (2018) used the PSOSH 
and SSOSH and effectively measured social network stigma and self-stigma toward helpseeking. Aside from Bird et al. (2018), the studies mentioned in the previous paragraph simply examined differences in stigma and attitudes between groups by their athletic status and did not examine the actual influence of stigma on attitudes or other help-seeking variables. This section will review various factors that influence student-athletes attitudes and intentions to seek help for psychological issues. First, the few interventions that have been conducted on NCAA studentathletes will be described. This is to provide continuity from the end of the previous section and allow it to funnel the topic down to the material most pertinent to this study. After describing these interventions, the general barriers student-athletes face regarding treatment will be discussed. This is meant to be a brief review and interested readers should consult a recent systematic review on the topic for a more detailed discussion (Moreland et al., 2018). Following that review, the factors related to attitudes toward treatment seeking for mental health services and a related construct, attitudes toward sport psychology will be overviewed. Finally, this section will end with a focused discussion on the role of stigma in attitudes toward help-seeking for student-athletes.

\section{Mental Health Interventions}

There have been few interventions aimed at improving attitudes toward mental health with NCAA student-athletes. Pilot interventions have been conducted with college athletes in other countries such as Ireland (Breslin, Haughey, et al.,2018). Similar types of workshops or interventions have been conducted with coaches regarding sport psychology attitudes (Zakrajsek \& Zizzi, 2008) and coaches and support staff of elite athletes regarding mental health literacy (Sebbens, Hassmén, Crisp, \& Wensley, 2016). For a full review of interventions implemented to address various components related to mental health such as knowledge and awareness, see 
Breslin, Shannon, Haughey, Donnelly, and Leavey (2017). The interventions that have been conducted with NCAA student-athletes revolve around contact and education (Corrigan et al., 2014). They will each be briefly discussed next. It should be noted that the term 'intervention' is used loosely here, and refers to any organized attempt to improve attitudes or knowledge surrounding mental health issues.

Beauchemin (2014) reported on an integrative outreach model conducted at a large Midwestern Division I university. The model was conducted either through a one-session workshop or three or five-session workshops as part of a class for student-athletes on overall wellness. The intervention was focused on the teaching of five mental skills: imagery, routines, self-talk, concentration, and relaxation. The author reported that there were also discussions surrounding mental health and counseling services. Participants completed surveys at the end of the course and some participated in follow-up interviews. Thirty-two participants completed the surveys, but it was not described how many student-athletes actually received the intervention. Ten participated in the interviews. The relevant results from this study described changes in perceptions of mental health. Twenty-seven respondents answered the question about how their attitudes toward mental health had changed. Of these, $37 \%$ reported having positive perceptions, $22 \%$ reported increased awareness or decreased stigma toward mental health issues, and 19\% reported no changes in their perceptions. Qualitative results essentially supported the quantitative findings, as student-athletes reported feeling more positive perceptions about seeking treatment for mental health issues.

Another study tested the impact and feasibility of using an online website (www.SupportForSport.org) to promote mental health knowledge amongst college studentathletes (Van Raalte, Cornelius, Andrews, Diehl, \& Brewer, 2015). They conducted studies 
testing the website with coaches and administrative staff as well as student-athletes to get perspectives on the utility of the website. Content was created from a mix of previously established resources and the final website contained the following sections: "Get Support," "Facts," "About," “Contact," "What Would You Do?" and "Having a Conversation." Contained within these sections were videos from individuals who have experienced mental health issues, the opportunity to make referral choices connected with a student-athlete with a mental health issue, and facts about various disorders. The student-athlete sample consisted of 153 participants from all three NCAA divisions. They were recruited through an email request. The sample contained 103 females. The participants were assigned to view the SupportForSport website or a control website (www.ncaa.org/student-athletes). They completed pre and post-intervention measures. The results found increased levels of referral knowledge and efficacy in the experimental group compared with the control group.

Finally, a recent study described preliminary results from Athletes Connected, a mental health awareness program at the University of Michigan (Kern et al., 2017). This was the first study to explicitly aim to reduce stigma associated with mental health amongst student-athletes. The model was delivered to teams at the university in a one-session presentation. A total of nine presentations were delivered, and the size of the groups varied between 30-100. In total, 626 student-athletes completed measures for the study out of a population of approximately 900 . The same members delivered the presentation each time. The format consisted of four primary sections of the presentation: an educational overview of how mental health relates to studentathletes, two brief videos of former student-athletes discussing their struggle with mental illness, additional disclosure from those student-athletes featured in the video live with the audience, and an open discussion with the former student-athletes. Over $60 \%$ of the sample reported 
experiencing an emotional or mental difficulty over the past four weeks that had impacted their athletic performance. The authors also administered pre and post-measures related to attitudes and knowledge surrounding help-seeking. The student-athletes reported being more comfortable talking about mental health with other teammates after completion of the intervention $(d=0.36)$, and reported increased confidence in their ability to assist a teammate to get mental health support $(d=0.55)$ and identify a mental health issue in a teammate $(d=0.49)$. The participants were also significantly more willing to seek help at the conclusion of the presentation $(d=0.48)$. Regarding stigma, the participants said they would accept someone who received mental health treatment as a friend significantly more after the presentation $(d=0.28)$. There was not a significant change regarding thinking less of a teammate who received treatment, although scores were slightly improved after the presentation. This was the first study to examine how a direct contact and education intervention could reduce stigma among student-athletes, with mild success.

As a group, these interventions were limited in two primary ways: a lack of follow-up measures and not using a control group. Follow-up was not conducted in any of the studies, so it is not possible to ascertain how long these effects may have lasted. This follow-up information is important because it can provide valuable data regarding the required length of interventions required to achieve adequate lasting impact. For example, Beauchemin (2014) described his method as students taking an entire class or attending a workshop. If participants in the one-day workshop maintain the same level of improvements as students who take an entire class, this can be critical information for practitioners conducting outreach.

Although Van Raalte et al. (2015) did include a control group in their study, the other two interventions did not. Therefore, it is difficult to generalize as a whole from these interventions 
that changes seen were due to the workshop or content. Again, this is important because in order to create evidence based strategies, there needs to be evidence that improvements are due to the actual intervention. Van Raalte et al.'s (2015) study provides some initial evidence that education can have an impact on knowledge gains, but other studies should follow suit in order to provide higher quality of evidence.

Despite these primary limitations, interventions relating to mental health show promise with student-athletes. Future studies should continue to target stigma as it has been shown to influence attitudes in student-athletes (e.g., Bird et al., 2018; Hilliard et al., 2018a; Wahto et al., 2016). The studies should include comparison groups and long-term follow up to better understand the maintenance of changes demonstrated from the intervention. Gulliver (2017) suggested that studies with long-term follow-up tend to be sparse because it requires more time to collect that data. Although this might be difficult for many academics who feel pressured to publish and do not have time to wait to collect follow-up, it is a worthy endeavor that will improve the quality of research in this area.

\section{Barriers to Help-Seeking for Student-Athletes}

Some research exists to suggest that student-athletes are not comfortable with helpseeking. A recent study of student-athletes across multiple divisions reported that $28 \%$ had little to no comfort in seeking mental health services (Moore, 2017). There are several reasons this discomfort could exist and understanding the barriers to receiving counseling could partially help us understand why this percentage is relatively high. Although barriers do not necessarily equate to discomfort, other studies looking at treatment utilization rates for college student-athletes find that approximately $25-30 \%$ of this population has sought mental health services in the past (Bird et al., 2018; Wahto, Swift, \& Whipple, 2016). 
The barriers that exist for student-athletes share many similarities with those of nonathletes. However, there are several unique factors that are more specific to the studentathlete population. One of these includes time (e.g., Leimer et al., 2014; López \& Levy, 2013; Watson, 2006). One group of student-athletes ranked lack of time as the top barrier to seeking counseling (López \& Levy, 2013), and it ranked third in another study outlining the barriers identified by athletes for not seeking counseling (Watson, 2006). Thus it is clear that time is a primary concern amongst student-athletes. The summary of the NCAA 2015 goals study found that athletes reported spending a range of 28.5 hours per week involved in athletics at Division III to 34 hours per week in Division I (NCAA, 2016). Further, at least half of the student-athletes across all three divisions reported spending nearly as much time devoted to their sport in the offseason compared to during the competitive season. This suggests that the offseason might not provide a more open window for seeking counseling services. In addition to athletics, the summary reported that student-athletes spent an average of 38.5 hours per week on academics in Divisions I and II and 40.5 hours per week in Division III (NCAA, 2016). Combined, that leaves little time in an athlete's schedule. As a result, it might be easier for many student-athletes to meet at later times in the evening when they have more availability (Watson \& Etzel, 2004). However, not all counseling centers are open late into the evening, which may present a barrier for student-athletes who wish to seek counseling.

Another prominent barrier cited by student-athletes is the concern that the counselor will not understand their needs. Specifically, various samples of student-athletes have reported that a lack of understanding from practitioners relating to the demands and lifestyle of student-athletes prevents them from seeking services (e.g., Gavrilova \& Donohue, 2018; López \& Levy, 2013; Moore, 2017). The unique sociocultural elements of intercollegiate athletics as well as various 
pressures and demands require specialized practitioner knowledge (Watson, Way, \& Hilliard, 2017). Therefore, athletic departments would be wise to hire individuals for sport psychologist positions who have the appropriate training to handle these issues. Although all athletic departments may not have the monetary resources to hire these professionals, counseling centers could reach out to athletic departments to make student-athletes aware of professionals who may be appropriately trained to understand the issues faced by student-athletes.

A third major barrier to athletes seeking mental health services often reported in the literature is fear of a lack of confidentiality or others knowing about the treatment seeking (e.g., López \& Levy, 2013; Moore, 2017). Specifically, athletes fear that close others such as coaches, athletic department personnel, or teammates will know they sought counseling (e.g., López \& Levy, 2013; Moore, 2017). Student-athletes are in a unique position for others to be aware of their help-seeking behaviors because of their potential recognizability on campus. The possibility of being recognized in a waiting room does not break any confidentiality rules, but could lead to others in the campus community being aware of the student-athlete's decision to seek mental health services (Etzel \& Watson, 2007). This fear of being recognized by others has also been reported as a barrier (López \& Levy, 2013).

In summary, student-athletes face many of the same issues as nonathletes when it comes to personal and emotional issues. In addition, added pressures from their sport and time demands can make college student-athletes a vulnerable population requiring psychological services (e.g., Etzel \& Watson, 2007; Jolly, 2008; Pinkerton et al., 1989). Research has found that they often possess worse, or sometimes equivalent, attitudes toward seeking counseling compared with nonathletes (e.g., Barnard, 2016; Bird et al., 2018; Leimer et al., 2014; Watson, 2005). Student-athletes also face similar barriers as nonathletes, but have unique barriers that 
nonathletes may not face. These results have come from self-report studies, which often have included open-ended qualitative responses (e.g., Moore, 2017; Watson, 2006). Some of the unique barriers include a lack of time, concerns about counseling professionals not having an understanding of athletic demands, worries over lack of confidentiality, and being recognized by others in their social network or campus community (e.g., Gavrilova \& Donohue, 2018; López \& Levy, 2013; Moore, 2017). It is important for counseling professionals to have knowledge of these barriers so that they can better service student-athletes and improve rates of utilization (e.g., Bird et al., 2018). Critically, there are steps practitioners can take to reduce some of these barriers. For example, to reduce concerns about confidentiality, counseling professionals should be clear about what confidentiality is and its limits so that student-athletes are aware of how the treatment relationship works.

\section{Stigma and Attitudes Toward Help Seeking in Athletes}

As previously mentioned, there is a relative dearth of research on attitudes of studentathletes toward counseling. However, researchers have investigated attitudes toward sport psychology consulting as well as mental health help-seeking. These are similar constructs but need to be examined separately because sport psychology consulting is related to performance enhancement whereas mental health services may be perceived as indicative of emotional troubles or weakness by athletes (Etzel \& Watson, 2007). Some evidence for this idea comes from early studies examining perceptions of an athlete who consults a sport psychologist. The first study consisted of introductory psychology students and had them provide draft ratings of college athletes who consulted with either a coach or sport psychologist for issues of concentration, consistency, or stress. The participants read vignettes of an athlete who played football, one who played basketball, and one who played baseball. The results found that the 
athletes who consulted a sport psychologist were perceived more negatively than those who consulted a coach for their performance issues (Linder, Pillow, \& Reno, 1989). However, when this research was extended using the same procedure by asking college football players about their perceptions of a quarterback seeking help from a sport psychologist or coach, there were no significant differences (Van Raalte, Brewer, Brewer, \& Linder, 1992). However, a psychotherapist was also added as an option in this study. Athletes who consulted a psychotherapist were perceived more negatively compared to those who consulted a coach. Therefore, the results of these two studies suggest the possibility for a "negative halo" to exist around athletes who ask for and receive psychological help. Although these studies are enlightening, both of them asked about performance based issues. Therefore, it is unknown how individuals might respond if they were asked to rate individuals based on seeking help for emotional issues. The introductory psychology students rated an athlete consulting with a sport psychologist as more emotionally unstable than one who met with a coach (Linder et al., 1989). This suggests the possibility that help-seeking for more emotional issues might be more stigmatized and perceived more negatively when compared to receiving services for performance enhancement services.

Attitudes toward sport psychology services have been examined more recently. An initial instrument was created to measure attitudes that was partially based on the ATSPPH (Martin, Wrisberg, Beitel, \& Lounsbury, 1997). Analysis found three subscales: stigma tolerance, confidence in a sport psychology consultant/recognition of need, and interpersonal openness/willingness to try a sport psychology consultant. These dimensions closely resemble some of the barriers student-athletes report towards seeking mental health services, such as stigma and recognition of need. The researchers found that levels of stigma were higher amongst 
male athletes and African American athletes. These results align well with the results of gender and race research in the general psychology literature regarding mental health counseling (e.g., Masuda et al., 2009; Nam et al., 2010). This instrument was later revised (Martin, Kellmann, Lavallee, \& Page, 2002) but has found consistent results. Stigma continues to be associated with sport psychology services (e.g., Martin, 2005; Martin et al., 2002; Martin, Zakrajsek, \& Wrisberg, 2012).

Stigma toward help-seeking services is prominent throughout athletics. This issue spreads across developmental levels from youth (Gulliver, Griffiths, \& Christen, 2012) to elite (Biggins, Burns, \& Uphill, 2017). It is also common amongst college student-athletes (e.g., Beauchemin, 2014; López \& Levy, 2013; Moore, 2017; Watson, 2006). These barriers related to stigma were reported in different formats. In one study requesting open-ended responses, the stigma attached to mental health disorders was identified as a barrier (Moore, 2017). Although this is not directly the same as stigma for help-seeking, it suggests that there is still fear of being perceived to have poor mental health. Fear of stigma for seeking services was perceived as the second biggest barrier in another sample of Division I athletes (López \& Levy, 2013), and perceptions of others was rated third in another study (Watson, 2006). A similar concept that was also highly rated was the idea that seeking help would make one appear weak (López \& Levy, 2013; Moore, 2017). This could potentially not be considered a direct measure of stigma, but it represents the internalization of stereotypes that are often associated with self-stigma (Corrigan, 2004). This is also seen as a barrier from the perspectives of coaches (Biggins et al., 2017).

The reason that seeking mental health services is stigmatized within sport could be related to the traditional ethos of sport culture. Sport culture often emphasizes toughness, which 
can be at odds with seeking help from others (Bauman, 2016; Schinke, Stambulova, Si, \& Moore, 2018). There is also a masculine nature embedded throughout sport, which partially accounts for the emphasis on toughness. Help-seeking may be seen as incongruent with masculine norms (Vogel \& Heath, 2016), and therefore seen less positively. Various sociocultural components of sport may undermine a willingness to seek help, as individuals prescribe to the perceived masculinity associated with sport (Gucciardi, Hanton, \& Fleming, 2017). Perceived stigma from influential others in the athletes' lives, such as coaches, has been found to be related to attitudes (Kroshus, 2017). Therefore, it is important that people who are in charge of athletes, such as coaches or administrators, work to de-stigmatize discussions surrounding mental health, and help-seeking in particular (Schinke et al., 2018).

Although the existence of stigma toward mental health help-seeking has been clearly established in the literature, less is understood about the process through which stigma might influence actual attitudes and intentions toward help-seeking. The TRA and models from the general psychology literature connecting public and self-stigma to attitudes and intentions is important to also examine amongst college student-athletes. This next section will review three studies in-depth that have investigated the public stigma/self-stigma/attitudes relationship. These studies have been integrated throughout this literature review, but considering their influence on the current study, it is important to provide some more depth on their methods and results.

One of these studies that examined the link between public stigma, self-stigma, and attitudes in college student athletes was conducted by Wahto et al. (2016). Their sample consisted of 43 student-athletes from a university that had sports competing at the Division I and II level in Alaska. The sample was 74\% female and 73\% White. The authors measured public stigma using the SSRPH, self-stigma using the SSOSH, and attitudes were measured using the 
Inventory of Attitudes Toward Seeking Mental Health Services (Mackenzie, Knox, Gekoski, \& Macaulay, 2004). They also asked the participants how likely they would be to seek counseling if referred from four different sources: self, teammate, family, or coach. Using hierarchical multiple regression analyses, public and self-stigma both significantly predicted counseling attitudes. These two variables accounted for $66 \%$ of the variance beyond gender and previous treatment history, which were included in block one as controls. The overall model accounted for $77 \%$ of the variance in attitudes. To further explore the relationship of public and self-stigma to attitudes, the authors conducted mediation analyses. Mediation analyses found that self-stigma partially mediated the relationship between public stigma and attitudes, although the direct path to attitudes was still significant. Finally, student-athletes were significantly more likely to seek help if referred by a family member compared with self, teammate, or coach. There were no differences amongst the last three conditions. Of the remaining three sources, a self-referral had the lowest mean score, followed by coach, and then teammates.

This study contributed to the previous research by corroborating the findings of public stigma and self-stigma's influence on attitudes. However, there were limitations to this study. The sample of only 43 student-athletes is cause for concern, although the authors note that because of the significant findings, power was not an issue. A more important limitation is that the sample was nearly three-quarters female, which could have implications because females have been found to have more favorable counseling attitudes (Nam et al., 2010; ten Have et al., 2010). Additionally, the authors note that their sample represented approximately $25 \%$ of the student-athlete population at the university, which lends itself to self-selection bias. Therefore, future research can build on this study by gathering a larger sample with a more balanced 
male/female ratio, a more culturally diverse sample, and by using methods that will result in less self-selection bias.

Bird et al. (2018) used a path model to examine the relationship between public stigma, self-stigma, and attitudes toward online and face-to-face counseling. The sample consisted of 101 student-athletes who were recruited through emails sent from the head coach and a human subjects pool. The sample contained 51 males and 51 who identified as White. They used the PSOSH as their measure for public stigma and the SSOSH for self-stigma. The Face-to-Face Counseling Attitudes Scale (FCAS) and Online Counseling Attitudes Scale (OCAS) were used as the attitude measures (Rochlen, Beretvas, \& Zack, 2004). Additionally, they asked participants what sources they would be willing to seek help from, such as family, coach, or a mental health professional. In their path model, public stigma significantly related to self-stigma $(\beta=.39)$, and self-stigma significantly negatively related to value for face-to-face counseling ( $\beta$ $=-.35)$ but was positively related to discomfort for face-to-face counseling $(\beta=.48)$. Both of these values are much stronger than in another study that used the SSOSH in relation to the FCAS. In that study of Korean college students, the relationship was much weaker $(\beta=-.22)$, but the authors only used the total scale score and did not divide it by value and discomfort (Bathje, Kim, Rau, Bassiouny, \& Kim, 2014). Compared to studies that have used other attitude measures, the structural coefficients for Bird et al. (2018) from self-stigma to attitudes is much smaller, where the coefficients have ranged from -.54 to -.77 (e.g., Garriott et al., 2017; Topkaya et al., 2017; Vogel et al., 2007). Regarding the relation of the PSOSH to self-stigma, the relationship was weaker than in samples of Asian born Asian, Asian American, and Pacific Islanders (AAPI) (Choi \& Miller, 2014) and continuing generation college students (Garriott et al., 2017), but stronger than samples of Turkish college students (Topkaya et al., 2017), the total 
sample of AAPI college students (Choi \& Miller, 2014), and in first-generation college students (Garriott et al., 2017).

The use of path analysis was a strength of the Bird et al. (2018) study, as it is the first to examine the relationship between stigma and help-seeking attitudes in student-athletes with this statistical method. However, there were still important limitations, and they mirror the ones present in Wahto et al. (2016). The 101 student-athletes who participated represented 20\% of the student-athlete population, which again leaves the possibility for self-selection bias to influence the results. Additionally, 101 is a small sample size for a path analysis, as a minimum threshold is often set at 200 for this type of analysis (Kline, 2016; Weston \& Gore, 2006). The participants also came from one Division I school, which further limits the generalizability of these results.

Finally, a recent study investigated stigma and attitudes of student-athletes participating in Division I and III (Hilliard et al., 2018a). The authors recruited 243 participants, which included 146 males. The SSRPH was used to measure public stigma, the SSOSH for self-stigma, and the ATSPPH-SF for counseling attitudes. The researchers used SEM to examine hypothesized pathways and found a positive relationship between public stigma and self-stigma $(\beta=.43)$ and self-stigma and attitudes $(\beta=-.73)$, which was reduced to .51 with the inclusion of an interaction term. One of the strengths of this study include a larger sample size that included two divisions, providing more generalizability to the stigma-attitudes relationship. However, similar to previous studies, self-selection bias likely influenced the results of the study as the online recruitment method resulted in a 30\% response rate. Therefore, future research would be strengthened by utilizing a sample design that can help eliminate the self-selection bias as well as obtain a larger sample size.

\section{Likelihood of Seeking Counseling for Specific Issues}


Research in the general psychology literature has found that specific groups might vary on their willingness to seek counseling for various issues. For example, Latinx participants in one study reported they would be most likely to seek help for social withdrawal or for family problems (Rastogi, Massey-Hastings, \& Weiling, 2012). Therefore, it is possible that within the unique population of student-athletes, there are some issues for which they might be more or less likely to seek help. There has been limited research on this topic amongst student-athletes. The studies that have explored this topic often inquire about a limited range of specific issues (e.g., asking about seeking help for injury or a performance slump) and ask from whom they would be most likely to seek help (e.g., Bird et al., 2018; Maniar, Curry, Sommers-Flanagan, \& Walsh, 2001), rather than specifying seeking help from a professional. However, there is some insight that can be gleaned from this small body of research.

One study examined preferences for topics to discuss in sport psychology consultation amongst athletes from the U.S. and Japan (Naoi, Watson, Deaner, \& Sato, 2011). This list included ten topics related to performance enhancement as well as various personal concerns. Overall, the top three issues were all performance related: burnout/overtraining, confidence, and dealing with stress. Academic concerns was fourth overall, career concerns was sixth, mental health concerns was ninth, and alcohol/drug issues was rated last. Although this makes participants' willingness to seek help for personal concerns appear bleak, it should be noted that they were asked to respond to topics they would prefer for sport psychology consultation. They may not have felt that discussing mental health concerns or drug/alcohol issues would be appropriate with a sport psychology consultant.

Another recent study examined preferential help-seeking topics (Moore, 2017). In that study, student-athletes ranked their comfort with seeking a range of behavioral services. They 
ranked comfort according to nine different services. Any topic associated to mental health was ranked lowest. Mental health as a broad category was ranked sixth, followed by alcohol addiction services, substance abuse services, and suicide prevention. Further, there was over a two point difference $(M=4.22)$ and the next closest topic, tutoring services $(M=6.61)$ on an 8 point Likert-scale. Academic advising $(M=7.06)$ and tutoring services $(M=6.61)$ received favorable ratings. However, student-athletes are required to meet with academic advisers and given wide access to tutors, so it is understandable that they would feel comfortable with these topics. This does not necessarily indicate that they would be likely to seek help for academic concerns. However, given the results of this study and Naoi et al. (2011), one could guess that academic or career concerns might be a subject that student-athletes are willing to talk about with a professional.

Other studies have given a limited range of issues and asked which sources they would most likely seek help from (e.g., Bird et al., 2018 Maniar et al., 2001). In Maniar et al. (2001), students were asked about treatment preferences for overcoming a slump, injury, or reaching optimal performance. In other words, the issues they were given were very performance driven. Student-athletes were mostly likely to desire seeking help for performance issues from informal, nonprofessional sources such as a coach, family, or friends. Sport titled professionals, even if their title included counselor or psychologist, were more desired than clinical psychologists or counselors. A statistic that is promising for counseling is that talking in depth to someone to resolve the three issues received fairly positive ratings, with the lowest score of 6.63 on a 9-point scale for optimal performance for males.

Supporting findings from Maniar et al. (2001), more student-athletes in Bird et al.’s (2018) study reported that they would seek out parents, friends, teammates, and the coach for an 
emotional problem before a sport psychologist. Only $18.8 \%$ said they would utilize a mental health professional. This corroborates literature for athletes seeking out consultation for sport psychology services (Naoi et al., 2011; Maniar et al., 2001). Further, when U.S. and Japanese college athletes were asked more specifically about seeking help for mental health concerns, the same pattern emerged (Naoi et al., 2011). In both studies, informal sources were desired above sport titled, and especially mental health professionals (Naoi et al., 2011; Maniar et al., 2001). One limitation of the Naoi et al. (2011) study is that it does not appear a mental health professional was listed as a source for help-seeking, but sport psychology consultants and doctors ranked as the two lowest sources so it is likely a mental health professional would have also fallen closer to the bottom.

The research on specific issues for which student-athletes might be interested in seeking counseling is limited. The studies that have been conducted do not specify treatment with a mental health professional for relevant issues. This is an important line of inquiry that can have implications for college counseling professionals. Knowledge of the most and least salient issues can be used to promote counseling services. Once it is understood which issues student-athletes would most likely seek help for, counseling centers can tailor their outreach to discuss how those issues can be addressed. On the other end, the ones that receive the lowest ratings can also be targeted to increase comfort and familiarity with the possibility of those issues being confidentially discussed.

\section{Future Research}

Unlike the research in the general counseling psychology literature, a major limitation of the research with college student-athletes is the lack of studies examining intentions and actual help-seeking behavior. Although studies have often collected data on whether or not participants 
in the sample had sought mental health services previously, that data has not been used in the study. Although research has found that intentions can be accurate predictors of actual behavior (e.g., Armitage \& Conner, 2001; Nagai, 2015), measuring actual help-seeking behavior would provide a more accurate and nuanced understanding of student-athlete behavior. Additionally, the role of stigma should be analyzed in direct relation to intentions and help-seeking behavior. Social network stigma could play an important role with student-athletes who have concerns over close others being aware of their seeking counseling (e.g., López \& Levy, 2013; Moore, 2017). Public stigma and social network stigma have yet to be examined in the same study with student-athletes. The measures for each of those concepts have been found to be able to discriminate and add uniquely to self-stigma, so understanding if public or social network stigma has a larger influence on help-seeking could help tailor interventions and outreach.

There is also a need to examine other variables that influence intentions and help-seeking behaviors. Although stigma has accounted for a significant amount of variance in predicting attitudes in several studies, there is still plenty left unaccounted for that might influence helpseeking behavior. It would be useful to include stigma in these studies as well to investigate how the relationship between other help-seeking factors might be moderated by stigma. As discussions about mental health continue to become more normalized, studying how stigma changes in groups of individuals longitudinally would provide a clearer picture of stigmas influence on help-seeking. Finally, with knowledge that altering stigma might lead to improved attitudes and intentions, intervention studies working to reduce stigma could be conducted with long-term follow-up to find programs that are most effective. 


\section{References}

Abdullah, T., \& Brown, T. L. (2011). Mental illness stigma and ethnocultural beliefs, values, and norms: An integrative review. Clinical Psychology Review, 31, 934-948. doi: doi:10.1016/j.cpr.2011.05.003

Ajzen, I. (2006). Constructing a theory of planned behavior questionnaire. Available from http://people.umass.edu/aizen/pdf/tpb.measurement.pdf

Ajzen, L, \& Fishbein, M. (1980). Understanding attitudes and predicting social behavior. Englewood Cliffs, NJ: Prentice-Hall.

Andoh-Arthur, J., Asante, K. O., \& Osafo, J. (2015). Determinants of psychological help-seeking intentions of university students in Ghana. International Journal for the Advancement of Counselling, 37, 330-345. https://doi.org/10.1007/s10447-015-9247-2

Arbuckle, J. L. (2017). Amos (Version 25.0) [Computer Program]. Chicago: IBM SPSS.

Armitage, C. J., \& Conner, M. (2001). Efficacy of the Theory of Planned Behaviour: A metaanalytic review. British Journal of Social Psychology, 40, 471-499. https://doi.org/10.1348/014466601164939

Associated Press. (2018, Jan 17). Washington State quarterback's death permeates NCAA convention discussions. Retrieved from https://www.usatoday.com/story/sports/ncaaf/2018/01/17/washington-state-quarterbackdeath-permeates-ncaa-convention-discussions/109556518/

Auerbach, R. P., Alonso, J., Axinn, W. G., Cuijpers, P., Ebert, D. D., Greif Green, J., .. . Bruffaerts, R. (2016). Mental disorders among college students in the WHO World Mental Health Surveys. Psychological Medicine, 46, 2955-2970.

doi: $\underline{10.1017 / S 0033291716001665}$ 
Barnard, J. D. (2016). Student-athletes' perceptions of mental illness and attitudes toward helpseeking. Journal of College Student Psychotherapy, 30, 161-175. http://dx.doi.org/10.1080/87568225.2016.1177421

Bathje, G. J., Kim, E., Rau, E., Bassiouny, M. A., \& Kim, T. (2014). Attitudes toward face-toface and online counseling: Roles of self-concealment, openness to experience, loss of face, stigma, and disclosure expectations among Korean college students. International Journal for the Advancement of Counselling, 36, 408-422. doi: 10.1007/s10447-0149215-2

Bauman, N. J. (2016). The stigma of mental health in athletes: Are mental toughness and mental health seen as contradictory in elite sport? British Journal of Sports Medicine, 50, 135136. doi:10.1136/bjsports-2015-095570

Biggin, I. J. R., Burns, J., \& Uphill, M. A. (2017). An investigation of athletes' and coaches' perceptions of mental-ill health in elite athletes. Journal of Clinical Sport Psychology, 11, 126-147. https://doi.org/10.1123/jcsp.2016-0017

Bird, M. D., Chow, G. M., Meir, G., \& Freeman, J. (2018). Student-athlete and student nonathletes' stigma and attitudes toward seeking online and face-to-face counseling. Journal of Clinical Sport Psychology, 12, 347-364. https://doi.org/10.1123/jcsp.2017-0010

Breslin, G., Haughey, T., O’Brien, W., Robertson, A., Caulfield, L., \& Lawlor, M. (2018). Increasing athlete knowledge of mental health and intentions to seek help: The State of Mind Ireland (SOMI) pilot program. Journal of Clinical Sport Psychology, 12, 39-56. https://doi.org/10.1123/jcsp.2016-0039

Breslin, G., Shannon, S., Haughey, T., Donnelly, P., \& Leavey, G. (2017). A systematic review of interventions to increase awareness of mental health and well-being in athletes, 
coaches and officials. Systematic Reviews, 6, 177. https://doi.org/10.1186/s13643-017-

\section{$\underline{0568-6}$}

Brewer, B. W., \& Cornelius, A. E. (2001). Norms and factorial invariance of the Athletic Identity Measurement Scale. Academic Athletic Journal, 15, 103-113.

Bright, J. E. H., \& Pryor, R. G. L. (2005). The chaos theory of careers: A user's guide. The Career Development Quarterly, 53, 291-305.

Cash, T. E., Begley, P. J., McCown, D. A., \& Weise, B. C. (1975). When counselors are heard but not seen: Initial impact of physical attractiveness. Journal of Counseling Psychology, 22, 273-279.

Cepeda-Benito, A., \& Short, P. (1998). Self-concealment, avoidance of psychological services, and perceived likelihood of seeking professional help. Journal of Counseling Psychology, 45, 58-64. http://dx.doi.org/10.1037/0022-0167.45.1.58

Chan, G., \& Yanos, P. T. (2018). Media depictions and the priming of mental illness stigma. Stigma and Health, 3, 253-264. http://dx.doi.org/10.1037/sah0000095

Cheng, H. L., Kwan, K. L., \& Sevig, T. (2013). Racial and ethnic minority college students' stigma associated with seeking psychological help: Examining psychocultural correlates. Journal of Counseling Psychology, 60, 98-111. doi: 10.1037/a0031169

Choi, N.-Y., \& Miller, M. J. (2014). AAPI college students' willingness to seek counseling: The role of culture, stigma, and attitudes. Journal of Counseling Psychology, 61, 340-351. http://dx.doi.org/10.1037/cou0000027

Clement, S., Schaumann, O., Graham, T., Maggioni, F., Evans-Lacko, S., Bezborodovs, N., . . .Thornicroft, G. (2015). What is the impact of mental-health related stigma on help 
seeking? A systematic review of quantitative and qualitative studies. Psychological Medicine, 45, 11-27. doi:10.1017/S0033291714000129

Corrigan, P. (2004). How stigma interferes with mental health care. American Psychologist, 59, 614-625. http://dx.doi.org/10.1037/0003-066X.59.7.614

Corrigan, P. W., Druss, B. G., \& Perlick, D. A. (2014). The impact of mental illness stigma on seeking and participating in health care. Psychological Science in the Public Interest, 15(2), 37-70. DOI: 10.1177/1529100614531398

Corrigan, P. W., Morris, S. B., Michaels, P. J., Rafacz, J. D., \& Rüsch, N. (2012). Challenging the public stigma of mental illness: A meta-analysis of outcome studies. Psychiatric Services, 63, 963-973. https://doi.org/10.1176/appi.ps.201100529

Currier, J. M., McDermott, R. C., \& McCormick, W. H. (2017). Mental health treatment-related stigma and professional help seeking among student veterans. Psychological Services, 14, 531-542. http://dx.doi.org/10.1037/ser0000129

Deane, F. P., \& Chamberlain, K. (1994). Treatment fearfulness and distress as predictors of professional psychological help-seeking. British Journal of Counselling \& Guidance, 22, 207-217. http://dx.doi.org/10.1080/03069889408260315

Deane, F. P., Wilson, C. J., \& Ciarrochi, J. (2001). Suicidal ideation and help-negation: Not just hopelessness or prior help. Journal of Clinical Psychology, 57, 901-914. http://dx.doi.org/10.1002/jclp.1058

DeBate, R. D., Gatto, A., \& Rafal, G. (2018). The effects of stigma on determinants of mental health help-seeking behaviors among male college students: An application of the Information-Motivation-Behavioral Skills Model. American Journal of Men's Health. Advanced online publication. https://doi.org/10.1177/1557988318773656 
DeLenardo, S., \& Lennox Terrion, J. (2014). Suck it up: Opinions and attitudes about mental illness stigma and help-seeking behavior of male varsity football players. Canadian Journal of Community Mental Health, 33, 43-56. doi:10.7870/cjcmh-2014-023

Efstathiou, G., Kouvaraki, E., Ploubidis, G., \& Kalantzi-Azizi, A. (2018). Self-stigma, publicstigma and attitudes toward professional psychological help: Psychometric properties of the Greek version of three relevant questionnaires. International Journal for the Advancement of Counselling. Advance online publication. https://doi.org/10.1007/s10447-018-9364-9

Etzel, E. F., \& Watson, J. C. (2007). Ethical challenges for psychological consultations in intercollegiate athletics. Journal of Clinical Sport Psychology, 1, 304-317.

\section{https://doi.org/10.1123/jesp.1.3.304}

Etzel, E. F., Watson, J. C., Visek, A. J., \& Maniar, S. D. (2006). Understanding and promoting college student-athlete health: essential issues for student affairs professionals. Journal of Student Affairs Research and Practice, 43, 518-546. doi: 10.2202/1949-6605.1685

Fischer, E. H., \& Farina, A. (1995). Attitudes toward seeking professional psychological help: A shortened form and considerations for research. Journal of College Student Development, $36,368-373$.

Fox, A. B., Earnshaw, V. A., Taverna, E. C., \& Vogt, D. (2018). Conceptualizing and measuring mental illness stigma: The Mental Illness Stigma Framework and critical review of measures. Stigma and Health, 3, 348-376. http://dx.doi.org/10.1037/sah0000104

Fripp, J. A., \& Carlson, R. G. (2017). Exploring the influence of attitude and stigma on participation of African American and Latino populations in mental health services. 
Journal of Multicultural Counseling and Development, 45, 80-94. DOI:

10.1002/jmcd.12066

Garriott, P. O., Raque-Bogdan, T. L., Yalango, K., Schaefer Ziemer, K., \& Utley, J. (2017). Intentions to seek counseling in first-generation and continuing-generation college students. Journal of Counseling Psychology, 64, 432-442. http://dx.doi.org/10.1037/cou0000210

Gavrilova, Y., \& Donohue, B. (2018). Sport-specific mental health interventions in athletes: A call for optimization models sensitive to sport culture. Journal of Sport Behavior, 41, 283-304.

Gucciardi, D. F., Hanton, S., \& Fleming, S. (2017). Are mental health and mental toughness contradictory concepts in elite sport? A narrative review of theory and evidence. Journal of Science and Medicine in Sport, 20, 307-311. https://doi.org/10.1016/j.jsams.2016.08.006

Gulliver, A. (2017). Commentary: Mental Health in Sport (MHS): Improving the early intervention knowledge and confidence of elite sport staff. Frontiers in Psychology, 8, 1209. https://doi.org/10.3389/fpsyg.2017.01209

Gulliver, A., Griffiths, K. M., \& Christensen, H. (2010). Perceived barriers and facilitators to mental health help-seeking in young people: A systematic review. BMC Psychiatry, 10, 113. https://doi.org/10.1186/1471-244X-10-113

Gulliver, A., Griffiths, K., \& Christensen, H. (2012). Barriers and facilitators to mental health help-seeking for young elite athletes: A qualitative study. BMC Psychiatry, 12:157. https://doi.org/10.1186/1471-244X-12-157 
Hackler, A. H., Cornish, M. A., \& Vogel, D. L. (2016). Reducing mental illness stigma: Effectiveness of hearing about the normative experiences of others. Stigma and Health, 1, 201-205. http://dx.doi.org/10.1037/sah0000028

Hammer, J. H., Parent, M. C., \& Spiker, D. A. (2018). Mental Help Seeking Attitudes Scale (MHSAS): Development, reliability, validity, and comparison with the ATSPPH-SF and IASMHS-PO. Journal of Counseling Psychology, 65, 74-85. http://dx.doi.org/10.1037/cou0000248

Hammer, J. H., \& Spiker, D. A. (2018). Dimensionality, reliability, and predictive evidence of validity for three help seeking intention instruments: ISCI, GHSQ, and MHSIS. Journal of Counseling Psychology, 65, 394-401. http://dx.doi.org/10.1037/cou0000256

Hilliard, R. C., Redmond, L. A., \& Watson II, J. C. (2018a). The relationships among selfcompassion, stigma, and attitudes toward counseling in student-athletes. Journal of Clinical Sport Psychology. Advance online publication. https://doi.org/10.1123/jcsp.2018-0027

Hilliard, R. C., Redmond, L. A., \& Watson II, J. C. (2018b). Differences in stigma and attitudes toward counseling amongst college student-athletes and nonathletes. Journal of College Student Psychotherapy. Advance online publication.

\section{https://doi.org/10.1080/87568225.2018.1504639}

Jennings, K. S., Goguen, K. N., Britt, T. W., Jeffirs, S. M., Wilkes III, J. R., Brady, A. R., . . DiMuzio, D. J. (2017). The role of personality traits and barriers to mental health treatment seeking among college students. Psychological Services, 14, 513-523. http://dx.doi.org/10.1037/ser0000157 
Jolly, J. C. (2008). Raising the question \#9 Is the student-athlete population unique? And why should we care? Communication Education, 57, 145-151.

\section{http://dx.doi.org/10.1080/03634520701613676}

Jung, H., von Sternberg, K., \& Davis, K. (2017). The impact of mental health literacy, stigma, and social support on attitudes toward mental health help-seeking. International Journal of Mental Health Promotion, 19, 252-267. https://doi.org/10.1080/14623730.2017.1345687

Kaier, E., DeMarni Cromer, L., Johnson, M. D., Strunk, K., \& Davis, L. (2015). Perceptions of mental illness stigma: Comparisons of athletes to nonathlete peers. Journal of College Student Development, 56, 735-739. https://doi.org/10.1353/csd.2015.0079

Kern, A., Heininger, W., Klueh, E., Salazar, S., Hansen, B., Meyer, T., \& Eisenberg, D. (2017). Athletes Connected: Results from a pilot project to address knowledge and attitudes about mental health among college student-athletes. Journal of Clinical Sport Psychology, 11, 324-336. https://doi.org/10.1123/JCSP.2016-0028

Ketchen Lipson, S., Gaddis, S. M., Heinze, J., Beck, K., \& Eisenberg, D. (2015). Variations in student mental health and treatment utilization across US colleges and universities. Journal of American College Health, 63, 388-396.

\section{http://dx.doi.org/10.1080/07448481.2015.1040411}

Kline, R. B. (2016). Principles and practice of structural equation modeling (4th ed.). New York, NY: Guilford Press.

Komiya, N., Good, G.E., \& Sherrod, N. B. (2000). Emotional openness as a predictor of college students' attitudes toward seeking psychological help. Journal of Counseling Psychology, 47, 138-143. DOI: 10.1037/AJ022-0167,47.1.138 
Kroshus, E. (2017). Stigma, coping skills, and psychological help seeking among collegiate athletes. Athletic Training \& Sports Health Care, 9, 254-262. https://doi.org/10.3928/19425864-20171010-02

Lally, J., O’Conghaile, A., Quigley, S., Bainbridge, E., \& McDonald, C. (2013). Stigma of mental illness and help-seeking intention in university students. The Psychiatrist, 7, 253260. doi: 10.1192/pb.bp.112.041483

Lannin, D. G., Vogel, D. L., Brenner, R. E., \& Tucker, J. R. (2015). Predicting self-esteem and intentions to seek counseling: The Internalized Stigma Model. The Counseling Psychologist, 43, 64-93. doi: 10.1177/0011000014541550

Lannin, D. G., Vogel, D. L., Brenner, R. E., Abraham, W. T., \& Heath, P. J. (2016). Does selfstigma reduce the probability of seeking mental health information? Journal of Counseling Psychology, 63, 351-358. http://dx.doi.org/10.1037/cou0000108

Leimer, A. D., Leon, R. A., \& Shelley, K. (2014). Stigmas and stereotypes: Counseling services for student-athletes. Journal for the Study of Sports and Athletes in Education, 8, 121135. doi: 10.1179/1935739714Z.0000000002

Li, W., Dorstyn, D. S., \& Denson, L. A. (2014). Psychosocial correlates of college students' help-seeking intention: A meta-analysis. Professional Psychology: Research and Practice, 45, 163-170. http://dx.doi.org/10.1037/a0037118

Linder, D. E., Pillow, D. R., \& Reno, R. R. (1989). Shrinking jocks: Derogation of athletes who consult a sport psychologist. Journal of Sport \& Exercise Psychology, 11, 270-280. https://doi.org/10.1123/jsep.11.3.270 
Link, B. G., Cullen, F. T., Struening, E., Shrout, P. E., \& Dohrenwend, B. P. (1989). A Modified Labeling Theory approach to mental disorders: An empirical assessment. American Sociological Review, 54, 400-423.

López, R., L., \& Levy, J., J. (2013). Student athletes' perceived barriers to and preferences for seeking counseling. Journal of College Counseling, 16, 19-31. doi: 10.1002/j.21611882.2013.00024.x

Loughran, M. J., \& Etzel, E. F. (2008). Ethical practice in a diverse world: The challenges of working with differences in the psychological treatment of college student-athletes. Athletic Insight, 10(4). Retrieved from http://athleticinsight.com/Vol10Iss4/Ethical.htm

Loya, F., Reddy, R., \& Hinshaw, S. P. (2010). Mental illness stigma as a mediator of differences in Caucasian and South Asian college students' attitudes toward psychological counseling. Journal of Counseling Psychology, 57, 484-490. doi: 10.1037/a0021113

Mackenzie, C. S., Erickson, J., Deane, F. P., \& Wright, M. (2014). Changes in attitudes toward mental health services: A 40-year cross-temporal meta-analysis. Clinical Psychology Review, 34, 99-106. https://doi.org/10.1016/j.cpr.2013.12.001

Maier, J. A., Gentile, D. A., Vogel, D. L., \& Kaplan, S. A. (2014). Media influences on selfstigma of seeking psychological services: The importance of media portrayals and person perception. Psychology of Popular Media Culture, 3, 239-256. doi:10.1037/a0034504

Maniar, S. D., Curry, L. A., Sommers-Flanagan, J., \& Walsh, J. A. (2001). Student-athlete preferences in seeking help when confronted with sport performance problems. The Sport Psychologist, 15, 205-223. https://doi.org/10.1123/tsp.15.2.205 
Martin, S. B. (2005). High school and college athletes' attitudes toward sport psychology. Journal of Applied Sport Psychology, 17, 127-139. https://doi.org/10.1080/10413200590932434

Martin, S. B., Kellmann, M., Lavallee, D., \& Page, S. J. (2002). Development and psychometric evaluation of the Sport Psychology Attitudes-Revised Form: A multigroup investigation. The Sport Psychologist, 16, 272-290. https://doi.org/10.1123/tsp.16.3.272

Martin, S. B., Wrisberg, C. A., Beitel, P. A., \& Lounsbury, J. (1997). NCAA Division I athletes' attitudes toward seeking sport psychology consultation: The development of an objective instrument. The Sport Psychologist, 11, 201-218. https://doi.org/10.1123/tsp.11.2.201

Martin, S. B., Zakrajsek, R. A., \& Wrisberg, C. A. (2012). Attitudes towards sport psychology and seeking assistance: Key factors and a proposed model. In C. Logan \& M. Hodge (Eds.), Psychology of attitudes (pp. 1-33). Hauppauge, NY: Nova Science Publishers.

Masuda, A., Anderson, P. L., Twohig, M. P., Feinstein, A. B., Chou, Y. Y., Wendell, J. W., \& Stormo, A. R. (2009). Help-seeking experiences and attitudes among African American, Asian American, and European American college students. International Journal for the Advancement of Counselling, 31, 168-180. doi: 10.1007/s10447-009-9076-2

Mendoza, H., Masuda, A., \& Swartout, K. M. (2015). Mental health stigma and self-concealment as predictors of help-seeking attitudes among Latina/o college students in the United States. International Journal for the Advancement of Counselling, 37, 207-222. doi: $10.1007 / \mathrm{s} 10447-015-9237-4$

Mittal, D., Sullivan, G., Chekuri, L., Allee, E., \& Corrigan, P. W. (2012). Empirical studies of self-stigma reduction strategies: A critical review of the literature. Psychiatric Services, 63, 974-981. https://doi.org/10.1176/appi.ps.201100459 
Moore, M. (2017). Stepping outside of their comfort zone: Perceptions of seeking behavioral health services amongst college athletes. Journal of Issues in Intercollegiate Athletics, 2017 special issue, 130-144.

Moreland, J. J., Coxe, K. A., \& Yang, J. (2018). Collegiate athletes' mental health services utilization: A systematic review of conceptualizations, operationalizations, facilitators, and barriers. Journal of Sport and Health Science, 7, 58-69. http://dx.doi.org/doi: 10.1016/j.jshs.2017.04.009

Nam, S. K., Choi, S. I., Lee, J. H., Lee, M. K., Kim, A. R., \& Lee, S. M. (2013). Psychological factors in college students' attitudes toward seeking professional psychological help: A meta-analysis. Professional Psychology: Research and Practice, 44, 37-45. http://dx.doi.org/10.1037/a0029562

Nam, S. K., Chu, H. J., Lee, M. K., Lee, H. H., Kim, N., \& Lee, S. M. (2010). A meta-analysis of gender differences in attitudes toward seeking professional psychological help. Journal of American College Health, 59, 110-116. http://dx.doi.org/10.1080/07448481.2010.483714

Naoi, A., Watson, J., Deaner, H., \& Sato, M. (2011). Multicultural issues in sport psychology and consultation. International Journal of Sport \& Exercise Psychology, 9, 110-125. http://dx.doi.org/10.1080/1612197X.2011.567101

National Collegiate Athletic Association. (2016). NCAA GOALS study of the student-athlete experience: Initial summary of findings January 2016. Retrieved from http://www.ncaa.org/sites/default/files/GOALS_2015_summary_jan2016_final_2016062 $\underline{\text { 7.pdf }}$ 
National Collegiate Athletic Association. (2017). Student-athlete participation: 1981-19822016-2017. Retrieved from http://www.ncaa.org/sites/default/files/2016-17NCAA0472_ParticRatesReport-FINAL_20171120.pdf

Pérez-Rojas, A. E., Lockard, A. J., Bartholomew, T. T., Janis, R. A., Carney, D. M., Xiao, H., . . . Hayes, J. A. (2017). Presenting concerns in counseling centers: The view from clinicians on the ground. Psychological Services, 14, 416-427. http://dx.doi.org/10.1037/ser0000122

Pheko, M. M., Chilisa, R., Balogun, S. K., \& Kgathi, C. (2013). Predicting intentions to seek psychological help among Botswana university students: The role of stigma and helpseeking attitude. SAGE Open, 3, 1-11. http://dx.doi.org/10.1177/2158244013494655

Pinkerton, R. S., Hinz, L. D., \& Barrow, J. C. (1989). The college student-athlete: Psychological considerations and interventions. Journal of American College Health, 37, 218-226. doi: $10.1080 / 07448481.1989 .993906$

Pinkerton, R. S., Hinz, L. D., \& Barrow, J. C. (1989). The college student-athlete: Psychological considerations and interventions. Journal of American College Health, 37, 218-226. doi: $10.1080 / 07448481.1989 .993906$

Pryor, R. G. L., Amundson, N. E., \& Bright, J. E. H. (2008). Probabilities and possibilities: The strategic counseling implications of the chaos theory of careers. The Career Development Quarterly, 56, 309-318.

Quinn, N., Wilson, A., MacIntyre, G., \& Tinklin, T. (2009). 'People look at you differently': Students' experience of mental health support within higher education. British Journal of Guidance \& Counselling, 37, 405-418. http://dx.doi.org/10.1080/03069880903161385 
Rafal, G., Gatto, A., \& DeBate, R. (2018). Mental health literacy, stigma, and help-seeking behaviors among male college students. Journal of American College Health, 66, 4, 284291. https://doi.org/10.1080/07448481.2018.1434780

Rao, A. L., Asif, I. M., Drezner, J. A., Toresdahl, B. G., \& Harmon, K. G. (2015). Suicide in National Collegiate Athletic Association (NCAA) athletes: A 9-year analysis of the NCAA Resolutions database. Sports Health: A Multidisciplinary Approach, 7, 452-457. doi: $10.1177 / 1941738115587675$

Rastogi, M., Massey-Hastings, N., \& Wieling, E. (2012). Barriers to mental health services in the Latino/a community: A qualitative analysis. Journal of Systemic Therapies, 31(4), 1-17.

Rochlen, A. B., Beretvas, S. N., \& Zack, J. S. (2004). The online and face-to-face counseling attitudes scales: A validation study. Measurement and Evaluation in Counseling and Development, 37, 95-111. https://doi.org/10.1080/07481756.2004.11909753

Sarac, N., Sarac, B., Pedroza, A., \& Borchers, J. (2018). Epidemiology of mental health conditions in incoming division I collegiate athletes. The Physician and Sportsmedicine, 46, 242-248. https://doi.org/10.1080/00913847.2018.1427412

Schinke, R. J., Stambulova, N. B., Si, G., \& Moore, Z. (2018). International Society of Sport Psychology position stand: Athletes' mental health, performance, and development. International Journal of Sport and Exercise Psychology, 16, 622-639. https://doi.org/10.1080/1612197X.2017.1295557

Scott, J. (2018, April). Focusing on student-athletes' mental health. Retrieved from https://www.athleticbusiness.com/health-fitness/focusing-on-student-athletes-mentalhealth.html?eid=61611281\&bid=2055406 
Seamark, D., \& Gabriel, L. (2018). Barriers to support: A qualitative exploration into the helpseeking and avoidance factors of young adults. British Journal of Guidance \& Counselling, 46, 120-131. https://doi.org/10.1080/03069885.2016.1213372

Sebbens, J., Hassmén, P., Crisp, D., \& Wensley, K. (2016). Mental Health in Sport (MHS): Improving the early intervention knowledge and confidence of elite sport staff. Frontiers in Psychology, 7, 911. https://doi.org/10.3389/fpsyg.2016.00911

Shaffer, P. A., Vogel, D. L., \& Wei, M. (2006). The mediating roles of anticipated risks, anticipated benefits, and attitudes on the decision to seek professional help: An attachment perspective. Journal of Counseling Psychology, 53, 442-452. http://dx.doi.org/10.1037/0022-0167.53.4.442

Shechtman, Z., Vogel, D. L., Strass, H. A., \& Heath, P. J. (2018). Stigma in help-seeking: The case of adolescents. British Journal of Guidance \& Counselling, 46, 104-119. http://dx.doi.org/10.1080/03069885.2016.1255717.

Shechtman, Z., Vogel, D., \& Maman, N. (2010). Seeking psychological help: A comparison of individual and group treatment. Psychotherapy Research, 20, 30-36. http://dx.doi.org/10.1080/10503300903307648

Shepherd, C. B., Rickard, K. M. (2012). Drive for muscularity and help-seeking: The mediational role of gender role conflict, self-stigma, and attitudes. Psychology of Men \& Masculinity, 13, 379-392. doi: 10.1037/a0025923

Stewart, H., Jameson, J. P., \& Curtin, L. (2015). The relationship between stigma and selfreported willingness to use mental health services among rural and urban older adults. Psychological Services, 12, 141-148. http://dx.doi.org/10.1037/a0038651 
Swan, L .K., Heesacker, M., \& King, K. M. (2016). Are some descriptions of psychotherapy perceived as more (or less) stigmatizing than others? A preliminary investigation. Stigma and Health, 1, 263-268. http://dx.doi.org/10.1037/sah0000033

ten Have, M., de Graaf, R., Ormel, J., Vilagut, G., Kovess, V., Alonso, J., \& the ESEMeD/MHEDEA 2000 investigators. (2010). Are attitudes towards mental health help-seeking associated with service use? Results from the European Study of Epidemiology of Mental Disorders. Social Psychiatry and Epidemiology, 45, 153-163. doi:10.1007/s00127-009-0050-4

Thornicroft, G., Mehta, N., Clement, S., Evans-Lacko, S., Doherty, M., Rose, D., . . \&\& Henderson, C. (2016). Evidence for effective interventions to reduce mental-healthrelated stigma and discrimination. The Lancet, 387(10023), 12-18. https://doi.org/10.1016/S0140-6736(15)00298-6

Topkaya, N. (2014). Gender, self-stigma, and public stigma in predicting attitudes toward psychological help-seeking. Educational Sciences: Theory and Practice, 14, 480-487. DOI: 10.12738/estp.2014.2.

Topkaya, N., Vogel, D. L., \& Brenner, R. E. (2017). Examination of the stigmas toward help seeking among Turkish college students. Journal of Counseling \& Development, 95, $213-$ 225. doi: 10.1002/jcad.12133

Tucker, J. R., Hammer, J. H., Vogel, D. L., Bitman, R. L., Wade, N. G., \& Maier, E. J. (2013). Disentangling self-stigma: Are mental illness and help-seeking self-stigmas different? Journal of Counseling Psychology, 60, 520-531. http://dx.doi.org/10.1037/a0033555

Van Raalte, J. L., Brewer, B. W., Brewer, D. D., \& Linder, D. E. (1992). NCAA Division II college football players' perceptions of an athlete who consults a sport psychologist. 
Journal of Sport \& Exercise Psychology, 14, 273-282.

https://doi.org/10.1123/jsep.14.3.273

Vogel, D. L., \& Heath, P. J. (2016). Men, masculinities, and help-seeking patterns. In S. R. Wester \& J. Wong (Eds.), APA handbook for the psychology of men and masculinities (pp. 685-707). Washington, DC: American Psychological Association.

Vogel, D. L., Armstrong, P. I., Tasi, P. C., Wade, N. G., Hammer, J. H., Efstathiou, G., . . .Topkaya, N. (2013). Cross-cultural validity of the Self-Stigma of Seeking Help (SSOSH) Scale: Examination across six nations. Journal of Counseling Psychology, 60, 303-310. http://dx.doi.org/10.1037/a0032055

Vogel, D. L., Bitman, R. L., Hammer, J. H., \& Wade, N. G. (2013). Is stigma internalized? The longitudinal impact of public stigma on self-stigma. Journal of Counseling Psychology, 60, 311-316. http://dx.doi.org/10.1037/a0031889

Vogel, D. L., Heath, P. J., Engel, K. E., Brenner, R. E., Strass, H. A., Al-Darmaki, F. R., . . Zlati, A. (2019). Cross-Cultural Validation of the Perceptions of Stigmatization by Others for Seeking Help (PSOSH) Scale. Stigma and Health, 4, 82-85. http://dx.doi.org/10.1037/sah0000119

Vogel, D. L., Gentile, D. A., \& Kaplan, S. A. (2008). The influence of television on willingness to seek therapy. Journal of Clinical Psychology, 64, 276-295. doi: 10.1002/jclp.20446

Vogel, D. L., Strass, H. A., Heath, P. J., Al-Darkmaki, F. R., Armstrong, P. I., Baptista, M. N., . . .Zlati, A. (2017). Stigma of seeking psychological services: Examining college students across ten countries/regions. The Counseling Psychologist, 45, 170-192. doi: $10.1177 / 0011000016671411$ 
Vogel, D. L., Wade, N. G., \& Ascheman, P. L. (2009). Measuring perceptions of stigmatization by others for seeking psychological help: Reliability and validity of a new stigma scale with college students. Journal of Counseling Psychology, 56, 301-308. http://dx.doi.org/10.1037/a0014903

Vogel, D. L., Wade, N. G., \& Haake, S. (2006). Measuring the self-stigma associated with seeking psychological help. Journal of Counseling Psychology, 53, 325-337. http://dx.doi.org/10.1037/0022-0167.53.3.325

Vogel, D. L., Wade, N. G., \& Hackler, A. H. (2007). Perceived public stigma and the willingness to seek counseling: The mediating roles of self-stigma and attitudes toward counseling. Journal of Counseling Psychology, 54, 40-50. http://dx.doi.org/10.1037/0022-

\section{$\underline{0167.54 .1 .40}$}

Vogel, D. L., Wade, N. G., Wester, S. R., Larson, L., \& Hackler, A. H. (2007). Seeking help from a mental health professional: The influence of one's social network. Journal of Clinical Psychology, 63, 233-245. doi 10.1002/jclp.20345

Wade, N. G., Vogel, D. L., Armistead-Jehle, P., Meit, S. S., Heath, P. J., \& Strass, H. A. (2015). Modeling stigma, help-seeking attitudes, and intentions to seek behavioral healthcare in a clinical military sample. Psychiatric Rehabilitation Journal, 38, 135-141. http://dx.doi.org/10.1037/prj0000131

Wade, N. G., Vogel, D. L., Armistead-Jehle, P., Meit, S. S., Heath, P. J., \& Strass, H. A. (2015). Modeling stigma, help-seeking attitudes, and intentions to seek behavioral healthcare in a clinical military sample. Psychiatric Rehabilitation Journal, 38, 135-141. http://dx.doi.org/10.1037/prj0000131 
Wahto, R. S., Swift, J. S., \& Whipple, J. L. (2016). The role of stigma and referral source in predicting college student-athletes' attitudes toward psychological help-seeking. Journal of Clinical Sport Psychology, 10, 85-98. http://dx.doi.org/10.1123/JCSP.2015-0025

Wallace, B. C., \& Constantine, M. G. (2005). Africentric cultural values, psychological helpseeking attitudes, and self-concealment in African American college students. Journal of Black Psychology, 31, 369-385. https://doi.org/10.1177/0095798405281025

Wang, P. S., Aguilar-Gaxiola, S., Alonso, J., Angermeyer, M. C., Borges, G., Bromet, E. J., \& ... Wells, J. E. (2007). Use of mental health services for anxiety, mood, and substance disorders in 17 countries in the WHO world mental health surveys. The Lancet, 370 (9590), 841-850.

Watson, J. C. (2005). College student-athletes' attitudes toward help-seeking behavior and expectations of counseling services. Journal of College Student Development, 46, 442449. https://doi.org/10.1353/csd.2005.0044

Watson, J. C. (2006). Student-athletes and counseling: Factors influencing the decision to seek counseling services. College Student Journal, 40, 35-42.

Watson, J. C., \& Etzel, E. F. (2004). Ethical issues affecting psychologists, counselors and sport psychology consultants' work with collegiate student athletes. Professional Studies Review, 1, 49-60.

Weatherhead, G. V. (2015). Impact of athletic identity and emotional competence on athletes' attitudes toward seeking professional psychological help (Doctoral dissertation). Dissertations. (Paper 749). 
Wei, Y., McGrath, P. J., Hayden, J., \& Kutcher, S. (2015). Mental health literacy measures evaluating knowledge, attitudes, and help-seeking: A scoping review. BMC Psychiatry, 15, 291. https://doi.org/10.1186/s12888-015-0681-9

Wei, Y., McGrath, P., Hayden, J., \& Kutcher, S. (2017). The quality of mental health literacy measurement tools evaluating the stigma of mental illness: A systematic review. Advanced online publication. Epidemiology and Psychiatric Sciences. https://doi.org/10.1017/S2045796017000178

Wester, S. R., Arndt, D., Sedivy, S. K., \& Arndt L. (2010). Male police officers and stigma associated with counseling: The role of anticipated risks, anticipated benefits and gender role conflict. Psychology of Men \& Masculinity, 11, 286-302. doi: 10.1037/a0019108

Wilbur, M. P., \& Kulikowich, J. M., Roberts-Wilbur, J., Torres-Rivera, E. (1995). Chaos theory and counselor training. Counseling \& Values, 39, 129-144.

Wilbur, M. P., Roberts-Wilbur, J., Torres-Rivera, E, \& Kulikowich, J. M. (1995). Future directions: Chaos theory and nonlinear counseling. Journal for the Professional Counselor, 10, 73-90.

Wolanin, A., Hong, E., Marks, D., Panchoo, K., \& Gross, M. (2016). Prevalence of clinically elevated depressive symptoms in college athletes and differences by gender and sport. British Journal of Sports Medicine, 50, 167-171. doi:10.1136/bjsports-2015-095756

Wu, I. H. C., Bathje, G. J., Kalibatseva, Z., Sung, D. H., Leong, F. T. L., \& Collins-Eaglin, J. (2017). Stigma, mental health, and counseling service use: A person-centered approach to mental health stigma profiles. Psychological Services, 14, 490-501. http://dx.doi.org/10.1037/ser0000165 
Yanos, P. T., Lucksted, A., Drapalski, A., Roe, D., \& Lysaker, P. (2015). Interventions targeting mental health self-stigma: A review and comparison. Psychiatric Rehabilitation Journal, 38, 171-178. doi: 10.1037/prj0000100

Zakrajsek, R. A., \& Zizzi, S. J. (2008). How do coaches' attitudes change when exposed to a sport psychology workshop? Journal of Coaching Education, 1(1), 66-83. 


\section{Appendix C: Perceptions of Stigmatization by Others for Seeking Help scale (Vogel et al., 2009)}

Imagine you had an emotional or personal issue that you could not solve on your own. If you sought counseling services for this issue, to what degree do you believe that the people you interact with would

1
Not at all

3

Some
4

A lot
5

A great deal 


\section{Appendix D: Stigma Scale for Receiving Psychological Help (Komiya et al., 2000)}

Definition of Stigma: Negative reactions from and often unfair beliefs held by others due to one's behavior, attitudes or background.

Please answer each of the following questions based on your feelings by circling your response. There are no "right" or "wrong" answers, simply be honest in your responses.

$\begin{array}{cccc}0 & 1 & 2 & 3 \\ \text { Strongly } & \text { Disagree } & \text { Agree } & \text { Strongly Agree } \\ \text { Disagree } & & & \end{array}$

1. Seeing a psychologist for emotional

$\begin{array}{llll}0 & 1 & 2 & 3\end{array}$

or interpersonal problems carries social

stigma.

2. It is a sign of personal weakness or

$\begin{array}{llll}0 & 1 & 2 & 3\end{array}$

inadequacy to see a psychologist for

emotional or interpersonal problems.

3. People will see a person in a less

$\begin{array}{llll}0 & 1 & 2 & 3\end{array}$

favorable way if they come to know that

he/she has seen a psychologist.

4. It is advisable for a person to hide from

$\begin{array}{llll}0 & 1 & 2 & 3\end{array}$

people that he/she has seen a psychologist.

5. People tend to like less those who are

receiving professional psychological

help. 
Appendix E: Self Stigma of Seeking Help scale (Vogel et al., 2006)

1

Strongly

Disagree
2

Disagree
3

Neutral
4

Agree
5

Strongly Agree

I would feel inadequate if I went to a therapist for psychological help.

_ My self-confidence would NOT be threatened if I sought professional help.

_ Seeking psychological help would make me feel less intelligent.

_ My self-esteem would increase if I talked to a therapist.

_ My view of myself would not change just because I made the choice to see a therapist.

_ It would make me feel inferior to ask a therapist for help.

_ I would feel okay about myself if I made the choice to seek professional help.

_ If I went to a therapist, I would be less satisfied with myself.

My self-confidence would remain the same if I sought help for a problem I could not solve.

I would feel worse about myself if I could not solve my own problems 


\section{Appendix F: Attitudes Toward Seeking Professional Psychological Help Scale-Short Form (Fischer \& Farina, 1995)}

Please read each of the following items carefully. Indicate the extent to which you agree or disagree with each item according to the rating scale below.

0

Disagree
1

Somewhat disagree
2

Somewhat agree

\section{3}

Agree

1. If_ If I believed I was having a mental breakdown, my first inclination would be to get professional attention

2. The idea of talking about my problems with a psychologist strikes me as a poor way to get rid of emotional conflicts

3. If_ If I were experiencing a serious emotional crisis at this point in my life I would be confident that I could find relief in psychotherapy

4. There is something admirable in the attitude of a person who is willing to cope with his or her conflicts and fears without resorting to professional help

5. __ I would want to get psychological help if I were worried or upset for a long period of time

6. ___ I might want to have psychological counseling in the future

7. ___ A person with an emotional problem is not likely to solve it alone; he or she is likely to solve it with professional help

8. ___ Considering the time and expense involved in psychotherapy, it would have doubtful value for a person like me.

9. ___ A person should work out his or her own problems; getting psychological counseling would be a last resort

10.

Personal and emotional troubles, like many things, tend to work out by themselves 


\section{Appendix G: Mental Help Seeking Intention Scale (Hammer \& Spiker, 2018)}

INSTRUCTIONS: For the purposes of this survey, "mental health professionals" include psychologists, psychiatrists, clinical social workers, and counselors. Likewise, "mental health concerns" include issues ranging from personal difficulties (e.g., loss of a loved one) to mental illness (e.g., anxiety, depression). Please mark the box that best represents your opinion.

If I had a mental health concern, I would intend to seek help from a mental health professional.
1
(Extremely
2
3
4
5
6
7 unlikely)

If I had a mental health concern, I would try to seek help from a mental health professional.
1
(Definitely
false)
2
3
4
5
6
7
(Definitely
true)

If I had a mental health concern, I would plan to seek help from a mental health professional.

1

(Strongly

disagree)
2

3
4

5
6

7

(Strongly

agree) 


\section{Appendix H: Help-Seeking Topics (Modified from the Intentions to Seek Counseling Inventory; Cash et al., 1975)}

Below is a list of issues people commonly bring to counseling. How likely would you be to seek counseling if you were experiencing these problems? Please mark the corresponding answer.
1
2
Very unlikely
Unlikely
3
Likely
4
Very likely

Disordered eating

Excessive alcohol use

Relationship difficulties

Concerns about sexuality

Depression

Family conflict

Anxiety

Choosing a major

Dealing with injury

Difficulty in sleeping

Drug problems

Self-esteem/confidence

Test anxiety

Difficulty with friends

Academic performance

Self-understanding

Loneliness

Body image concerns

Stress

Athletic performance 


\section{Appendix I: Demographics}

Age:

Gender:

Year in college: Freshman Sophomore Junior Senior

What division do you participate in? Division II Division III

What sport(s) do you play?

Race: $\quad$ American Indian/Native American

Asian/Pacific Islander

Black/African American

Hispanic/Latinx

White/Caucasian

Biracial/multiracial

Other:

Have you ever received treatment for mental health issues from a mental health professional (e.g., psychologist, counselor, therapist, psychiatrist, or social worker)?

Have you ever worked with a sport psychology professional on issues related to mental performance in sport that did not include mental health concerns? (e.g., imagery, confidence, motivation, self-talk)

$\begin{array}{ll}\text { Are you currently on any psychiatric medications? } & \text { Yes }\end{array}$

Which of the following statements most closely reflects your feelings about mental health services?

(Please exclude the influence of summer if that is the reason you are not currently in services, but were at the end of the semester)

a. I am currently not seeking mental health services, and I do not intend to seek mental health services in the next 6 months

b. I am currently not seeking mental health services, but I am thinking about seeking mental health services in the next 6 months

c. I am currently seeking mental health services, but I just started in the last 6 months

d. I am currently seeking mental health services, and I have done so for longer than 6 months 


\section{Appendix J: Post-hoc analyses for self-stigma}

The finding that self-stigma was associated with an increased likelihood of having previously sought services was a novel finding that did not theoretically align with previous research. One possible explanation for why this may have occurred could be suppression in the model or some unique way that self-stigma and attitudes interacted in the current study. A few different analyses were done to examine the role of self-stigma, including correlations and several logistic regressions. First, correlations between attitudes, self-stigma, and previous helpseeking was examined. Self-stigma was not correlated with previous help-seeking history, $r=$ $.06, p=.28$, whereas attitudes was significantly positively correlated, $r=.20, p=.001$. Further, when entered as a sole predictor of previous help-seeking, self-stigma was not significant, $\beta=$ $0.24, p=.28$. However, the inclusion of attitudes lead to a significant fitting model where selfstigma $(\beta=0.90, \mathrm{p}=.001, \operatorname{Exp} \beta=2.53,95 \% \mathrm{CI}=[1.4,4.46])$ and attitudes $(\beta=1.56, p<.001$, $\operatorname{Exp} \beta=4.77,95 \% \mathrm{CI}=2.39,9.54])$ were significant predictors of help-seeking history.

As a result of these initial findings, an interaction between self-stigma and attitudes was examined. When entered as the sole predictor, the interaction was significant, $\beta=0.58, p<.001$, $\operatorname{Exp} \beta=1.78,95 \% \mathrm{CI}=[1.39,2.27]$. However, when this interaction was added in the full model that included all variables, none of the variables significantly predicted previous help-seeking history.

Overall, these results suggest that there was likely statistical influence present in the study that resulted in this novel finding for self-stigma. In the current study it did not have predictive value on its own, but only with the inclusion of attitudes. Future research using these variables is warranted to flesh out this issue. 


\section{Appendix K: IRB Approval}

\section{W. WestVirginiaUniversity. \\ Office of Research Integrity and Compliance \\ 888 Chestnut Ridge Road Morgantown, WV 26506}

\section{Acknowledgement of Exemption}

To: Jack Watson

From: WVU Office of Research Integrity \& Compliance

Protocol Type: Exempt

Submission Type: Initial

Funding: N/A

WVU Protocol \#: 1807181516

Protocol Title: Stigma, attitudes, and intentions to seek mental health services in college student-athletes
Approval Date: 08/02/2018

Expiration Date: 08/01/2021

The West Virginia University Institutional Review Board has reviewed your submission of Exempt protocel 1807181516. Additional details regarding the review are below:

- This research study was granted an exemption because the Research involves educational tests, survey procedures, interview procedures or observation of public behavior and (1) information obtained is recorded in such a manner that human subjects cannot be identified, directly or through identifiers linked to the subjects; and (ii) any disclosure of the human subjects responses outside the research could not reasonably place the subjects at risk of criminal or civil liability or be damaging to the subjects financial standing, employability, or reputation [45 CFR 46.101(2)]. All exemptions are only good for three years. If this research extends more than three years beyond the approved date, then the researcher will have to request another exemption. The following documents have been acknowledged for use in this study and are available in the WVU+kc system:

- Note: This study is only permitted for Waynesburg until Fairmont State signs a permission letter.

The following documents were reviewed and approved for use as part of this submission. Only the documents listed below may be used in the research. Please access and print the files in the Notes \& Attachments section of your approved protocol.

Protocol $\# .1807181516$

FWA: 00005078

IORG: 0000194
Phove: $304-293-7073$

Fas 304-293-3098

Ensail: IRB@mail.wweedu 
- WU Letter of Permission Hilliard-WVU.pdf

- FSU dissertation cover letter.docx

- WU dissertation cover letter.docx

- Dissertation recruitment script.docx

- Dissertation questionnaires.docx

\section{WVU IRB acknowledgement of protocol 1807181516 will expire on 08/01/2021}

If the study is to continue beyond the expiration date, a renewal application must be submitted no later than two (2) weeks prior to expiration date. It is your responsibility to submit your protocol for renewal.

Once you begin your human subjects research, the following regulations apply:

1. Unanticipated or serious adverse events and/or side effects encountered in this research study must be reported to the IRB within five (5) days, using the Notify IRB action in the electronic protocol.

2. Any modifications to the study protocol should be submitted only if there will be an increase in risk to subjects accompanying the proposed change(s).

3. You may not use a modified information sheet until it has been reviewed and acknowledged by the WVU IRB prior to implementation.

The Office of Research Integrity and Compliance will be glad to provide assistance to you throughout the research process. Please feel free to contact us by phone, at 304.293 .7073 or by email at $\underline{\mathrm{IRB} @ \text { mail.wruedu. }}$

Sincerely,

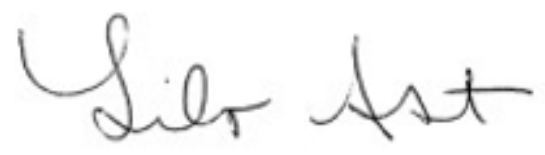

Lile Ast

IRB Administrator 